\title{
Taxonomic revision of the genus Lactarius (Russulales, Basidiomycota) in Korea
}

\author{
Hyun Lee ${ }^{1} \cdot$ Komsit Wissitrassameewong ${ }^{1} \cdot$ Myung Soo Park $^{1} \cdot$ Annemieke Verbeken $^{2} \cdot$ John Eimes $^{3} \cdot$ \\ Young Woon $\operatorname{Lim}^{1}$
}

Received: 1 October 2018/Accepted: 13 April 2019/Published online: 10 May 2019

(c) The Author(s) 2019

\begin{abstract}
The genus Lactarius Pers. (Russulales) is a cosmopolitan group of Basidiomycota that forms ectomycorrhizal relationships primarily with both deciduous and coniferous trees. Although the genus has been well-studied in Europe and North America, only fragmentary researches have been carried out on Asian species. In particular, the distribution of Lactarius species in South Korea is poorly understood due to insufficient morphological descriptions and a lack of DNA sequence data. In addition, the misuse of European and North American names has added to confusion regarding the taxonomy of Asian Lactarius species. In this study, the diversity of Lactarius in South Korea was evaluated by employing both morphological and phylogenetic approaches. A multi-locus phylogenetic analysis of 729 Lactarius specimens collected between 1960 and 2017 was performed using the internal transcribed spacer (ITS) region, partial nuclear ribosomal large subunit (nrLSU), partial second largest subunit of RNA polymerase II (rpb2), and minichromosome maintenance complex component 7 ( $\mathrm{mcm} 7$ ). 49 Lactarius species were identified in three Lactarius subgenera: L. subg. Russularia (17 spp.), $L$. subg. Lactarius (22 spp.), and L. subg. Plinthogalus (10 spp.). Among them, 28 Lactarius species were identified as new to science, while just 17 were previously described Lactarius species. Four of the taxa remain un-named due to paucity of materials. A key to Korean Lactarius species, molecular phylogenies, a summary of diversity, and detailed description are provided.
\end{abstract}

Keywords Intercontinental conspecificity $\cdot m c m 7 \cdot$ Milkcaps $\cdot$ Multi-locus phylogeny $\cdot$ Species delimitation

\section{Introduction}

Lactarius Pers. is a well known ectomycorrhizal genus that is characterized by the presence of latex (Persoon 1797), hence the common name milkcaps. The genus has long

Electronic supplementary material The online version of this article (https://doi.org/10.1007/s13225-019-00425-6) contains supplementary material, which is available to authorized users.

Young Woon Lim

ywlim@snu.ac.kr

1 School of Biological Sciences and Institute of Microbiology, Seoul National University, 1 Gwanak-ro, Gwanak-gu, Seoul 08826, Korea

2 Department of Biology, Research Group Mycology, Ghent University, K.L. Ledeganckstraat 35, 9000 Ghent, Belgium

3 University College, Sungkyunkwan University, 2066 Seoburo, Jangan-gu, Suwon 16419, Korea been recognized as one of two major groups (together with the larger genus Russula Pers.) in the family Russulaceae. A recent multi-locus study revealed that species identified as Lactarius spp. actually represent three genera: Multifurca Buyck \& V. Hofst (Buyck et al. 2008), Lactarius, and Lactifluus (Pers.) Roussel (Buyck et al. 2010; Verbeken et al. 2011, 2012; Stubbe et al. 2012).

Microscopically, all Lactarius species have basidiospores with an amyloid ornamentation, sphaerocytes (rounded cells) in the trama, and pseudocystidia in the hymenium (Hesler and Smith 1979; Heilmann-Clausen et al. 1998). Lactarius species are distributed in all terrestrial ecosystems (Hesler and Smith 1979; Montoya and Bandala 1996, 2003; Heilmann-Clausen et al. 1998; Basso 1999; Verbeken and Horak 1999, 2000; Verbeken et al. 2002; Nuytinck et al. 2006; Le et al. 2007a, b; YaminPasternak 2008; Verbeken and Walleyn 2010; Wisitrassameewong et al. 2014a, b, 2015, 2016; Wang 2016, 2017a, b, 2018; Das et al. 2017, Herrera et al. 2018; 
Shi et al. 2018; Unipal et al. 2018; Wang et al. 2015, 2018a, b). To date, 583 Lactarius species have been recorded globally (Kirk et al. 2008, http://www.catalo gueoflife.org/col/browse/tree). While most milkcaps are edible and popular as food in certain areas (e.g. L. deliciosus (L.) Gray, L. indigo (Schwein.) Fr., and L. sanguifluus (Paulet) Fr.) (Singer 1986; Sanmee et al. 2003), others produce mutagenic compounds (e.g. L. helvus (Fr.) Fr. and L. necator (Bull.) Pers.) (Von Wright et al. 1982; Suortti et al. 1983).

Until recently, species identification of Lactarius was based on morphological characters such as latex colour and colour change, pileus features, spore ornamentation, the presence/absence of cystidia and pileipellis structures (Hesler and Smith 1979; Heilmann-Clausen et al. 1998). Classification of Lactarius species has historically been problematic, as mycologists often use different morphological characters for infrageneric classification. Pileipellis structure has been the most frequently used character for infrageneric classification in Lactarius. However, Neuhoff (1956) divided the milkcaps into two subgenera based on pileipellis structure, while Hesler and Smith (1979) classified North American species of Lactarius s.1. into six subgenera using pileus and latex features. For European Lactarius, Heilmann-Clausen et al. (1998) described six subgenera using pileipellis structure as well as features of cystidia, while Basso (1999) proposed six subgenera based on the pileipellis structure and ecological complements.

While some Lactarius species are easily identified to the species level using only morphological characters, most Lactarius species are difficult to distinguish due to subtle morphological differences between species (HeilmannClausen et al. 1998; Stubbe et al. 2010; Nuytinck and Ammirati 2014). As the sequence data available in public nucleotide databases such as GenBank and UNITE have increased in recent years, the combination of morphological, molecular, and ecological data has greatly improved the accuracy of species identification in the Lactarius (Nuytinck and Verbeken 2003; Lee et al. 2015a). The internal transcribed spacer (ITS) region is commonly used as a fungal barcode (Schoch et al. 2012) and has been instrumental in identifying new Lactarius species (Verbeken et al. 2001; Das et al. 2015). The accuracy of phylogenies has been further enhanced through the use of a multi-locus approach, for example the partial nuclear ribosomal large subunit $28 \mathrm{~S}$ (nrLSU) and the conserved region between domain 6 and 7 of the second largest subunit of RNA polymerase II ( $r p b 2)$ (Stubbe 2012; Verbeken et al. 2014; Wisitrassameewong et al. 2016).

Based on recent molecular studies, three Lactarius subgenera are currently recognized: Lactarius subgenus Lactarius, L. subg. Russularia (Fr. ex Burl.) Kauffman, and L. subg. Plinthogalus (Burl.) Hesler \& A.H. Sm. (Verbeken and Nuytinck 2013; Wisitrassameewong et al. 2014a). Only L. subg. Plinthogalus is well-supported by molecular data in the most recent global phylogeny (Eberhardt and Verbeken 2004). Before the twenty-first century, the taxonomy of Lactarius was well-studied in Europe and North America (Hesler and Smith 1979; Heilmann-Clausen et al. 1998). As a result, European and North American nomenclature was applied to Lactarius species found in other continents or relatively distant geographical regions (e.g. Central and South America) (Pegler and Fiard 1979; Singer et al. 1983) and East Asia (Tanaka 1890; Imai 1935; Hongo 1957a, b, 1971, 1979). Recent studies based on molecular analysis demonstrated that most Lactarius species are not cosmopolitan and certain species are distributed to specific geographical regions (Le et al. 2007a; Nuytinck et al. 2007; Wisitrassameewong et al. 2016). Consequently, many Asian Lactarius species have been misidentified, often using European and American species names. Similar situations have been reported in South Korea (Lee et al. 2014, 2015a; Kim et al. 2015). Thus a reevaluation of Korean Lactarius species is warranted.

Uyeki (1936) identified the first three Lactarius species in Korea: L. akahatsu Nobuj. Tanaka, L. hatsudake Nobuj. Tanaka and L. piperatus (L.) Pers. (now Lactifluus piperatus (L.) Roussel). Since then 64 additional Lactarius species have been recorded in South Korea, with 49 of these belonging to the Lactarius s. str. (Bok and Shin 1985; Lee et al. 2015b, 2018). These species were identified based on phenotypic similarities to European and North American Lactarius and lacked detailed descriptions and molecular data. Recently, several studies found that Asian members of many fungal genera, e.g., Amanita Pers., Laccaria Berk. \& Broome, Russula, and Sparassis Fr. as well as Lactarius, are divergent from their European and North American counterparts, and many specimens were reported as new species (Zhao et al. 2013; Lee et al. 2017; Vincenot et al. 2017; Cho et al. 2018; Cui et al. 2018). Thus, it is likely that the diversity of Korean Lactarius taxa is different from what is currently described. Here, we investigated 729 Korean Lactarius specimens collected from 1960 to 2017 using morphological data and phylogenetic analyses of sequences from four markers: the ITS, nrLSU, rpb2 and minichromosome maintenance complex component 7 ( $\mathrm{mcm} 7)$.

\section{Materials and methods}

\section{Sampling}

A total of 729 Lactarius specimens were obtained from five herbaria in South Korea: Seoul National University (SFC), Kangwon National University (TPML), National Institute 
of Agricultural Sciences (HCCN), National Institute of Biological Resources (NIBR), and Korea National Arboretum (KA). Samples were collected in South Korea from 1960 to 2017. All specimens were initially identified using morphological characters and collection information was obtained from each herbarium where available.

\section{Morphology}

Newly collected specimens were preliminary identified using field guides (Romagnesi 1985; Heilmann-Clausen et al. 1998; Kränzlin 2005; Park and Lee 2011) and the Russulales news website (http://www.mtsn.tn.it/russulalesnews/) in order to have a provisional working name. The terminology of macro-morphology is in accordance with Verbeken and Walleyn (2010). We observed latex colour when it was exuded from basidiocarps and colour changes when exposed to the air. The Methuen Handbook of Colour (Kornerup and Wanscher 1978) was used for colour indications.

Microscopic characters were studied and illustrated from dried specimens using an Eclipse 80i light microscope (Nikon, Tokyo, Japan). Specimens were mounted in 3-5\% (w/v) KOH and 1\% (w/v) phloxine (Largent et al. 1977) to observe hyphae contents. To compare with other published data, we measured at least 20 basidia and cystidia per specimen. All elements on the hymenium and pileal structure were observed using 5\% (w/v) Congo red solution (Clémençon 1973) to observe cell walls and to measure the size of elements. The amyloidity of the plage on basidiospores was observed using Melzer's reagent (Largent et al. 1977). The length and width of basidiospores were measured in lateral size using scanning electron microscope (SEM). Pieces of dried lamellae were attached to aluminum stubs using double sided adhesive tape, coated with platinum in a sputter coater (EM ACE200, Leica, Austria), and then examined with a SEM (SUPRA 55VP, Carl Zeiss, Germany). Pileipellis was observed from the middle part of pileus. Twenty basidiospores were measured per collection. Basidiospore size and shape are calculated as (MIN -$)[\mathrm{AVa}-2 \times$ $\mathrm{SD}]-A V a-A V b-[\mathrm{AVb}+2 \times \mathrm{SD}](-\mathrm{MAX}), \quad$ in which $\mathrm{MIN}=$ the minimum value, $\mathrm{MAX}=$ the maximum value, $\mathrm{AVa}=$ lowest mean value for the measured collection, $\mathrm{AVb}=$ highest mean value for the measured collection and $\mathrm{SD}=$ standard deviation. $\mathrm{Q}$ value represents basidiospore "length/width ratio which corresponds to basidiospore shape and is reported as MIN - QAVa$Q A V b$ - MAX, where QAVa and QAVb are the lowest and the highest mean ratio for a measured specimen, respectively. For species with only one sample, the size and shape are calculated as (MIN -) [AV $-2 \times \mathrm{SD}]-$ $A V-[\mathrm{AV}+2 \times \mathrm{SD}](-\mathrm{MAX})$ and $\mathrm{MIN}-Q A V-$
MAX, in which AV = mean value for the measured collection and $\mathrm{QAV}=$ mean ratio for a measured specimen. All average values are in italics. The size of hymenial elements and pileal structure were presented as MIN-MAX and rounded up up to $0.5 \mu \mathrm{m}$.

\section{DNA extraction, PCR amplification, and sequencing}

Genomic DNA was extracted from fresh or dried material using a modified CTAB extraction protocol of Rogers and Bendich (1994) (Park et al. 2013). Four loci were amplified and sequenced: the ITS, nrLSU, $m c m 7$, and $r p b 2$. PCR amplification and sequencing were conducted in two steps. First, we amplified and sequenced the ITS region from all specimens. Second, we sequenced the nrLSU, $\mathrm{mcm} 7$, and $r p b 2$ loci from the representative specimens of each putative species, which was delimitated by the ITS phylogeny and morphological features.

PCR amplifications were conducted using AccuPower ${ }^{\circledR}$ PCR premix (Bioneer Co., Daejeon, Korea) in a C1000 thermal cycler (Bio-Rad, Hercules, CA, USA). The ITS region was amplified using two primer sets: forward primers ITS1F or ITS5 (White et al. 1990; Gardes and Bruns 1993) and reverse primers ITS4B or Russ3R (Gardes and Bruns 1993; Park et al. 2013). PCR conditions for the ITS are described in Park et al. (2013). The nrLSU region was amplified using ITS3 and LR5 primers (Vilgalys and Hester 1990; White et al. 1990). The PCR conditions for the nrLSU locus were: $5 \mathrm{~min}$ initial denaturation at $95{ }^{\circ} \mathrm{C}$ followed by 35 cycles of $40 \mathrm{~s}$ at $95{ }^{\circ} \mathrm{C}, 40 \mathrm{~s}$ at $55^{\circ} \mathrm{C}$ and $60 \mathrm{~s}$ at $72{ }^{\circ} \mathrm{C}$ with a final extension step for $7 \mathrm{~min}$ at $72{ }^{\circ} \mathrm{C}$. The partial $r p b 2$ locus was amplified using two sets of primers. The first amplification was conducted using the fRPB2-5F and bRPB2-8.2R primers (Liu et al. 1999; Matheny et al. 2007) under the following amplification conditions: $5 \mathrm{~min}$ initial denaturation step at $95^{\circ} \mathrm{C}$, followed by 35 cycles of $1 \mathrm{~min}$ at $95^{\circ} \mathrm{C}, 1 \mathrm{~min}$ at $50^{\circ} \mathrm{C}$ with $0.3{ }^{\circ} \mathrm{C}$ ramp per s to $72{ }^{\circ} \mathrm{C}$ and $1 \mathrm{~min}$ at $72{ }^{\circ} \mathrm{C}$, and a final extension for $10 \mathrm{~min}$ at $72{ }^{\circ} \mathrm{C}$. The primers bRPB2-6F and bRPB2-7.1R or bRPB2-7R (Matheny 2005) were used to amplify domain 6 to 7 of the $r p b 2$ in the second amplification. The PCR program consisted of an initial $5 \mathrm{~min}$ denaturation step at $95{ }^{\circ} \mathrm{C}$, followed by 35 cycles of $40 \mathrm{~s}$ at $95{ }^{\circ} \mathrm{C}, 40 \mathrm{~s}$ at $58^{\circ} \mathrm{C}$ and $60 \mathrm{~s}$ at $72{ }^{\circ} \mathrm{C}$, and a final extension $7 \mathrm{~min}$ at $72{ }^{\circ} \mathrm{C}$. We developed four Russulaceaespecific $\mathrm{mcm} 7$ primers using Primer3 (Rozen and Skaletsky 2000): mcm7-Russ1F (GRA ARG AGT TYA CBC CYA TT), mcm7-Russ2F (GAC TGY CAG AAY GAG AAC GA), mcm7-Russ1R (TGA KAT CSC CAC GRA TYY TCA T), and mcm7-Russ2R (GCT TTC TTS ACG TCR AYR TG). The first amplification of the $m c m 7$ locus was conducted using either the primers mcm7-Russ $1 \mathrm{~F} / \mathrm{mcm} 7$ - 
Russ1R or mcm7-Russ2F/mcm7-Russ $2 \mathrm{R}$ with the same amplification conditions previously described for nrLSU.

All PCR amplicons were checked on a 1\% agarose gel stained with EcoDye DNA staining solution (SolGent Co., Daejeon, Korea). PCR products were purified with the Expin PCR Purification Kit (GeneAll Biotechnology, Seoul, Korea) according to the manufacturer's instructions. DNA sequencing was performed by Macrogen (Seoul, South Korea), using the same set of primers for each locus on an ABI3730 automated DNA Sequencer. Forward and reverse sequences were checked and edited when necessary using FinchTV 1.4.0 (Geospiza, Inc.; http://www.geospiza. com/finchtv) and assembled in Mega 6 (Tamura et al. 2013). Sequences of all DNA regions generated in this study were deposited in GenBank (Supplementary Table 1).

\section{Phylogenetic analyses}

ITS sequences were aligned with Lactarius reference sequences from GenBank and UNITE using MAFFT v. 7.380 (Katoh and Standley 2013). Ambiguously aligned positions were determined using Gblock (Castresana 2000) and excluded from further analyses. Maximum likelihood (ML) analyses were performed using RAxML v. 7.03 (Stamatakis 2006) and the GTR + G model with 1000 bootstrap replicates. A jModelTest 2.1.7 (Darriba et al. 2012) was used to determine the model of character evolution. Bayesian inference (BI) analyses were executed with MrBayes v. 3.2.6 (Ronquist and Huelsenbeck 2003) using the model $\mathrm{K} 80+\mathrm{I}+\mathrm{G}$. The BI analyses were performed with four independent runs in which each run had four chains. Each run had 20 million generations at a sampling frequency of 1000. All analyses were done on the CIPRES Science Gateway (Miller et al. 2010).

Phylogenetic relationships among Korean Lactarius species were determined using sequences of the four loci. Phylogenetic tree was constructed using only sequences from Korean Lactarius species because no reference sequences of the $m c m 7$ locus were available. Sequences of each locus were aligned and analyzed separately. Sequence
Fig. 1 Phylogram generated from Maximum Likelihood (RAxML) analysis based on ITS sequence data of Lactarius. ML bootstrap support values/Bayesian posterior probability greater than 70\%/0.95 are indicated. Korean specimens are marked in bold. Names of the species in red, and green represent new species and previously described species in South Korea, respectively. The names in blue are potentially new species but not be presented as new in this study because they lack morphological data or photographs of basidiomata

alignments were performed using the same method as that of the ITS described above. Alignment properties of each gene were analyzed using MEGA v. 6 (Tamura et al. 2013). ML and BI analyses were performed on the CIPRES Science Gateway with the same criteria used for the ITS. The BI analysis models for the nrLSU, $m c m 7$, and rpb2 loci were $\mathrm{K} 80+\mathrm{I}+\mathrm{G}$, HKY $+\mathrm{I}+\mathrm{G}$, and $\mathrm{SYM}+\mathrm{I}+\mathrm{G}$, respectively. Finally, a combined analysis of the ITS, nrLSU, $m c m 7$, and $r p b 2$ sequences was conducted using the same methods and models previously assigned for each gene. Clades were considered to be independent evolutionary lineages when strongly supported (bootstrap support exceeding 70 and the posterior probability exceeding 0.95).

\section{Results}

\section{Diversity of Lactarius in South Korea}

Among 729 Korean Lactarius specimens examined, ITS fragments of 650-700 bp were successfully sequenced from 525 specimens. The other 204 specimens were excluded from the study due to missing information or poor condition. ITS sequences from 525 sepcimens in Korea was analysized with 238 reference ITS sequences and found to represent 49 species (Fig. 1). To confirm species identity and infer the phylogenetic relationships of Korean Lactarius, three additional loci were amplified and sequenced for 128 specimens representing the 49 species: nrLSU (540-550 bp), rpb2 (630-670 bp), and $\mathrm{mcm} 7$ (420-440 bp). The ITS, nrLSU, rpb2, and $m c m 7$ sequence

Table 1 Alignment properties and nucleotide substitution models

\begin{tabular}{|c|c|c|c|c|c|}
\hline & ITS & nrLSU & $r p b 2$ & $m c m 7$ & Combined 4 loci \\
\hline Characters included (with gaps) & 1068 & 554 & 656 & 453 & 2731 \\
\hline Invariable positions & 693 & 451 & 400 & 254 & 1798 \\
\hline Parsimony informative positions (\%) & $327(31)$ & $92(17)$ & $231(35)$ & $184(41)$ & $834(30)$ \\
\hline Uninformative variable positions & 48 & 11 & 25 & 15 & 99 \\
\hline Number of branches $>70 \%$ bootstrap ML analysis & 11 & 5 & 14 & 18 & 22 \\
\hline Nucleotide substitution models & $\mathrm{K} 80+\mathrm{I}+\mathrm{G}$ & $\mathrm{K} 80+\mathrm{I}+\mathrm{G}$ & $\mathrm{SYM}+\mathrm{I}+\mathrm{G}$ & $\mathrm{HKY}+\mathrm{I}+\mathrm{G}$ & \\
\hline
\end{tabular}




\section{Subgenus}

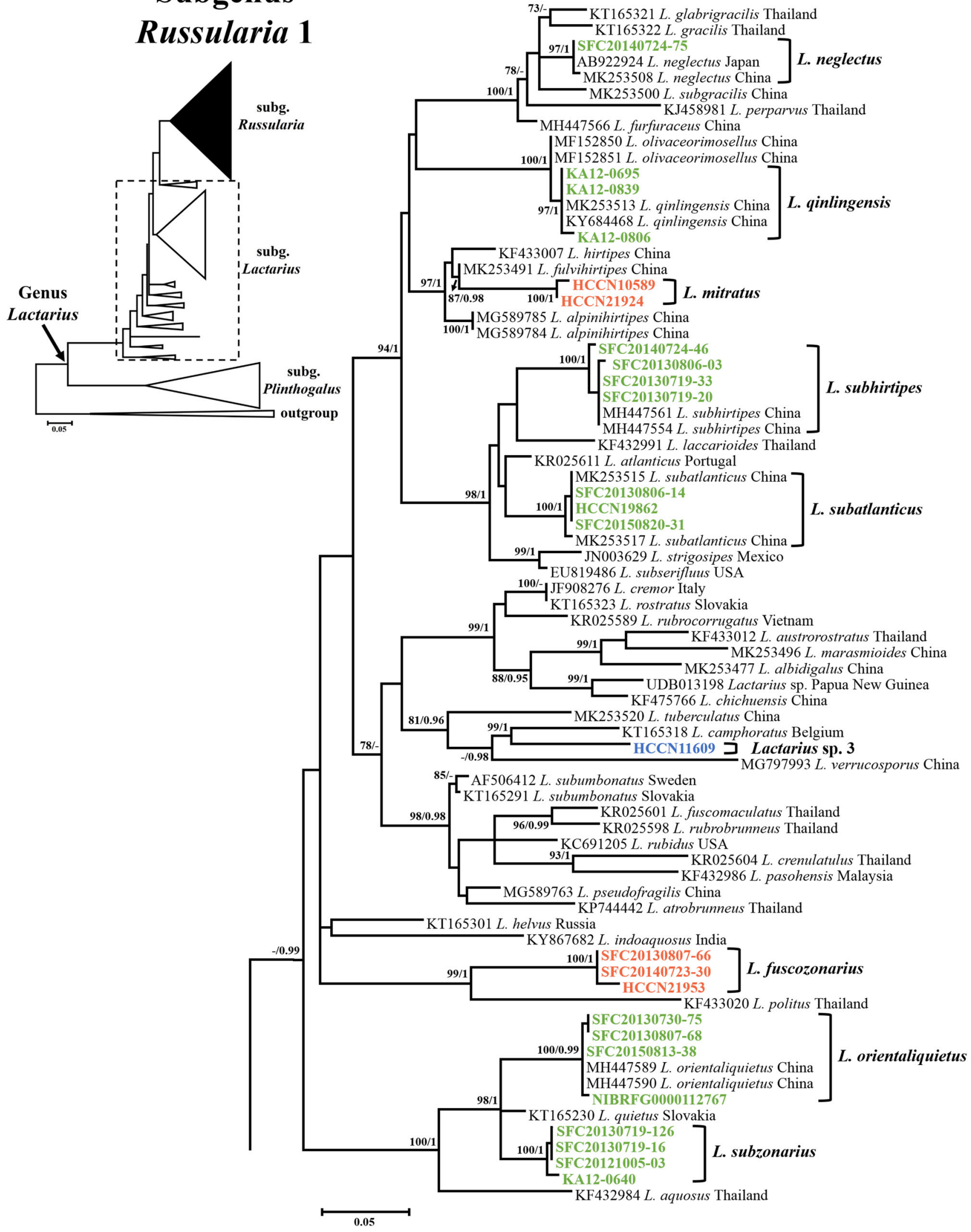






Fig. 1 continued 


\section{Subgenus}

\section{Lactarius 1}

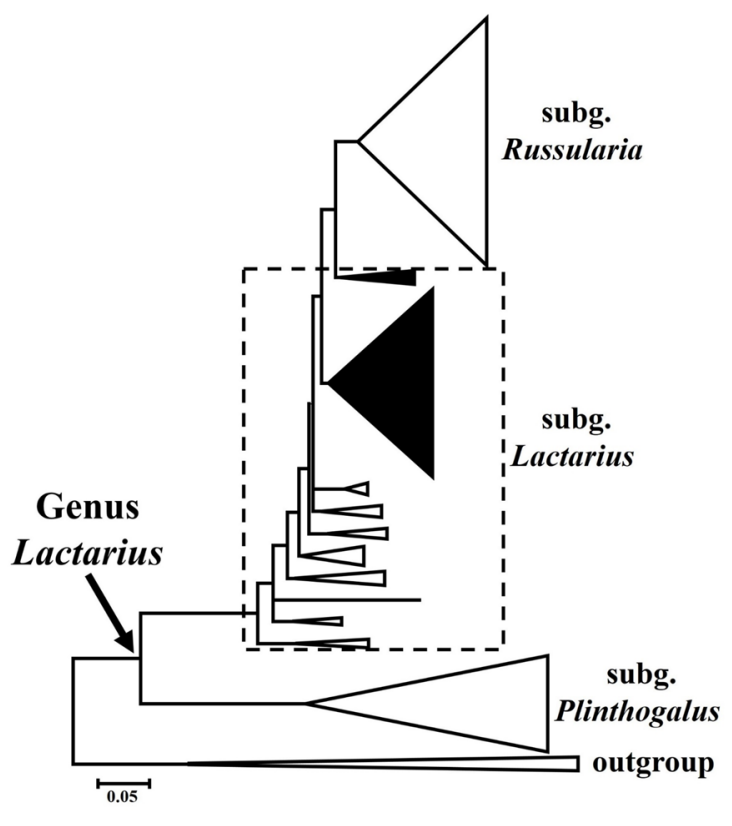

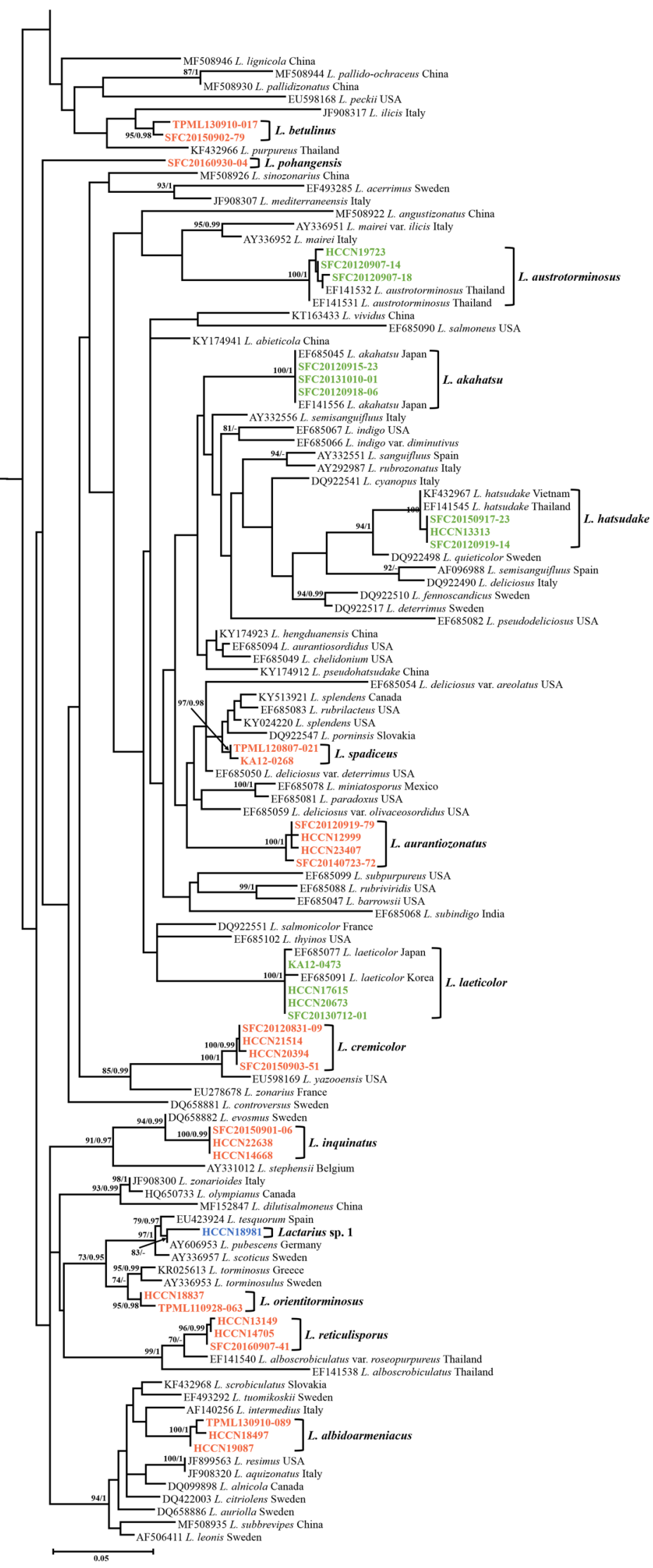

Fig. 1 continued 


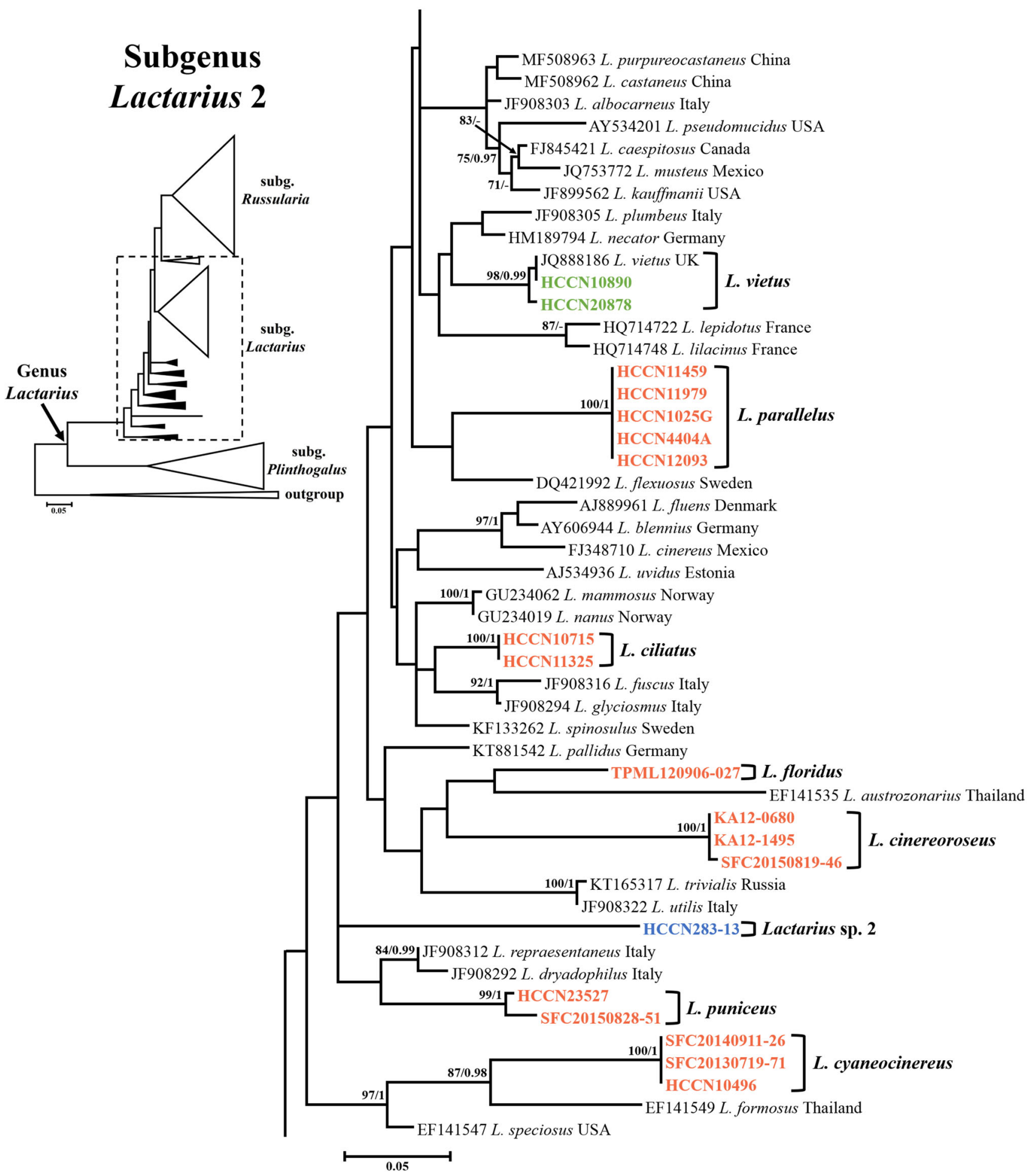

Fig. 1 continued 


\section{Subgenus}

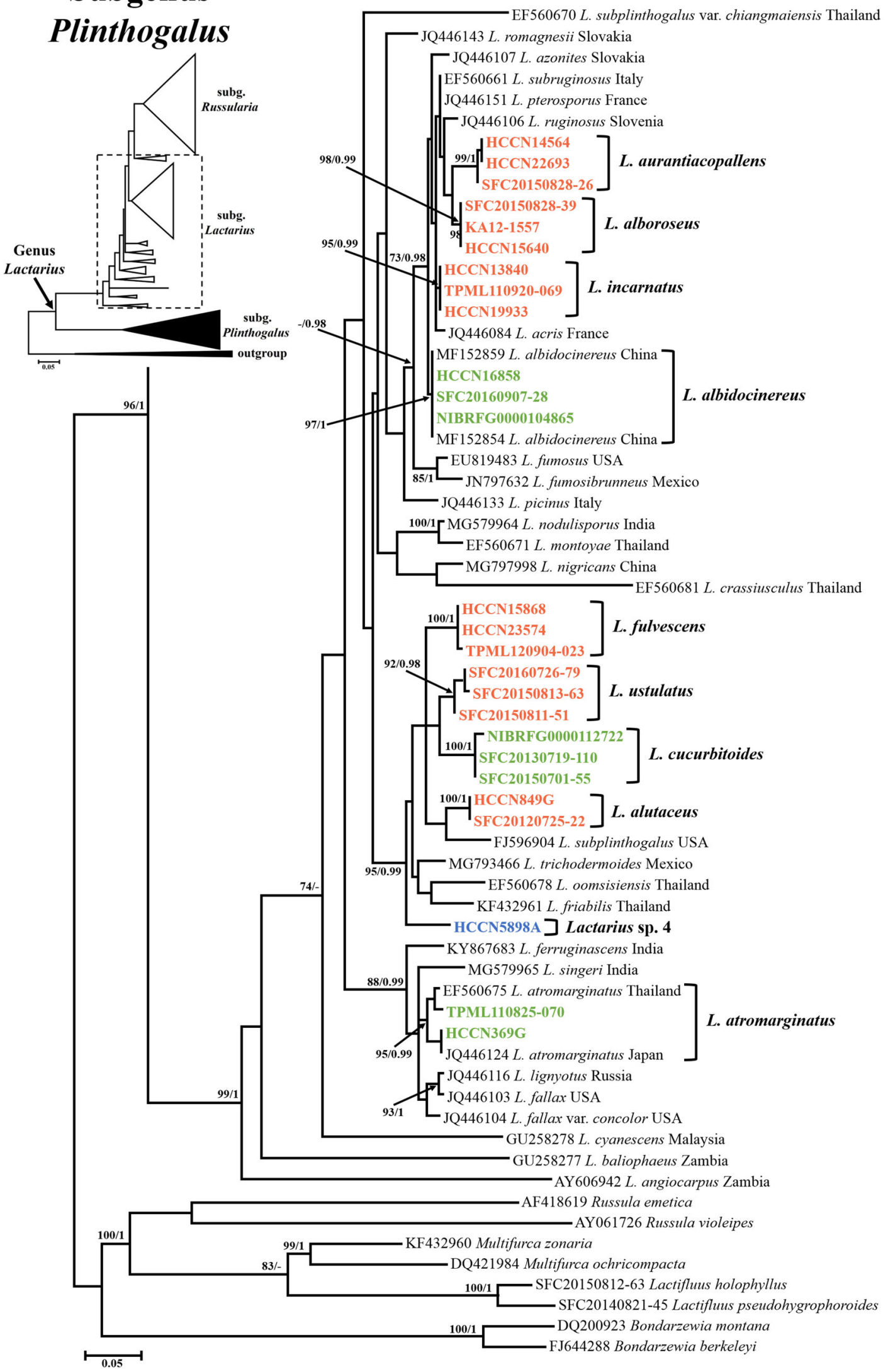

Fig. 1 continued 
alignments consisted of $1068,554,656$, and 453 characters including gaps, variable sites $(375,103,256$, and 199), and informative sites (327, 92, 231 and 184), respectively (Table 1). The ratio of parsimony informative characters of the $m c m 7$ locus (41\%) was the highest among the four loci (Table 1). All species branches were well supported on the $m c m 7$ and $r p b 2$ trees, and the phylogenies were consistent with the ITS tree (data not shown). The nrLSU phylogeny, while largely consistent with the other loci, lacked sufficient bootstrap support for some species (ML bootstrap value/BI posterior probability $<70 / 0.95$ ) (data not shown). Branch numbers representing ML/BI exceeding 70/0.95 were $11,5,14$, and 18 in the phylograms of ITS, nrLSU, $r p b 2$, and $m c m 7$, respectively (Table 1). In the combined dataset, the aligned four loci matrix contained 2,734 bases. Of these aligned bases, 2416 positions were retained using Gblocks. The ML and BI analyses generated nearly identical tree topologies with minimal variation in statistical support values. A ML tree is presented in Fig. 2.

A total 17 taxa were identified as previously described species: Lactarius akahatsu, L. albidocinereus X.H. Wang et al., L. atromarginatus Verbeken \& E. Horak, L. austrotorminosus H.T. Le \& Verbeken, L. cinnamomeus W.F. Chiu, L. conglutinatus X.H. Wang, L. cucurbitoides H. Lee \& Y.W. Lim, L. hatsudake, L. laeticolor (S. Imai) Imazeki ex Hongo, L. neglectus X.H. Wang, L. orientaliquietus X.H.Wang, L. qinlingensis X.H. Wang, L. subatlanticus X.H. Wang, L. subhirtipes X.H. Wang, L. subzonarius Hongo, L. tabidus Fr., and L. vietus (Fr.) Fr. The other 32 taxa formed distinct branches not corresponding to any of the described species. Four of these taxa lack morphological data or photographs of basidiomata, and thus remain un-named until additional data are collected. The other 28 species were confirmed as new to science after morphological comparison with closely related species.

While two subgenera, Lactarius subg. Russularia and $L$. subg. Plinthogalus, form monophyletic clades with strong support, L. subg. Lactarius appears to be paraphyletic (Figs. 1 and 2). The 49 Korean species belong to the three different subgenera in Lactarius: 17 in L. subg. Russularia, 22 species in L. subg. Lactarius, and 10 in L. subg. Plinthogalus (Fig. 1). Lactarius subg. Russularia includes seven new species, one undetermined species and nine previously described species (L. cinnamomeus, L. conglutinatus, L. neglectus, L. orientaliquietus, L. qinlingensis, $L$. subatlanticus, $L$. subhirtipes, $L$. subzonarius, and $L$. tabidus). Lactarius subg. Lactarius appears to be the most diverse in South Korea, with 15 new species, two undetermined species and five previously described species $(L$. akahatsu, L. austrotorminosus, L. hatsudake, L. laeticolor, and $L$. vietus). The smallest subgenus is Lactarius subg. Plinthogalus, with six new species, one undetermined species and three previously described species (L. albidocinereus, L. atromarginatus and L. cucurbitoides).

\section{Morphological characters of Korean Lactarius species}

Lactarius subg. Russularia contains four well supported clades and two unclustered species (Fig. 2). Most species in this subgenus have transparent to watery white or white latex and show no discoloration. A few species have white latex turning pale yellow or strong yellow. Some species have an orange brown pileus or a hispid stipe. Microscopically, the presence of cheilo- and pleuro-macrocystidia and pileipellis structure are variable among species. In this subgenus, clade 1 consists of $L$. citrinus and $L$. lutescens, which is part of the "chrysorrheus group". They have common characters such as a zonate and dry pileus, white latex which turns lemon yellow, and a cutis as pileipellis structure (Fig. 2). Five species (L. mitratus, for description see below, L. neglectus, L. qinlingensis, L. subatlanticus, and L. subhirtipes) in clade 2 have an orange-brown pileus and slender or small basidiomata. Lactarius sp. 3 and $L$. fuscozonarius, see below, form an unsupported clade with long branches which is sister to clade 2 (Fig. 2). Clade 3 contains six species (L. cinnamomeus, $L$. conglutinatus, $L$. tabidus and the new taxa described below, namely $L$. microbuccinatus, L. pectinatus and $L$. subomphaliformis). Species in this clade are characterized by an azonate pileus, a striate pileus margin and incompletely reticulate spore ornamentation with plage inamyloid to slightly amyloid in the distal part. L. orientaliquietus and $L$. subzonarius in clade 4 are placed at the base of this subgenus and belong to the "quietus group" (Figs. 1 and 2). Both species have a zonate pileus and white to watery pale cream latex (Fig. 2).

Lactarius subg. Lactarius contains three clades and seven unclustered species (Fig. 2). These species have a zonate pileus, scrobiculate pileus and stipe, hispid pileus margins, visicid to slimy pileus, and ixocutis to ixotrichoderm pileipellis. Relationships within this subgenus are unclear because of paraphyly and low branch support. Phylogenetic placement of $L$. betulinus (see taxonomic part) is unclear, but morphologically this species fits well in $L$. subg. Lactarius because of the sticky pileus surface with inconspicuous zonation and an ixotrichoderm type pileipellis. Eight species in clade 5 have a variety of morphological features. Lactarius species with lilac, violet, and olive discolouration of latex were included in this clade (Fig. 2). Five species in clade 6 are classified as $L$. section Deliciosi (Fr.) Redeuilh et al. All species have orange or reddish latex, except for $L$. spadiceus and $L$. aurantiozonatus (see taxonomic part below) with white and unchanging latex (Fig. 2). These species are associated with conifers such as Pinus and Abies. Lactarius 

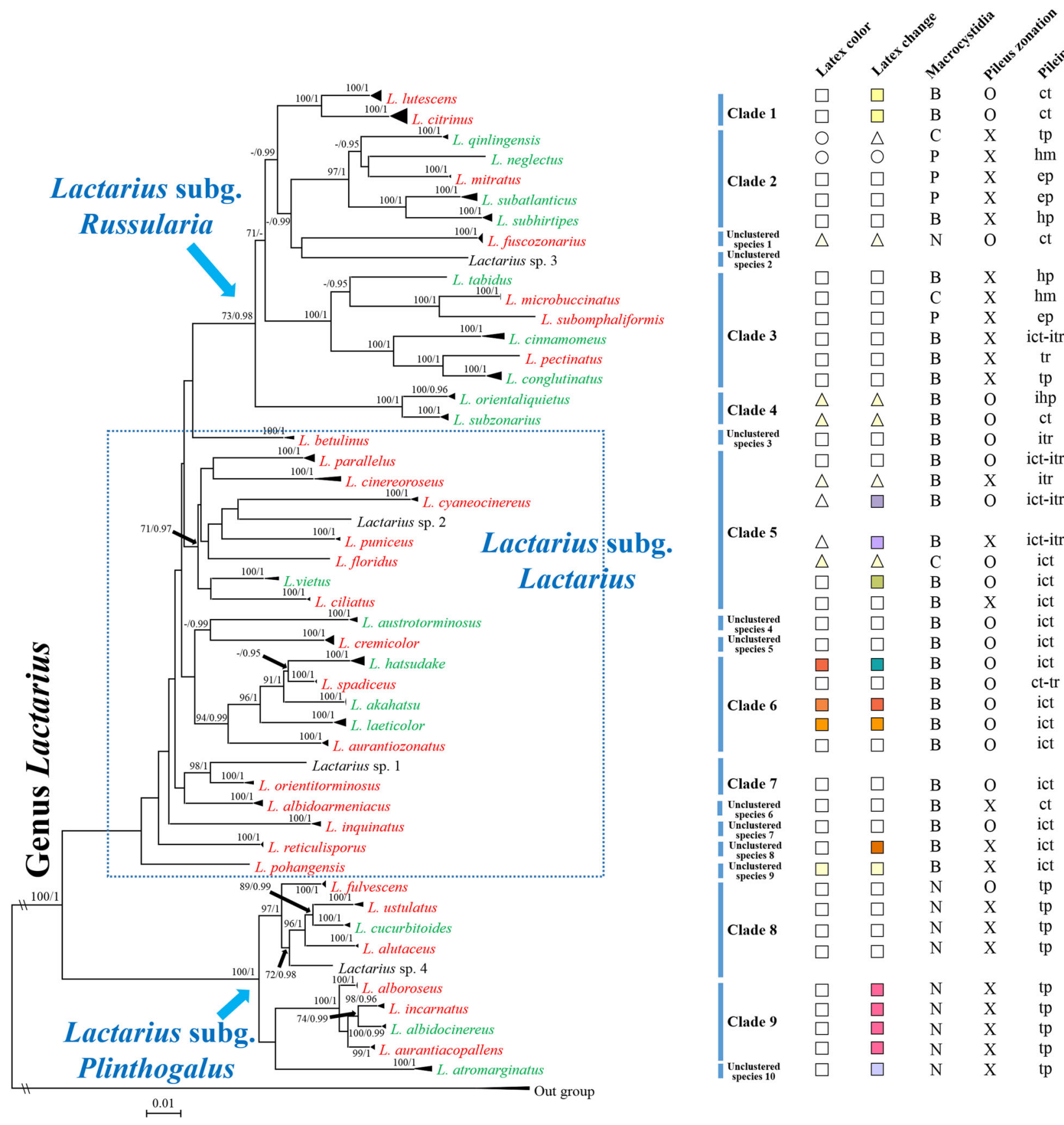

Fig. 2 Phylogram generated from Maximum Likelihood (RAxML) analysis based on combined sequence data of ITS, nrLSU, $r p b 2$, and $m c m 7$ of Korean Lactarius. ML bootstrap support values/Bayesian posterior probability greater than $70 \% / 0.95$ are indicated. Names of the species in red, and green represent new species and previously described species in South Korea, respectively. Abbreviations in Latex color: open square opaque, open triangle translucent, open

austrotorminosus and L. cremicolor (see below) are weakly supported by share characters such as a fibrillose to hispid pileus and white latex. Clade 7 contains two species ( $L$. orientitorminosus, see below, and Lactarius sp. 1). They have a common character such as hispid pileus. $L$. circle transparent latex. Abbreviations in macrocystidia: B both of pleuromacrocystidia and cheilocystidia present, $\mathbf{C}$ only cheilomacrocystidia present, $\mathbf{P}$ only pleuromacrocystidia present, $\mathbf{N}$ no macrocystidia. Abbreviations in pileipellis type: ct cutis, ep epithelium, hm hymenoepithelium, hp hyphoepithelium, ict ixocutis, ihp ixohyphoepithelium, itr ixotrichoderm, tp trichopalisaded, tr trichoderm

albidoarmeniacus (see below) has a slightly tomentose pileus and is a sister to clade 7. The other unclustered new species $L$. inquinatus, L. pohangensis, and L. reticulisporus (see below) are placed at the base of the major clade of subg. Lactarius/Russularia. 

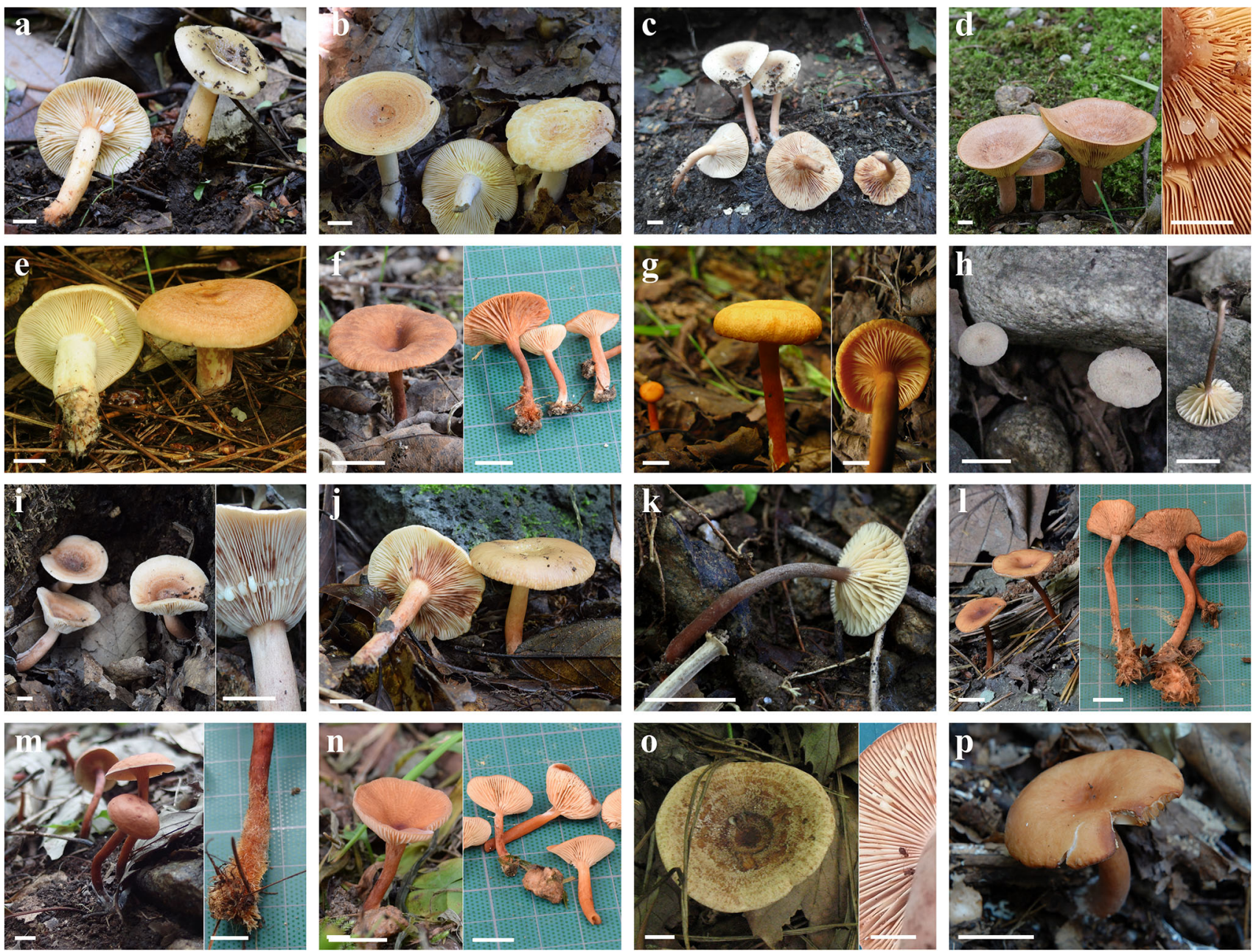

Fig. 3 Fruiting bodies of Korean species of Lactarius subg. Russularia. a $L$. cinnamomeus, b $L$. citrinus, c $L$. conglutinatus, $\mathbf{d} L$. fuscozonarius, e L. lutescens, $\mathbf{f} L$. microbuccinatus, $\mathbf{g} L$. mitratus, $\mathbf{h} L$. neglectus, $\mathbf{i} L$. orientaliquietus, $\mathbf{j} L$. pectinatus, $\mathbf{k} L$. qinlingenesis, $\mathbf{l} L$.

Lactarius subg. Plinthogalus has two supported clades and one unclustered species (Fig. 2). The dry, velvety and azonate pileus (typical for the subgenus) are shown in all species except $L$. fulvescens (see taxonomic part). Microscopically, Korean species of $L$. subg. Plinthogalus share a winged spore ornamentation, a trichopalisade, presence of cheiloleptocystidia, and absence of macrocystidia. Clade 8 contains five taxa that are characterized by unchanging white latex (Fig. 2). Clade 9 consists of four species $(L$. albidocinereus, $L$. incarnatus, and the other two new taxa, namely $L$. alboroseus and $L$. aurantiacopallens) which have pinkish discolouring latex. Finally, L. atromarginatus, which exhibits white latex with lilac discolouration, is placed at the basal position of clade 9 (Figs. 2, 3, 4).

subatlanticus, $\mathbf{m}$ L. subhirtipes, $\mathbf{n}$ L. subomphaliformis, o $L$. subzonarius, $\mathbf{p}$ L. tabidus. Scale bar $=1 \mathrm{~cm}$. $\mathbf{a}$ and $\mathbf{p}$ are reproduced from Lee et al. (2018)

\section{Taxonomy}

Taxonomic keys to species in South Korea and the full descriptions of the new species are provided below. Abbreviations in Figs. 5, 6, 7, 8, 9, 10, 11, 12, 13, 14, 15, $16,17,18,19,20,21,22,23,24,25,26,27,28,29,30,31$, 32, 33, 34, 35, and 36 are as follows: ba basidia, clc cheiloleptocystidia, cmc cheilomacrocystidia, me marginal cells, pc pseudocystidia, pmc pleuromacrocystidia, pp pileipellis. All scale bars $=10 \mu \mathrm{m}$. Horizontal scale bars are for pileipellis and vertical scale bars are for other microscopic features. 

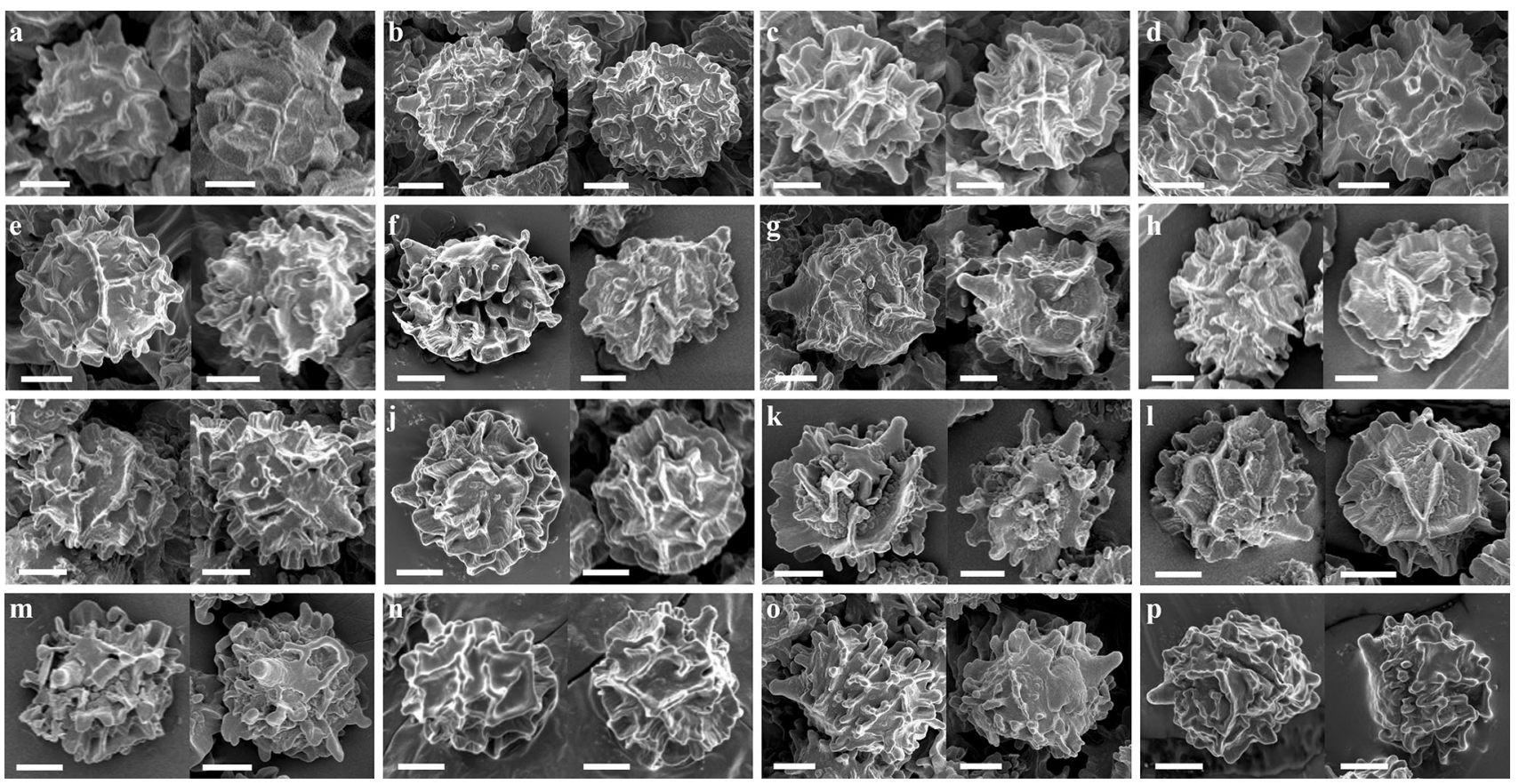

Fig. 4 Basidiospores (SEM) of Korean species of Lactarius subg. Russularia. a L. cinnamomeus, $\mathbf{b} L$. citrinus, $\mathbf{c}$ L. conglutinatus, $\mathbf{d} L$. fuscozonarius, e L. lutescens, $\mathbf{f} L$. microbuccinatus, $\mathbf{g}$ L. mitratus, $\mathbf{h} L$. neglectus, $\mathbf{i}$ L. orientaliquietus, $\mathbf{j}$ L. pectinatus, $\mathbf{k}$ L. qinlingenesis, $\mathbf{l} L$.

\section{Key to the species of Lactarius subgenus Russularia in South Korea}

1. Completely transparent latex; small-sized basidiomata; pileus colour of full grown specimen dark brown to violet brown; pileipellis a trichopalisade

\section{L. qinlingensis}

1. Latex white or cream ..................................2

2. White latex turning lemon yellow quickly on exposure; pileipellis a cutis......................................

2. Latex unchanging or slowly turning pale yellow on exposure; pileipellis not a cutis ........................4

3. Associated with Pinus; pleurocystidia with moniliform apex .................................... L. lutescens

3. Associated with Quercus; pleurocystidia with obtuse apex.......................................... L. citrinus

4. Latex turning slowly pale yellow, turning pale on white cotton tissue, associated with Betula ......... L. tabidus

4. Latex unchanging .................................. 5

5. Pileus size smaller than $25 \mathrm{~mm}$ diam. ................. 6

5. Pileus size larger than $25 \mathrm{~mm}$ diam. ................. 8

6. Distant lamellae; pleurocystidia with distinctively acuminate to rostrate apex; pileipellis a hymenoepithelium .................................... L. neglectus

6. Crowded lamellae .........................................

7. Spore ornamentation up to $0.6 \mu \mathrm{m}$ high; pileipellis a trichopalisade

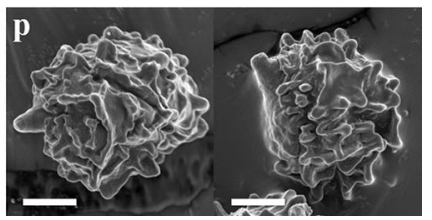

subatlanticus, m L. subhirtipes, n L. subomphaliformis, o L. subzonarius, $\mathbf{p}$ L. tabidus. Scale bar $=2 \mu \mathrm{m}$. $\mathbf{a}$ and $\mathbf{p}$ are adapted from Lee et al. (2018)

7. Spore ornamentation mininum up to $1.1 \mu \mathrm{m}$ high; pileipellis an epithelium ............ L. subomphaliformis

8. Macrocystidia absent; basidiospores almost reticulate ........................................ L. fuscozonarius

8. Macrocystidia present................................ 9

9. Pileus often viscid in moist condition, pileipellis gelatinized ................................................ 10

9. Pileus dry; pileipellis never with gelatinous layer............................................ 11

10. Pileus zonate; basidiomata pinkish buff; pileipellis an ixohyphoepithelium of approximately $85-120 \mu \mathrm{m}$ thick ..L. orientaliquietus

10. Pileus azonate; basidiomata grayish yellow to reddish blond; pileipellis an ixocutis to ixotrichoderm of approximately $150-200 \mu \mathrm{m}$ thick

L. cinnamomeus

11. Relatively thick and short stipe.................... 12

11. Thin and long stipe ................................ 13

12. Zonate pileus with reddish brown colour.................. ............................................L. subzonarius

12. Azonate pileus with light orange colour, pileus margin distinctively pectinate ........................ L. pectinatus

13. Long stipe with strigose base, pileus colour of full grown specimens warm orange brown to reddish brown ............................................ 14

13. Long stipe without strigose base, pileus colour of full grown specimen pale orange brown ................... 15 
Fig. 5 Microscopic features of Lactarius citrinus
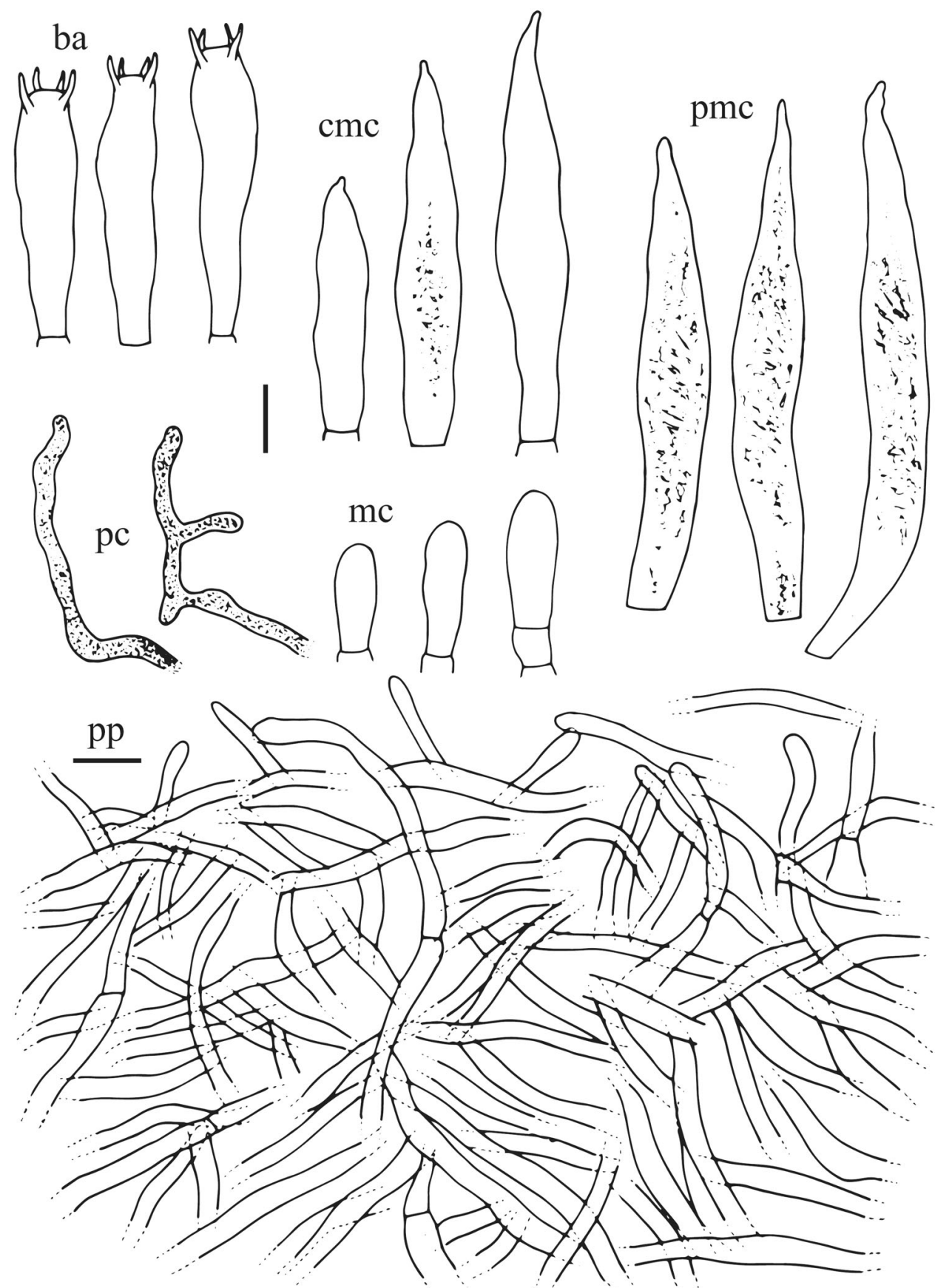

14. Pileipellis a hyphoepithelium, often thinner than $100 \mu \mathrm{m}$, terminal cells covered by parallel cylindrical hyphae L. subhirtipes

14. Pileipellis an epithelium, often thicker than $100 \mu \mathrm{m}$, terminal cells globose L. subatlanticus

15. Pileipellis an epithelium, $90-150 \mu \mathrm{m}$ thick; pleurocystidia with capitate apex .L. mitratus

15. Pileipellis a trichopalisade, $130-210 \mu \mathrm{m}$ thick; pleurocystidia with mucronate to moniliform apex L. conglutinatus

\section{Lactarius subgenus Russularia}

Lactarius citrinus H. Lee, Wisitr. \& Y.W. Lim, sp. nov.

MycoBank: MB 827895

Etymology: 'citrinus' means lemon-coloured referring to the lemon yellow discolouration of latex.

Holotypus: SOUTH KOREA, Jeollabuk-do, Jinan-gun, Unjangsan Natural Recreation Forest, alt. $464 \mathrm{~m}$, N35 $53^{\prime} 56^{\prime \prime}$ E127 $25^{\prime} 05^{\prime \prime}$, 11 Sep 2014 (SFC20140911-60) 
Fig. 6 Microscopic features of Lactarius fuscozonarius

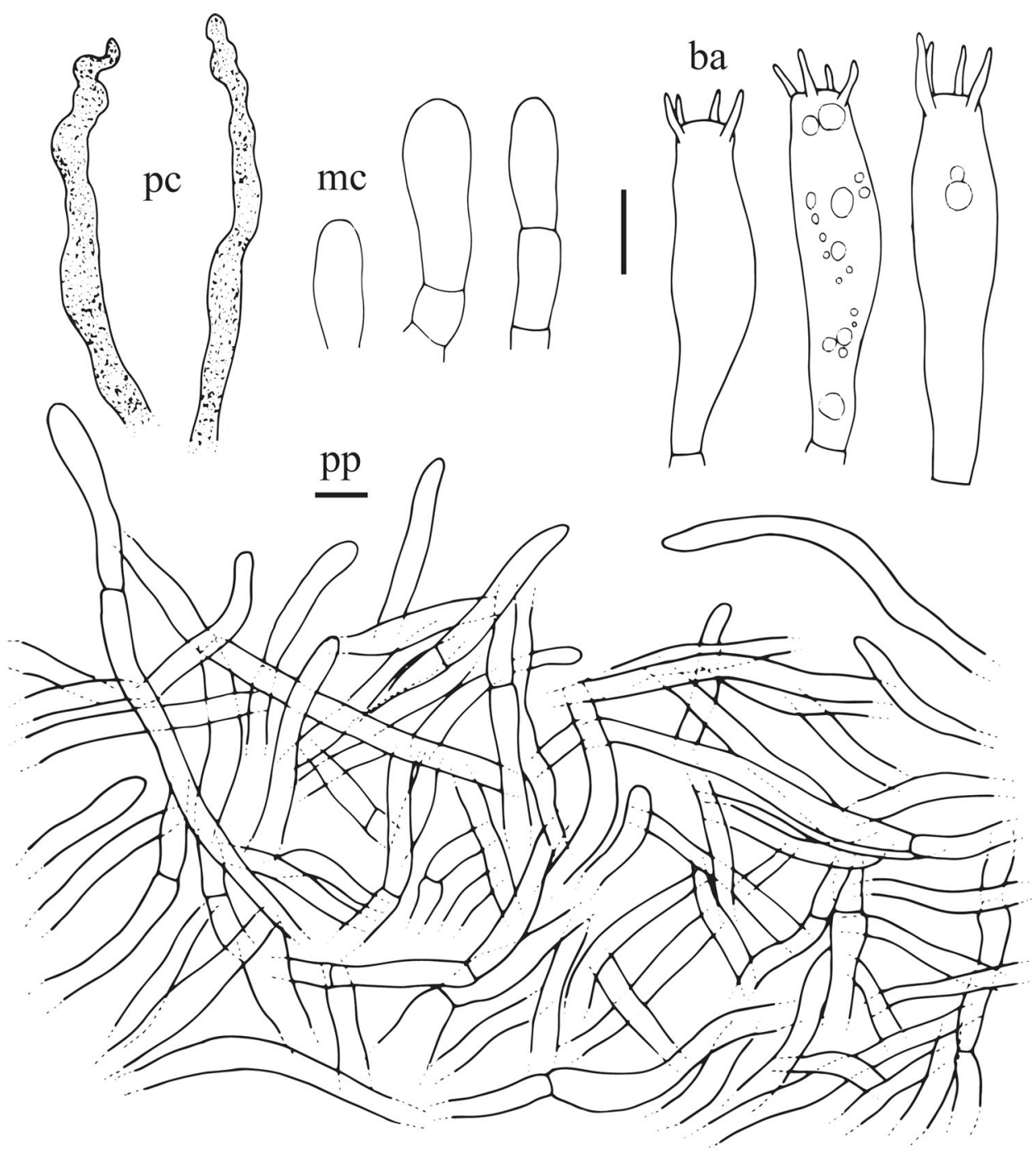

Pileus $30-70 \mathrm{~mm}$ diam., convex then applanate to infundibuliform; margin first inrolled, in age expanded, uneven; surface orange white (5A2) to pale red (7A3), often with yellowish tinges, smooth, fibrillose, rugulose when young, often inconspicuously zonate, sometimes distinctly zonate, with pale orange brown spots in the zonation. Lamellae adnate to slightly decurrent, rather crowded, sometimes forked, with abundant lamellulae, up to $5 \mathrm{~mm}$ broad, white to pale apricot when young, cream to pale orange brown in age, staining pale greyish brown when bruised. Stipe $35-80 \times 10-25 \mathrm{~mm}$, cylindrical, fistulose in age; surface whitish grey when young, concolourous with lamellae or darker in age, sometimes slightly longitudinally striated, sometimes with white mycelia at the base. Odour unremarkable. Taste mild, sometimes slightly acrid. Latex rather abundant, white quickly changing to lemon yellow, drying pale yellowish ocher.
Basidiospores $(\mathrm{n}=40),(6.4-) 6.6-7.8-7.9-9.0 \times$ $5.7-6.4-6.6-7.5 \mu \mathrm{m}, \mathrm{Q}=1.03-1.14-1.17-1.29$, mostly subglobose to broadly ellipsoid, few globose; ornamentation amyloid, composed of up to $0.8 \mu \mathrm{m}$ high, irregular and branched short ridges and isolated warts, connected by fine lines, forming an incomplete reticulum; plage inamyloid. Basidia $34-51 \times 7.5-10 \mu \mathrm{m}$, 4-spored, cylindrical to narrowly clavate. Pleuromacrocystidia numerous, $68.5-87 \times 10-11.5 \mu \mathrm{m}$, narrowly fusiform to lanceolate, mostly emergent beyond the hymenium; apex mucronate to slightly acute. Lamellar edges consisting of marginal cells, cheilomacrocystidia and basidia; marginal cells cylindrical to narrowly clavate; cheilomacrocystidia numerous, $35-61 \times 7.5-11 \mu \mathrm{m}$, narrowly fusiform to cylindrical, apex slightly acute to obtuse. Pseudocystidia numerous, aseptate, mostly embedded, sometimes inconspicuously emergent, irregular, 2-5 $\mu \mathrm{m}$ broad, sometimes multiple branched near apex; apex rounded, sometimes slightly broader. Pileipellis a cutis, 110-190 $\mu \mathrm{m}$ thick, 
composed of parallel to intricate cylindrical hyphae; terminal cells $15-70 \times 3-6 \mu \mathrm{m}$.

Habitat: Scattered to gregarious on soil in forests dominated by Quercus.

Additional studied material: SOUTH KOREA, Gyeongsangbuk-do, Sangju-si, Seongjubong Natural Recreation Forest, alt. 269 m, N36 $31^{\prime} 58^{\prime \prime}$ E $128^{\circ} 02^{\prime} 24^{\prime \prime}, 19$ Jul 2013 (SFC20130719-87); ibid., alt. 179 m, N37 $17^{\prime} 38^{\prime \prime}$ E127 $18^{\prime} 42^{\prime \prime}$, 6 Aug 2013 (SFC20130806-14).

Comments: Lactarius citrinus is phylogenetically related to L. chrysorrheus Fr. (Europe), L. lutescens (see below), L. indochrysorrheus K. Das \& Verbeken (India), L. vinaceorufescens A.H. Sm. (North America), L. xanthogalactus Peck (North America), and L. xanthogalus Verbeken \& E. Horak (Papua New Guinea). These species have common characters such as quickly changing latex, distinct pileus zonation, and $( \pm)$ ixocutis. Lactarius chrysorrheus has smaller cheilomacrocystidia $(25-50 \times 5-9 \mu \mathrm{m})$ than L. citrinus (Heilmann-Clausen et al. 1998). The host tree and the more greyish lamellae distinguish $L$. lutescens from L. citrinus. Lactarius vinaceorufescens and $L$. indochrysorrheus can be distinguished from $L$. citrinus by the gelatinous pileipellis (Hesler and Smith 1979, Das et al. 2015). L. xanthogalactus has globose spores and darker pileus (pinkish cinnamon to reddish brown) than L. citrinus (Hesler and Smith 1979). The basidiospore ornamentation of $L$. xanthogalus is distinguished from the other species by its zebroid ornamentation (Verbeken and Horak 2000).

Lactarius fuscozonarius H. Lee, Wisitr. \& Y.W. Lim, sp. nov.

\section{MycoBank: MB 827899}

Etymology: 'fusco' means dark brown, 'zonarius' means zonation. It refers to the dark brown zonation on the pileus.

Holotypus: SOUTH KOREA, Jeollabuk-do, Jinan-gun, Unjangsan Natural Recreation Forest, alt. $520 \mathrm{~m}$, N35 54'45" E127²4'10", 23 Jul 2014 (SFC20140723-30) Pileus $30-100 \mathrm{~mm}$ diam., convex then applanate to infundibuliform; margin first decurved, in age expanded, uneven to crenate, striated; surface orange white (6A2) to pastel red (9A4), with brown to dark brown zonation dry, minutely fibrillose, inconspicuously zonate to distintly zonate. Lamellae slightly decurrent to decurrent, rather crowded, often forked near the stipe, rarely multifurcate, with abundant lamellulae, up to $3 \mathrm{~mm}$ broad, pale cream when young, concolourous to pileus in age. Stipe $20-80 \times 8-15 \mathrm{~mm}$, cylindrical, sometimes tapering downwards, fistulose; surface pale brown when young, dark brown in age, sometimes slightly longitudely striated. Odour unremarkable to slightly fruity. Taste mild, sometimes slightly acrid. Latex rather abundant, translucent cream to watery white, unchanging.

Basidiospores $\quad(\mathrm{n}=40), \quad 6.3-7.1-7.5-8.2 \times$ $5.6-6.3-6.5-7.1(-7.2) \quad \mu \mathrm{m}, \quad \mathrm{Q}=1.00-1.13-$ $1.15-1.28$, globose to broadly ellipsoid; ornamentation amyloid, composed of up to $0.7 \mu \mathrm{m}$ high, irregular and branched long ridges and isolated small warts, forming almost complete reticulum, connected by fine lines; plage inamyloid to weakly amyloid in the distal part. Basidia $38.5-47 \times 8.5-11 \mu \mathrm{m}, 4$-spored, mostly cylindrical to narrowly clavate, sometimes ventricose. Macrocystidia absent. Lamellar edges consisting of marginal cells and basidia; marginal cells mostly cylindrical, sometimes cylindrical to narrowly clavate, Pseudocystidia numerous, aseptate, mostly conspicuous emergent, sometimes embedded, irregular, 2-4 $\mu \mathrm{m}$ broad, multiple branched near apex; apex rounded, sometimes moniliform. Pileipellis $90-160 \mu \mathrm{m}$ thick, a cutis, composed of parallel to intricate cylindrical hyphae; terminal cells $35-85 \times 2-7 \mu \mathrm{m}$.

Habitat: Scattered to gregarious on moss covered soil in mixed forests dominated by Pinus.

Additional studied material: SOUTH KOREA: Gangwondo, Pyeongchang-gun, Mt. Odae, alt. $1155 \mathrm{~m}, 37^{\circ} 45^{\prime} 30^{\prime \prime}$ E128 35'44", 26 Aug 2011 (HCCN21953); Gyeongsangbuk-do, Yecheon-gun, Mt. Maebong, alt. $538 \mathrm{~m}$, N36 $44^{\prime} 03^{\prime \prime}$ E128 $21^{\prime} 54^{\prime \prime}, 7$ Aug 2013 (SFC20130807-66).

Comments: Lactarius fuscozonarius is characterized by the orange white to pastel red coloured, zonate and fibrillose pileus surface, and watery white to milky latex. This species is distinguished from other species of $L$. subg. Russularia in Korea by the absence of macrocystidia and the almost completely reticulate basidiospore. Lactarius politus Wisitr. \& K.D. Hyde from Thailand is the phylogenetically closest species to L. fuscozonarius (Fig. 1). However, the Thai species has much darker colour and heavier basidiospore ornamentation (up to $2.5 \mu \mathrm{m}$ ) than $L$. fuscozonarius (Wisitrassameewong et al. 2015).

Lactarius lutescens H. Lee, Wisitr. \& Y.W. Lim, sp. nov. MycoBank: MB 827901

Etymology: 'lutescens' means becoming yellow which refers to the yellowing milk of the species.

Holotypus: SOUTH KOREA, Gangwon-do, Wonju-si, Mt. Chiak, alt. $494 \mathrm{~m}, \mathrm{~N} 37^{\circ} 24^{\prime} 51^{\prime \prime}$ E128 $03^{\prime} 34^{\prime \prime}, 1$ Oct 2011 (SFC20111001-11)

Pileus $30-60 \mathrm{~mm}$ diam., convex then applanate to infundibuliform; margin first decurved, in age expanded, sometimes uneven; surface orange white (6A2) to pale red (8C3), often with yellowish tinge, with greyish red 
Fig. 7 Microscopic features of Lactarius lutescens


zonation, often with red brown spots, with distinct zonation, sometimes inconspicuous zonate, smooth, fibrillose, rugulose when young. Lamellae adnate, rather crowded, very rarely forked near the stipe, with abundant lamellulae, up to $5 \mathrm{~mm}$ broad, white to pale apricot when young, cream to pale greyish brown in age. Stipe $30-50 \times 8-15 \mathrm{~mm}$, cylindrical, fistulose; surface whitish grey when young, concolourous with lamellae, with pale greyish brown tinge, sometimes with white mycelia at the base. Odour unremarkable to faintly fruity. Taste slightly acrid. Latex rather abundant, white rapidly turning to lemon yellow.

$$
\text { Basidiospores } \quad(\mathrm{n}=40), \quad 5.9-6.8-6.9-8.0
$$
$\times(5.0-) 5.1-6.0-6.2-7.0 \mu \mathrm{m}, \mathrm{Q}=1.06-1.15-$ 1.30, subglobose to broadly ellipsoid; ornamentation amyloid, composed of up to $0.7 \mu \mathrm{m}$ high, irregular and branched short ridges and isolated warts, forming an incomplete reticulum, connected by fine lines; plage amyloid in the distal part. Basidia
$36-48.5 \times 8.5-11 \mu \mathrm{m}, 4$-spored, cylindrical to narrowly clavate. Pleuromacrocystidia numerous, $65.5-82 \times 8.5-10 \mu \mathrm{m}$, narrowly fusiform to lanceolate, mostly emergent beyond the hymenium, apex obtuse. Lamellar edges consisting of marginal cells, cheilomacrocystidia and basidia; marginal cells cylindrical to narrowly clavate; cheilomacrocystidia numerous, $45-78 \times 8.5-11.5 \mu \mathrm{m}$, cylindrical to fusiform. Pseudocystidia numerous, aseptate, mostly embedded, sometimes inconspicuous emergent, irregular, 2-5 $\mu \mathrm{m}$ broad, branched near apex; apex rounded, sometimes slightly broader. Pileipellis 130-250 $\mu \mathrm{m}$ thick, a cutis, comprised of parallel to intricate cylindrical hyphae; terminal cells $35-110 \times 1.5-4 \mu \mathrm{m}$, underlying layer of isodiametric cells $6-28 \mu \mathrm{m}$ broad.

Habitat: Scattered to gregarious on soil in forests dominated by Pinus. 
Additional studied material: SOUTH KOREA, Gangwondo, Pyeongchang-gun, Mt. Odae, alt. 985 m, N37 $45^{\prime} 39^{\prime \prime}$ E128 $35^{\prime} 10^{\prime \prime}$, 18 Oct 2010 (HCCN20945); ibid., alt. $888 \mathrm{~m}, \quad \mathrm{~N} 37^{\circ} 45^{\prime} 07^{\prime \prime} \quad \mathrm{E} 128^{\circ} 34^{\prime} 59^{\prime \prime}, \quad 9 \quad$ Sep 2013 (TPML130909-073).

Comments: Lactarius citrinus (see above) and L. lutescens are members of the chryssorheus group. They are distinguished by their host trees; the former is associated with Quercus and the latter with Pinus. For a comparison with other species of the chrysorrheus group, refer the comments of L. citrinus mentioned above.

Lactarius microbuccinatus H. Lee, Wisitr. \& Y.W. Lim, sp. nov.

\section{MycoBank: MB 827902}

Etymology: 'microbuccinatus' means small and trumpetshaped which refers to small-sized and funnel-shaped like trumpet of the basidiomata.

Holotypus: SOUTH KOREA, Gyeonggi-do, Goyang-si, Seo-o-reung Royal Tombs, alt. $147 \mathrm{~m}, \mathrm{~N} 37^{\circ} 37^{\prime} 60^{\prime \prime}$ E126 54'19", 13 Aug 2015 (SFC20150813-62)
Pileus $8-25 \mathrm{~mm}$ diam., convex then applanate to infundibuliform with obtuse umbo; margin first decurved, in age expanded, often rugose to crenate; surface orange (6A6) to brownish orange (7C6), dry, smooth, radially rugulose to striated, pruinose when young. Lamellae decurrent, rather crowded, rarely forked near the stipe, with abundant lamellulae, up to $2 \mathrm{~mm}$ broad, pale cream to pale orange brown, staining greyish brown when bruised. Stipe $10-40 \times 2-4 \mathrm{~mm}$, cylindrical, fistulose in age; surface concolourous with pileus or darker, pruinose to slightly tomentose, with pale cream to orange brown hairs at the base, sometimes fasciculate with stipes of 2-3 basidiomata. Odour unremarkable. Taste bitter. Latex rather scarce, white, unchanging on exposure.

Basidiospores $(\mathrm{n}=40), 5.9-6.6-6.8-7.8(-8.0) \times$ $4.8-5.7-5.8-6.8(-7.0) \quad \mu \mathrm{m}, \quad \mathrm{Q}=1.00-1.19-$ 1.42 , globose to ellipsoid; ornamentation amyloid, composed of up to $0.6 \mu \mathrm{m}$ high, irregular and branched short ridges and isolated warts, forming an incomplete reticulum, connected by fine lines, joined by fine lines; plage inamyloid. Basidia $30.1-38.9 \times 8.4-10.4 \mu \mathrm{m}$, 4-spored, narrowly clavate to clavate. Pleuromacrocystidia absent. Lamellar
Fig. 8 Microscopic features of Lactarius microbuccinatus
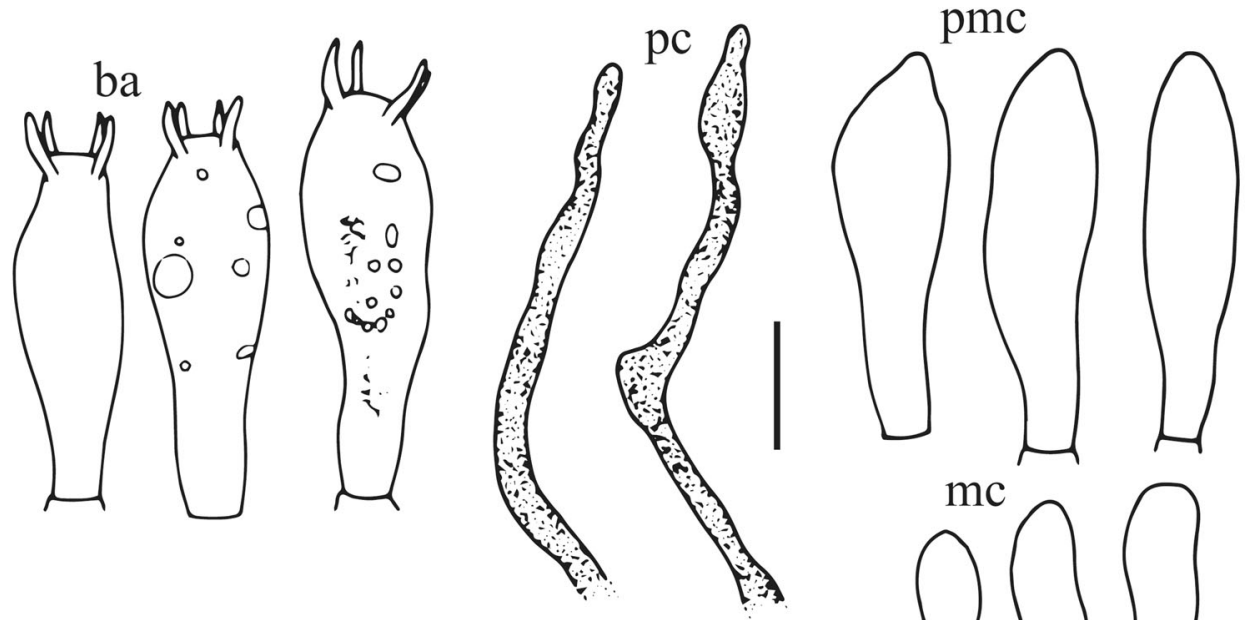

$\mathrm{mc}$
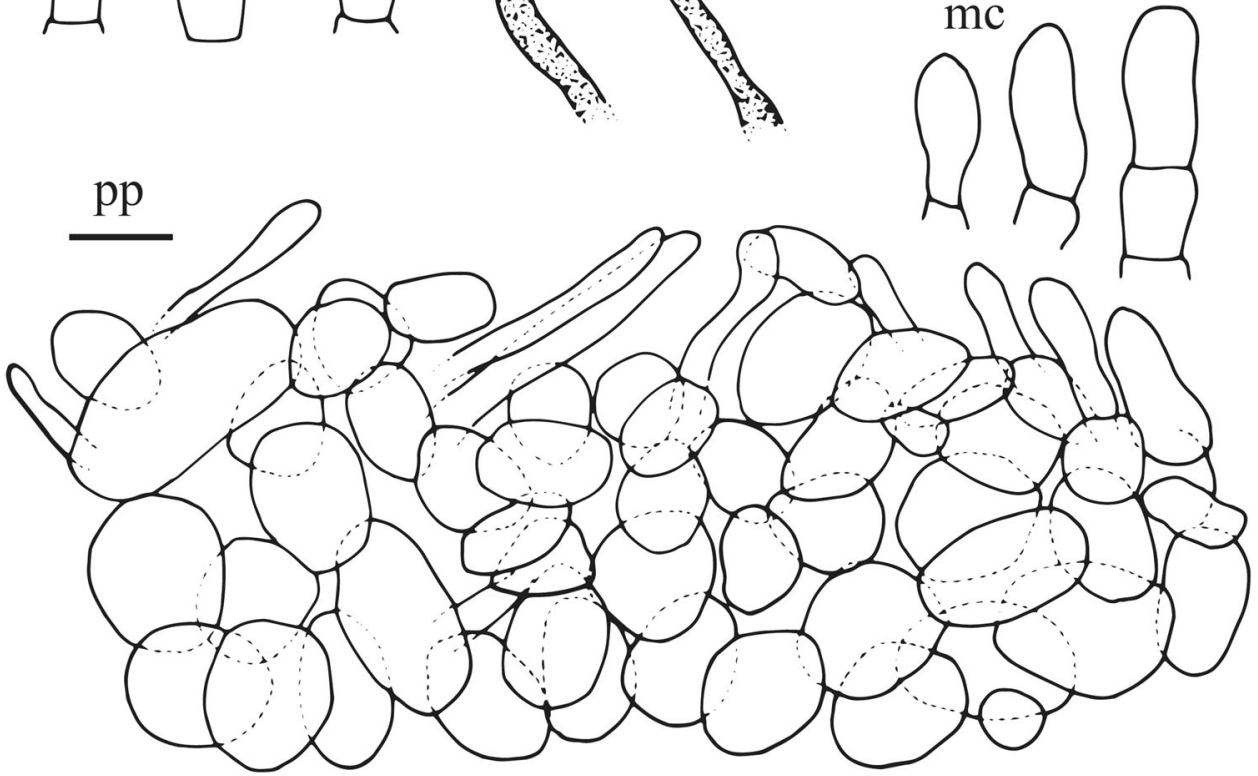
edges consisting of marginal cells, cheilomacrocystidia and basidia; marginal cells cylindrical to clavate; cheilomacrocystidia abundant, $18.5-29.5 \times 7.5-9.5 \mu \mathrm{m}$, fusiform to ventricose, apex obtuse to slightly acute. Pseudocystidia numerous, aseptate, embedded, rarely inconspicuous emergent, irregular, sometimes branched near apex, apex rounded, often slightly broader, 2-5 $\mu \mathrm{m}$ broad. Pileipellis $50-110 \mu \mathrm{m}$ thick, a trichopalisade; terminal cells $7.5-21 \times$ $4.5-8.5 \mu \mathrm{m}$, cylindrical; subpellis comprised of globose to isodiametric cells, up to $25 \mu \mathrm{m}$ broad.

Habitat: Solitary or scattered on soil in mixed forests dominated by Quercus.

Additional studied material: SOUTH KOREA, Gyeonggido, Pocheon-si, Korean Arboretum, alt. 121 m, 3744 $55^{\prime \prime}$ E12709'55", 8 Aug 2012 (KA12-0944).

Comments: Lactarius microbuccinatus is characterized by its small size and the funnel-shaped pileus in mature specimens, the hispid stipe, incompletely reticulate basidiospores, and hymenoepithelium pileipellis. This species can be distinguished from the other small-sized species in South Korea by the series of lamellulae and absence of pleurocystidia. This species is phylogenetically closely related to the European L. omphaliformis Romagn (Fig. 1). However, L. omphaliformis has pleuromacrocystidia and larger basidiospores $(6.9-9.6 \times 5.5-7.8 \mu \mathrm{m})$ (Heilmann-Clausen et al. 1998).

Lactarius mitratus H. Lee, Wisitr. \& Y.W. Lim, sp. nov. MycoBank: MB 827903

Etymology: 'mitratus' means hood or felt pileus, referring to the capitate or knob-like head on the apex of pleuromacrocystidia.

Holotypus: SOUTH KOREA, Gyeongsangbuk-do, Yeongju-si, Mt. Sobaek, alt. $669 \mathrm{~m}$, N36 $55^{\prime} 50^{\prime \prime}$ E128 29'28', 24 Aug 2011 (HCCN21924; isotype, SFC)

Pileus 20-50 mm diam., convex then applanate to wide infundibuliform; margin first slight depression with inrolled, in age decurved, even, sometimes crenulate; surface orange yellow (4A6) to light orange (5A5), rough, dry, finely rugulose. Lamellae slightly decurrent to decurrent, rather distant, rarely forked, with abundant lamellulae, up to $6 \mathrm{~mm}$ broad, yellowish orange, staining orange to reddish brown when bruised. Stipe $30-65 \times$ $5-15 \mathrm{~mm}$, cylindrical, fistulose in age; surface concolourous with lamellae or darker, surface slightly
Fig. 9 Microscopic features of Lactarius mitratus
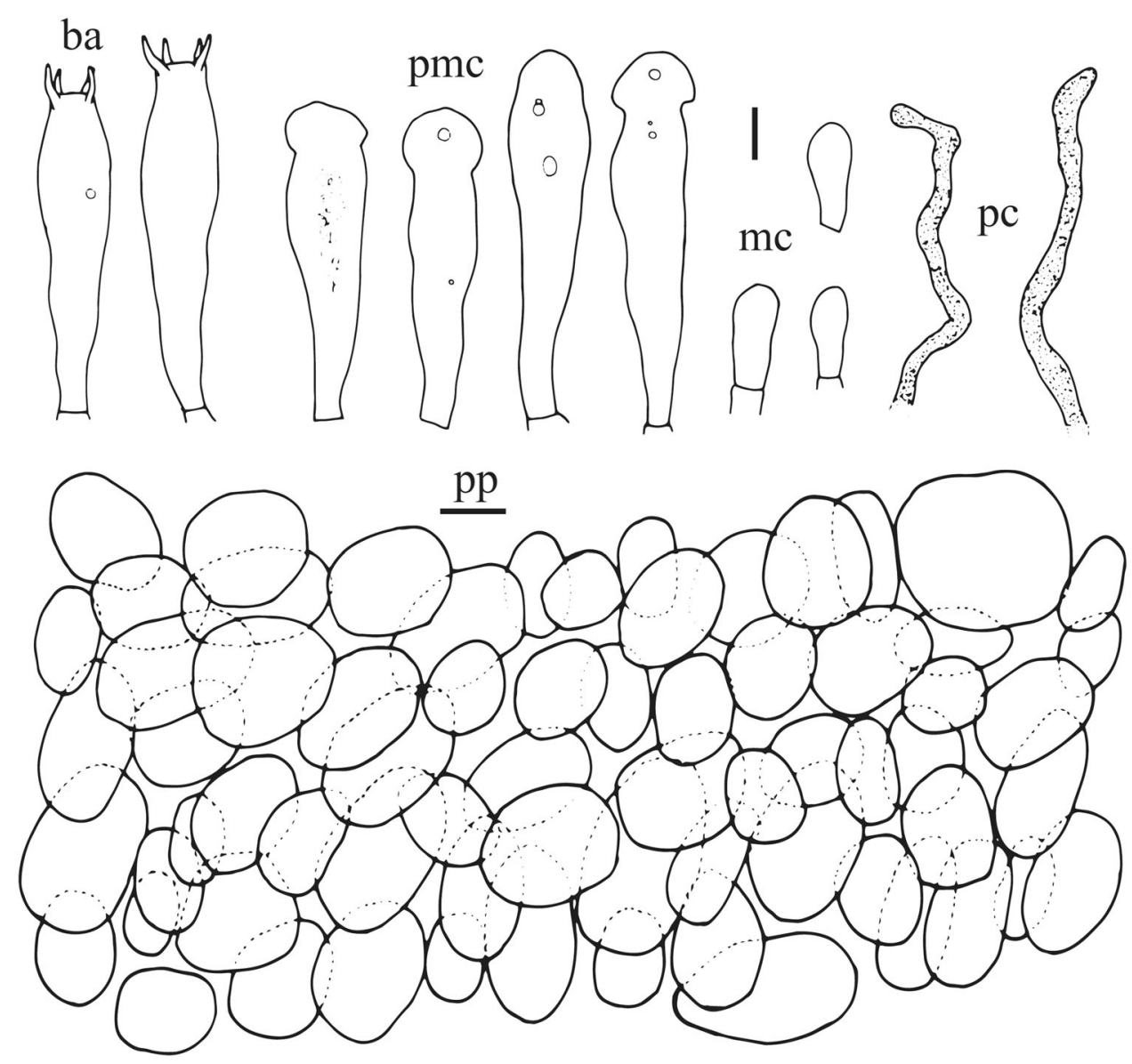
longitudinaly striated. Latex rather scarce, white, unchanging on exposure.

Basidiospores $\quad(\mathrm{n}=40), \quad 7.1-8.1-8.4-9.5$ $(-9.6) \times 6.2-7.2-7.3-8.4 \mu \mathrm{m}$,

$\mathrm{Q}=1.02-1.14-1.16-1.32$, subglobose to ellipsoid, few globose; ornamentation amyloid, composed of up to $1.3 \mu \mathrm{m}$ high, irregular and branched long ridges and isolated warts, forming an incomplete reticulum; plage amyloid in the distal part. Basidia $45.5-61 \times 10-12.5 \mu \mathrm{m}$, 4-spored, narrowly clavate. Pleuromacrocystidia numerous, $47-61 \times 10-12.5 \mu \mathrm{m}$, narrowly clavate, irregular to straight, slightly emergent beyond the hymenium; apex obtuse, mostly capitate. Lamellar edges consisting of marginal cells and basidia; marginal cells narrowly clavate to clavate; cheilomacrocystidia absent. Pseudocystidia numerous, 2-5 $\mu \mathrm{m}$ broad, aseptate, embedded to slightly emerging, irregular, sometimes branched near apex, apex rounded, often slightly broader. Pileipellis 90-150 $\mu \mathrm{m}$ thick, an epithelium, comprised of globose to isodiametric cells, up to $30 \mu \mathrm{m}$ broad.

Habitat: Scattered on soil in mixed forests dominated by Abies.

Additional studied material: SOUTH KOREA: Jeollabukdo, Muju-gun, Baekryeonsa temple, alt. $909 \mathrm{~m}$, N35 $51^{\prime} 38^{\prime \prime}$ E127 $46^{\prime} 03^{\prime \prime}, 17$ Aug 2002, HCCN10589 $(\mathrm{HCCN})$.

Comments: Lactarius mitratus is characterized by the knob-like head on the apex of pleuromacrocystidia. This species is phylogenetically closely related to L. hirtipes Ying (Fig. 1), However, L. hirtipes has lanceolate macrocystidia while L. miratus has capitate macrocystidia (Wang and Liu 2002).

Lactarius pectinatus H. Lee, Wisitr. \& Y.W. Lim, sp. nov. MycoBank: MB 827904

Etymology: 'pectinatus' means the form of a comb and refers to the radially striated and rugulose pileus margin.
Holotypus: SOUTH KOREA, Jeju-do, Jeju-si, Dongbaekdongsan, alt. $144 \mathrm{~m}, \mathrm{~N} 33^{\circ} 30^{\prime} 57^{\prime \prime}$ E126 $43^{\prime} 15^{\prime \prime}$, 1 Jul 2015 (SFC20150701-64)

Pileus 25-45 mm diam., convex to applanate with slightly depressed centre, with obtuse umbo; margin decurved, often crenulate to radially folded; surface pale yellow (4A3) to light orange (5A4), slightly viscid in moist condition. Lamellae adnate to slightly decurrent, rather crowded, rarely forked near the stipe, with abundant lamellulae, up to $5 \mathrm{~mm}$ broad, pale yellow to pale cream, staining greyish red brown when bruised. Stipe $25-55 \times 6-12 \mathrm{~mm}$, cylindrical, fistulose; surface concolourous with pileus when young, orange brown to reddish brown with age, longitudinally striated, pruinose to slightly tomentose, with white mycelial strains at the base. Odour faintly fishy. Taste mild. Latex rather scarce, pale cream, unchanging on exposure, drying whitish.

Basidiospores $\quad(\mathrm{n}=20), \quad 6.4-7.3-8.2 \times(5.6-)$ $5.7-6.4-7.1 \mu \mathrm{m}, \quad \mathrm{Q}=1.03-1.14-1.28, \quad$ mostly subglobose to broadly ellipsoid, few globose; ornamentation amyloid, composed of up to $1.3 \mu \mathrm{m}$ high, irregular and forked ridges and isolated warts, forming an incomplete reticulum, closed meshes present; plage inamyloid to slightly amyloid in the distal part. Basidia $35-44.5 \times 8.5-11 \mu \mathrm{m}$, narrowly clavate, mostly 4-spored, 2-spored and 1-spored present. Pleuromacrocystidia rare, $64.5-86 \times 5.5-11 \mu \mathrm{m}$, narrowly fusiform to lanceolate, conspicuous emergent, narrowly fusiform, irregular to straight, apex mucronate. Lamellar edges consisting of marginal cells, cheilomacrocystidia and basidia; marginal cells cylindrical to narrowly clavate; cheilomacrocystidia abundant, $23.5-43.5 \times 5-9 \mu \mathrm{m}$, emergent, narrowly fusiform to lanceolate, apex mucronate. Pseudocystidia abundant, aseptate, mostly emergent, tortuous, 2-5 $\mu \mathrm{m}$ broad; apex rounded. Pileipellis a trichoderm, 75-110 $\mu \mathrm{m}$ thick, terminal cells $9.5-42.5 \times$ $2-4 \mu \mathrm{m}$, cylindrical, subpellis comprise isodiametric oval cells, up to $28 \mu \mathrm{m}$ broad. 
Fig. 10 Microscopic features of Lactarius pectinatus

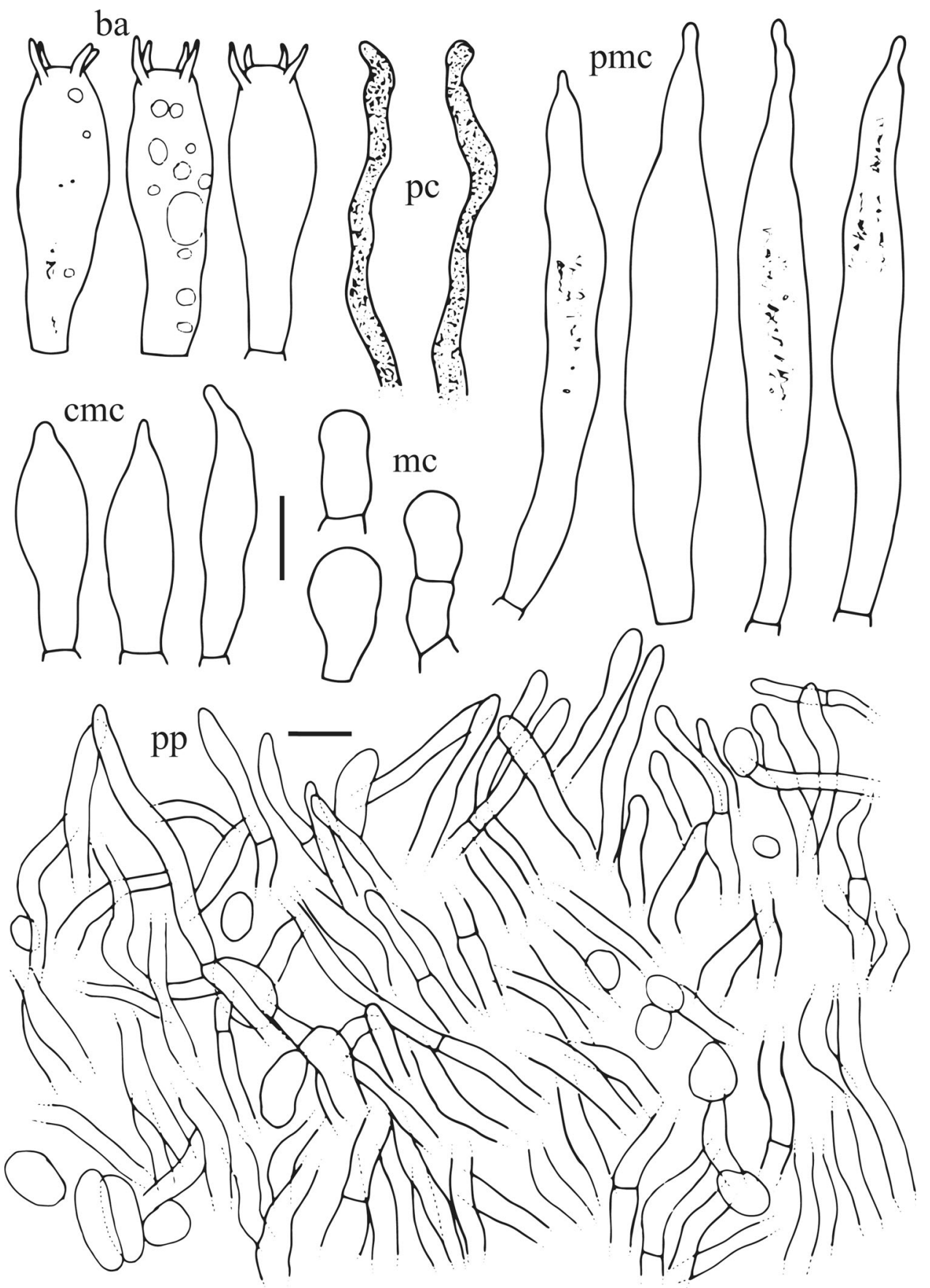

Habitat: Scattered on humid soil in mixed forests dominated by Pinus and evergreen Quercus.

Comments: Lactarius pectinatus is distinguished from the other species of $L$. subg. Russularia by its brightly yellow pileus, conspicuously pectinate pileus margin, pale cream latex, flesh staining greyish red brown on places with dried latex, and pileipellis an epithelium. This species is phylogenetically closely related to $L$. imperceptus Beardslee \& Burl. (North America), L. eucalypti O.K. Mill. \& R.N. Hilton (Australia), and L. conglutinatus from China
(Fig. 1). However, L. eucalypti can be distinguished from this species by the more reddish brown pileus (Miller \& Hilton 1986). Lactarius imperceptus has a glabrous and zonate pileus, latex tuning yellowish, and gelatinous pileipellis (Hesler and Smith 1979). Lactarius conglutinatus can be distinguished from L. pectinatus by its pale yellowish brown pileus, white, unchanging latex, and gelatinous pileipellis (Wang 2018).

Lactarius subomphaliformis H. Lee, Wisitr. \& Y.W. Lim, sp. nov. 
Fig. 11 Microscopic features of Lactarius subomphaliformis

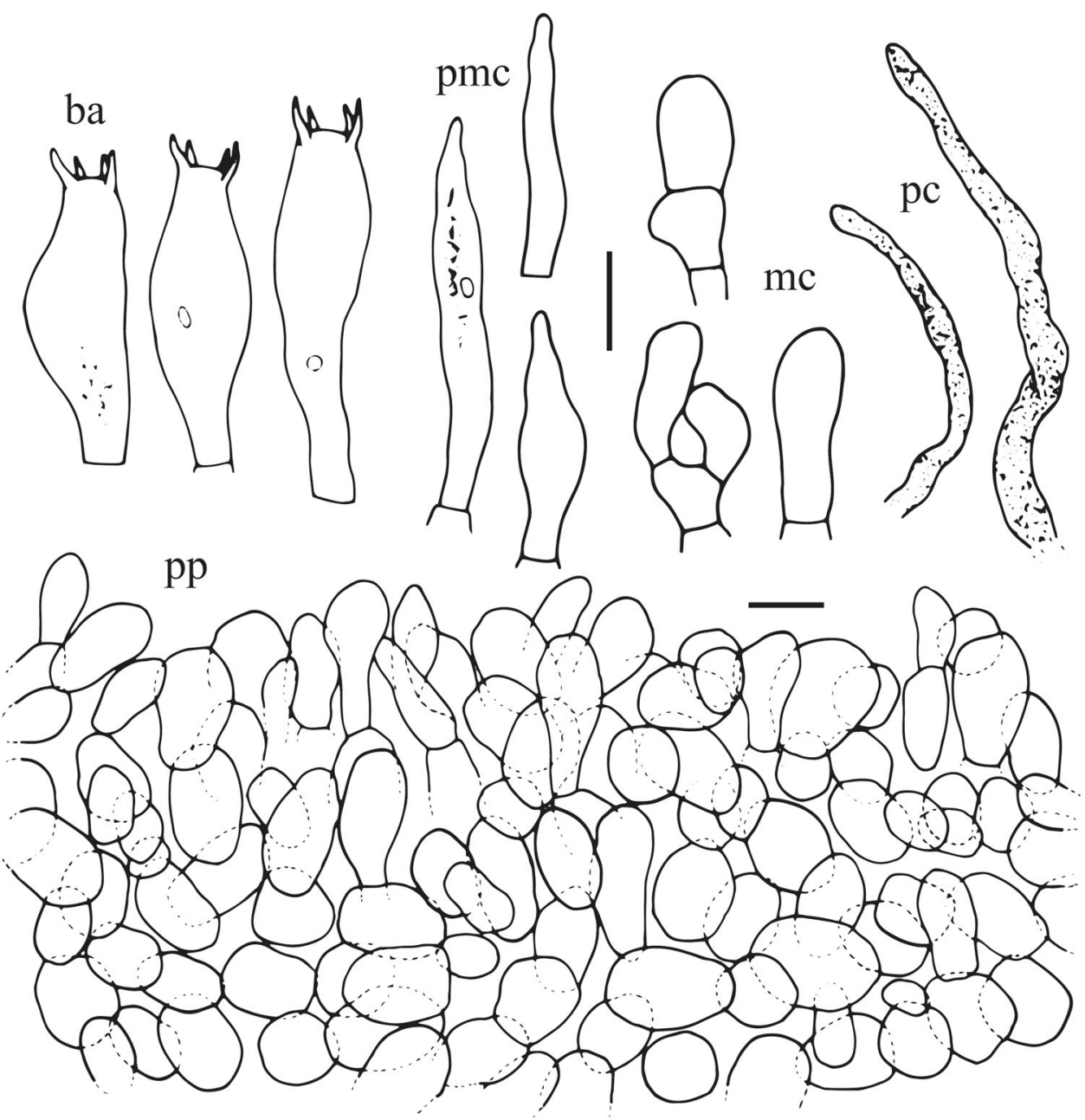

\section{MycoBank: MB 827905}

Etymology: 'sub' means almost and 'omphaliformis' means L. omphaliformis. This name refers the similar features of L. omphaliformis.

Holotypus: SOUTH KOREA, Gyeonggi-do, Guri-si, Donggu-reung Royal Tombs, alt. $46 \mathrm{~m}, \mathrm{~N} 37^{\circ} 37^{\prime} 07^{\prime \prime}$ E12707'50', 11 Aug 2015 (SFC20150811-30)

Pileus 8-25 mm diam., convex then applanate to infundibuliform with obtuse umbo; margin first decurved, in age expanded, often uneven to crenulate; surface orange (6A6) to brownish orange (7C6), dry, smooth, radially rugulose to striated, cracked pattern in age, pruinose when young. Lamellae decurrent, rather crowded, rarely forked near the stipe, with abundant lamellulae, up to $2 \mathrm{~mm}$ broad, pale cream to pale orange brown, staining greyish brown when bruised. Stipe $10-40 \times 2-4 \mathrm{~mm}$, cylindrical, fistulose in age; surface concolourous with pileus or darker, pruinose to slightly tomentose, with pale cream to orange brown hairs at the base, sometimes fasciculate with stipes of 2-3 basidiomata. Odour unremarkable. Taste mild. Latex rather scarce, white, unchanging on exposure.

Basidiospores $\quad(\mathrm{n}=20), \quad 5.7-6.6-7.5(-8.1) \times 5.0$ $-5.4-5.9(-6.1) \mu \mathrm{m}, \mathrm{Q}=1.11-1.21-1.33$, mostly subglobose to broadly ellipsoid, rarely ellipsoid; ornamentation amyloid, composed of up to $1.1 \mu \mathrm{m}$ high, irregular and branched ridges and isolated warts, forming an incomplete reticulum, ridge round to slightly acute; plage inamyloid to slightly amyloid in the distal part. $B a$ sidia $23-32 \times 8-10 \mu \mathrm{m}$, narrowly clavate, mostly 4-spored, 2-spored and 1-spored present, contents small granules and guttulate. Pleuromacrocystidia rare, $19.5-44 \times 2.5-6.5 \mu \mathrm{m}$, if present, rather small, not emergent to inconspicuous emergent, narrowly fusiform, irregular to straight, slightly acute to mucronate apex. Lamellar edges consisting of marginal cells and basidia; marginal cells cylindrical to narrowly clavate in general, obovoid to clavate uncommon; cheilocystidia absent. Pseudocystidia abundant, aseptate, 2.5-5 $\mu \mathrm{m}$ broad, tortuous, round apex. Pileipellis an epithelium, 60-90 $\mu \mathrm{m}$ thick; suprapellis with terminal cells $7.5-19 \times 5.5-10 \mu \mathrm{m}$, 
narrowly clavate, sometimes broadly clavate and obovoid cells, subpellis contains isodiametric cells mixed with inflated or broadly cylindrical hyphae, $7-16 \mu \mathrm{m}$ broad, lactiferous hyphae present.

Habitat: Scattered on the ground in mixed forests dominated by Quercus.

Comments: Lactarius subomphaliformis is characterized by its slender and small basidiomata, orange pileus, cracks on the pileus center of mature specimens, the presence of cystidia, and pileipellis an epithelium. This species is similar to L. obscuratus (Lasch) Fr., L. cyathuliformis Bon, and $L$. omphaliformis reported from Europe. These European species are all exclusively ectomycorrhizal with Alnus trees (Heilmann-Clausen et al. 1998), while the Korean species is found in Quercus forests. In addition, European species have bigger basidiospores and pleurocystidia (Heilmann-Clausen et al. 1998).
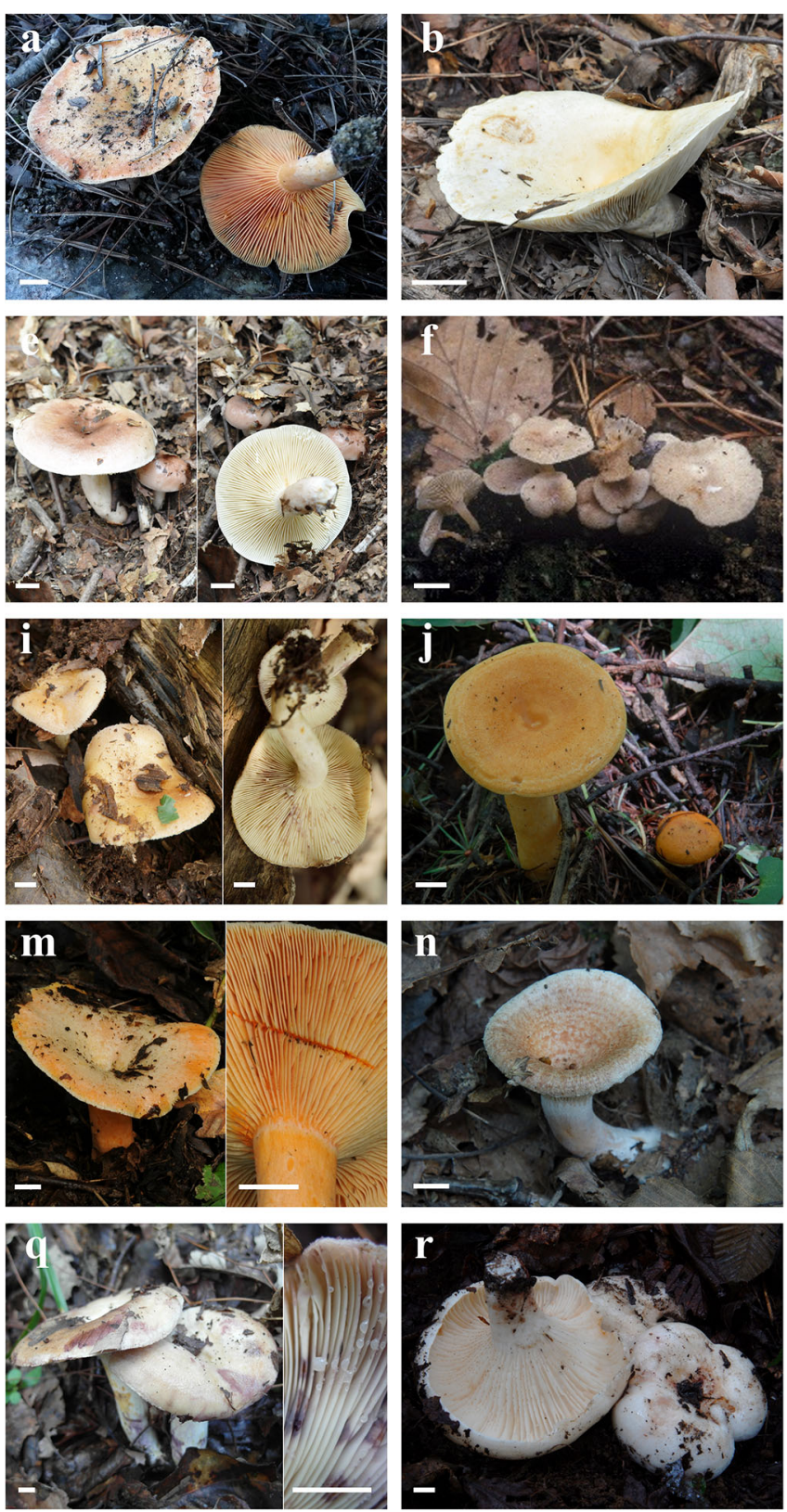

Fig. 12 Fruiting bodies of Korean species of Lactarius subg. Lactarius. a L. akahatsu, b L. albidoarmeniacus, c L. aurantiozonatus, d $L$. austrotorminosus, e $L$. betulinus, f $L$. ciliatus, g $L$. cinereoroseus, $\mathbf{h}$ L. cremicolor, $\mathbf{i}$ L. cyaneocinereus, $\mathbf{j}$ L. floridus, $\mathbf{k} L$.
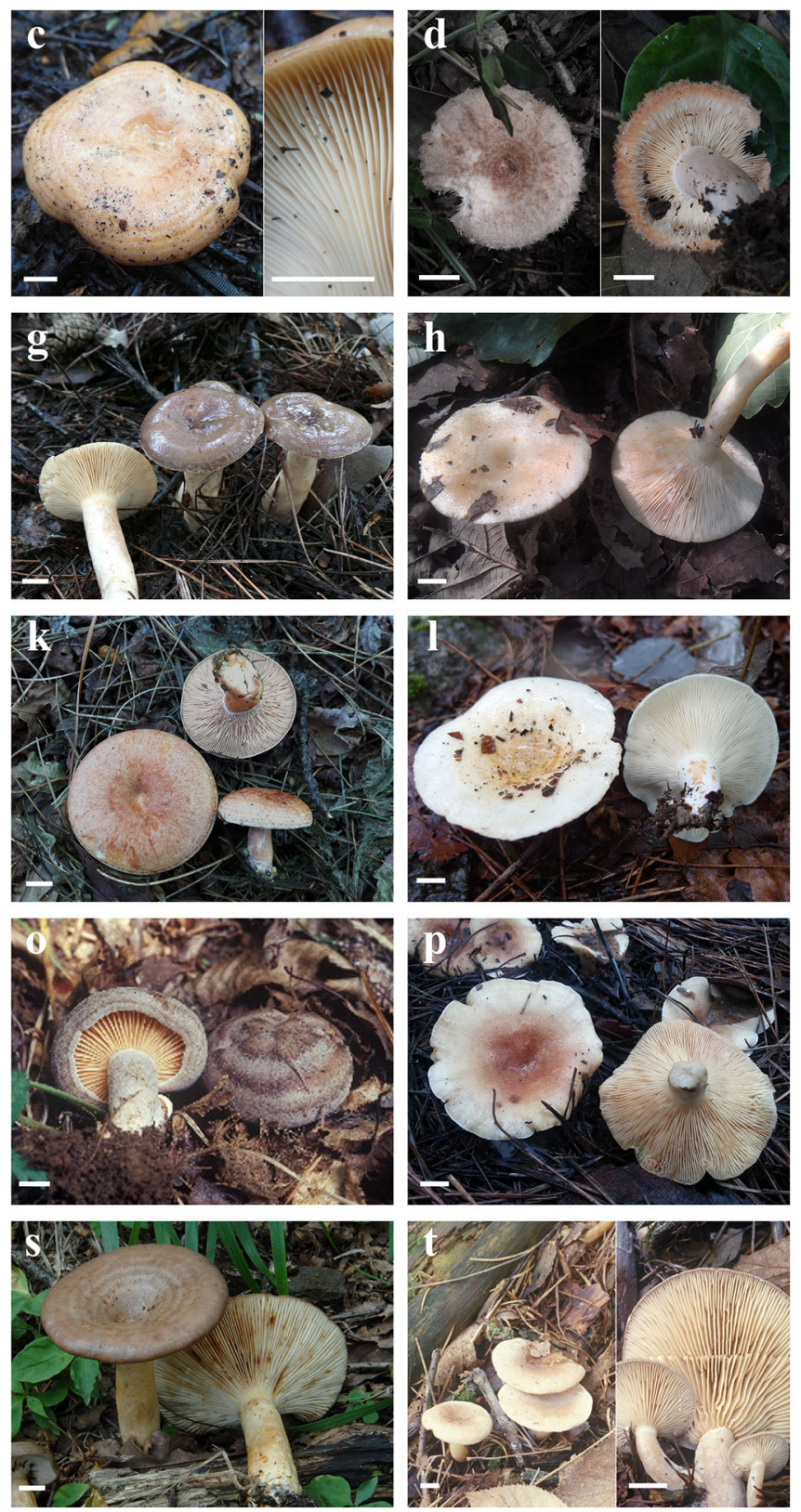

hatsudake, $\mathbf{l}$ L. inquinatus, $\mathbf{m}$ L. laeticolor, $\mathbf{n}$ L. orientitorminosus, $\mathbf{o}$ L. parallelus, $\mathbf{p}$ L. pohangensis, $\mathbf{q} L$. puniceus, $\mathbf{r}$ L. reticulisporus, $\mathbf{s} L$. spadiceus, $\mathbf{t} L$. vietus. Scale bar $=1 \mathrm{~cm}$. $\mathbf{d}$ and $\mathbf{t}$ are reproduced from Lee et al. (2018) 

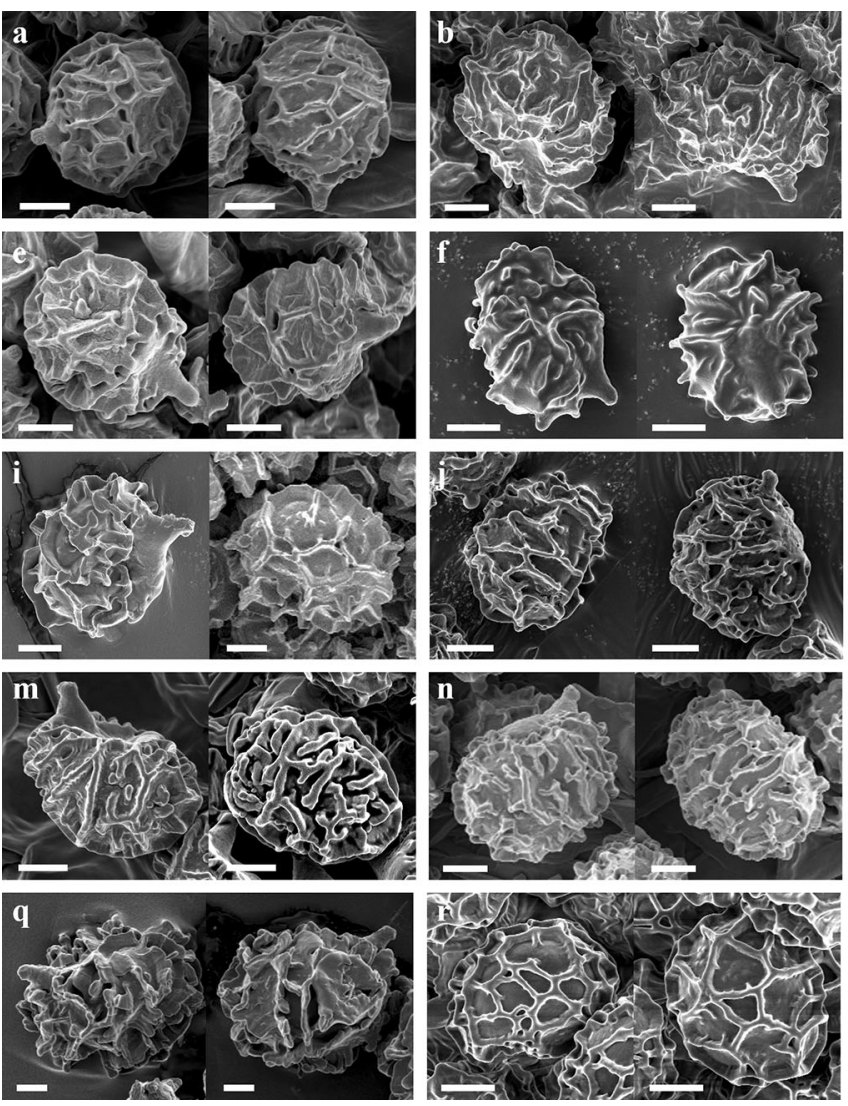

Fig. 13 Basidiospores (SEM) of Korean species of Lactarius subg. Lactarius. a L. akahatsu, b L. albidoarmeniacus, c L. aurantiozonatus, d $L$. austrotorminosus, e $L$. betulinus, f $L$. ciliatus, $\mathbf{g} L$. cinereoroseus, $\mathbf{h}$ L. cremicolor, $\mathbf{i}$ L. cyaneocinereus, $\mathbf{j} L$. floridus, $\mathbf{k} L$.

\section{Key to the species of Lactarius subgenus Lactarius in South Korea}

1. Latex orange, reddish orange, vinaceous red .......... 2

1. Latex transparent, white, watery white, watery cream ...

..............................................

2. Latex reddish orange and unchanging; pileus tomentose; stipe scrobiculate ............................. L. laeticolor

2. Latex orange or vinaceous red ......................... 3

3. Pileus scaly and tomentose; associated with Quercus L. aurantiozonatus

3. Pileus glabrous; associated with Pinus ................ 4

4. Latex orange; flesh staining vinaceous red when bruised L. akahatsu

4. Latex vinaceous red; flesh staining greenish blue when bruised L. hatsudake

5. Latex transparent or watery cream.................... 6

5. Latex white or watery white........................... 8

6. Latex transparent, changing to greyish lilac on exposure..................................... L. cyaneocinereus

6. Latex watery cream................................... 7
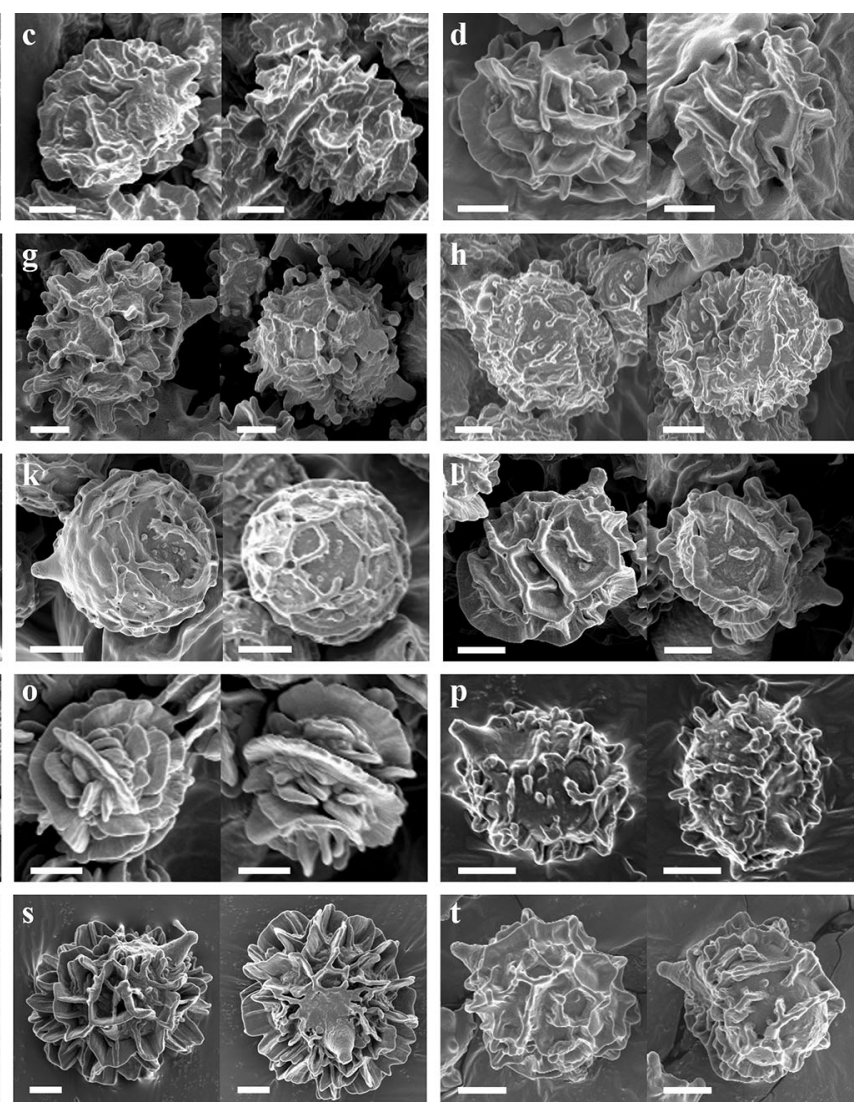

hatsudake, $\mathbf{l}$ L. inquinatus, $\mathbf{m}$ L. laeticolor, $\mathbf{n}$ L. orientitorminosus, o $L$. parallelus, $\mathbf{p} L$. pohangensis, $\mathbf{q} L$. puniceus, $\mathbf{r} L$. reticulisporus, $\mathbf{s} L$. spadiceus, $\mathbf{t}$ L. vietus. Scale bar $=2 \mu \mathrm{m}$. $\mathbf{d}$ and $\mathbf{t}$ are adapted from Lee et al. (2018)

7. Pileus greyish yellow to greyish red; lamellae attachment sinuate to adnate; pleuromacrocystidia present.......................................... L. cinereoroseus

7. Pileus light yellow to orange, scrobiculate; lamellae attachment decurrent with long tooth; pleuromacrocystidia absent .................................... floridus

8. Latex changes to different colours on exposure ................................................ 9

8. Latex unchanging ................................ 13

9. Pileus glabrous; latex changing to orange brown; spore ornamentation completely reticulate...

L. reticulisporus

9. Pileus with tomentose to hairy margin; spore ornamentation incompletely reticulate........................... 10

10. Latex changing to greenish grey on exposure; associated with Betula L. vietus

10. Latex changing to yellowish or reddish violet on exposure; associated with Quercus ................... 11

11. Latex changing to reddish violet; pleuromacrocystidia $>80 \mu \mathrm{m}$ long. L. puniceus 
Fig. 14 Microscopic features of Lactarius albidoarmeniacus
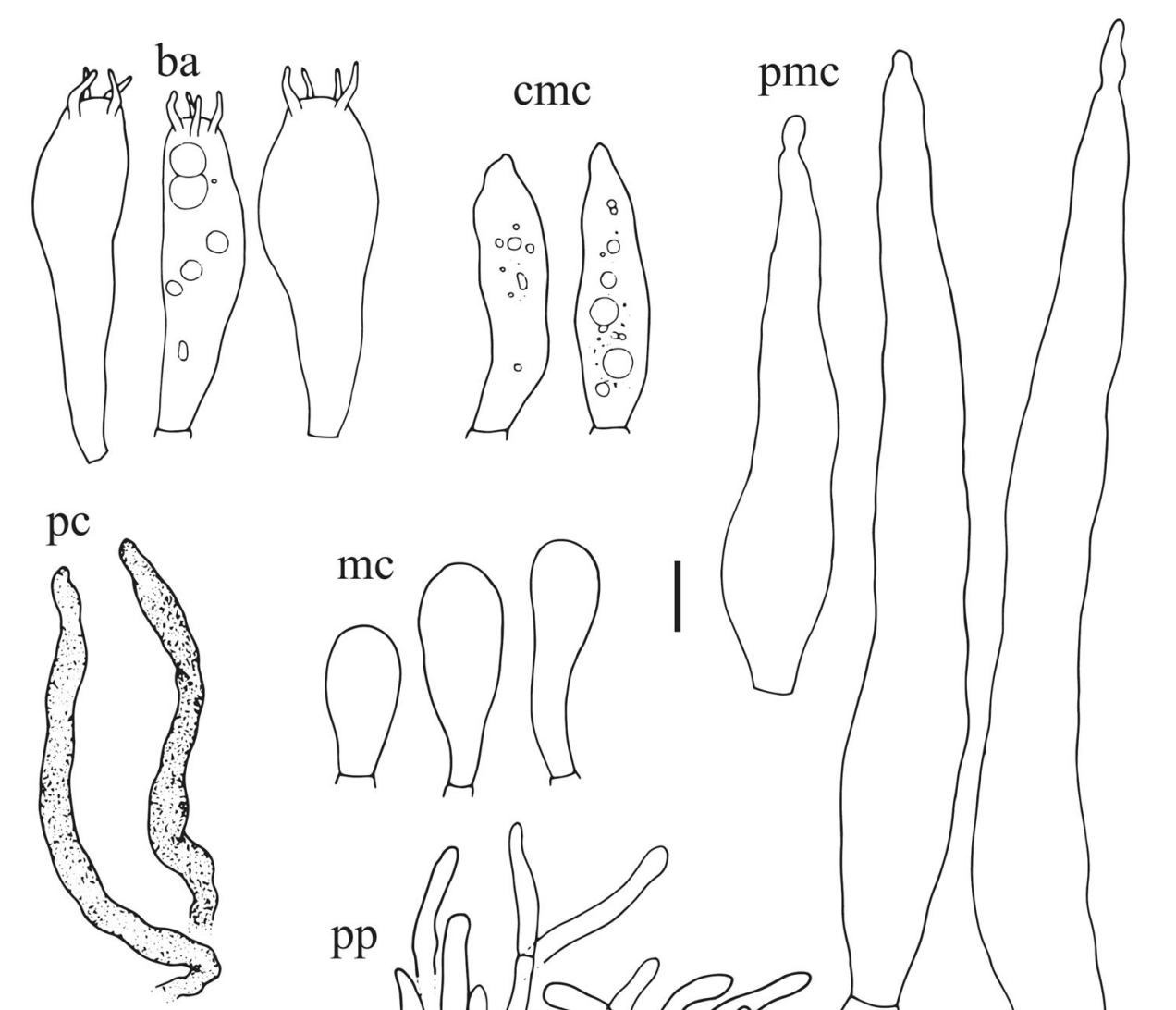
15. Pileus pinkish white to reddish grey and azonate; spore ornamentation almost completely reticulate L. albidoarmeniacus

16. Spore ornamentation zebroid; macrocystidia cyindrical .................................. parallelus

16. Spore ornamentation incomplete to almost complete reticulum; macrcystidia fusiform to lanceolate ...... 17

17. Pileus hygrophanous; spore ornamentation almost completely reticulate; associated with Betula ......................................... betulinus

17. Pileus non-hygrophanous; spore ornamentation incompletely reticulate; associated with Pinus or Quercus ......................................... 18

18. Pileus azonate; association with Pinus.

L. pohangensis

18. Pileus zonate; association with Quercus .19

19. Pileus orange white to brownish orange, with hairy margin; pileipellis, 150-230 $\mu \mathrm{m}$ thick

L. orientitorminosus

19. Pileus white to yellowish white, without hairs at the margin; pileipellis, 100-220 $\mu \mathrm{m}$ thick.

L. inquinatus

\section{Lactarius subgenus Lactarius}

Lactarius albidoarmeniacus H. Lee, Wisitr. \& Y.W. Lim, sp. nov.

\section{MycoBank: MB 827931}

Etymology: 'albido' means whitish and 'armeniacus' means reddish grey to apricot coloured which refers to the pale reddish grey pileus of the species.

Holotypus: SOUTH KOREA, Gangwon-do, Hongcheongun, Mt. Odae, alt. $751 \mathrm{~m}, \mathrm{~N} 37^{\circ} 50^{\prime} 00^{\prime \prime} \mathrm{E} 128^{\circ} 31^{\prime} 52^{\prime \prime}, 10$ Sep 2013 (TPML130910-089; isotypus, SFC)

Pileus $30-75 \mathrm{~mm}$ diam., convex to applanate with depressed centre; margin slightly incurved, sometimes uneven; surface pinkish white (7A2) to reddish grey (8B2), darker in center (8D5, reddish brown), viscid, sometimes sticky, slightly tomentose. Lamellae crowded, adnate to slightly decurrent, sometimes forked near the stipe, with abundant lamellulae, up to $3 \mathrm{~mm}$ broad, pale cream to cream-coloured, staining slowly yellow ocher when bruised. Stipe $30-85 \times 8-15 \mathrm{~mm}$, cylindrical, tapering downwards, fistulose with age; surface white to pinkish white, sometimes yellow ochre spots. Latex rather abundant, white, unchanging on exposure.

Basidiospores $\quad(\mathrm{n}=60), \quad 7.9-8.7-8.8-9.8(-9.9)$ $\times 6.0-6.5-6.7-7.3 \mu \mathrm{m}, \quad \mathrm{Q}=1.18-1.32-1.36$ -1.45 , broadly ellipsoid to ellipsoid; ornamentation amyloid, composed of up to $1 \mu \mathrm{m}$ high, continuous and branched ridges and isolated warts, forming an incomplete to almost complete reticulum; plage inamyloid to slightly amyloid in distal part. Basidia $41-53 \times 8.5-12.5 \mu \mathrm{m}$, 4-spored, narrowly clavate. Pleuromacrocystidia abundant, $35.5-148.5 \times 5.5-16 \mu \mathrm{m}$, not emergent to emergent beyond the hymenium, narrowly fusiform; apex slightly acute to mucronate. Lamellar edges consisting of marginal cells, cheilomacrocystidia and basidia; marginal cells narrowly clavate to clavate, sometimes cylindrical; cheilomacrocystidia rare, $30.5-37.5 \times 5-9.5 \mu \mathrm{m}$, mostly not emergent, narrowly fusiform, irregular to straight, apex mucronate. Pseudocystidia numerous, aseptate, irregular, 3-5.5 $\mu \mathrm{m}$ broad, sometimes branched near apex; apex rounded, often slightly broader. Pileipellis $( \pm)$ ixocutis, partially a trichoderm, 110-160 $\mu \mathrm{m}$ thick, parallel hyphae, piles of erect hyphae locally, terminal cells $15-45 \times 1-4.5 \mu \mathrm{m}$.

Habitat: Solitary or scattered on soil in mixed forests with Abies and Quercus.

Additional studied material: SOUTH KOREA, Gangwondo, Wonju-si, Sangwonsa temple, alt. 1009, N37 $18^{\prime} 23^{\prime \prime}$ E128 03'21', 30 Jul 2009 (HCCN18981); ibid., Pyeongchang-gun, Mt. Odae, alt. $1235 \mathrm{~m}$, N37 $46^{\prime} 52^{\prime \prime}$ E128 33'07", 24 Sep 2009 (HCCN19087).

Comments: Lactarius albidoarmeniacus is phylogenetically closely related to European species (Lactarius aquizonatus Kytöv., L. auriolla Kytöv., L. citriolens Pouzar, L. intermedius Krombh. ex Berk. \& Broome, L. leonius Kytöv., L. resimus (Fr.) Fr., L. scrobiculatus (Scop.) Fr., and L. tuomikoskii Kytöv.) and North American species ( $L$. alnicola A.H. Sm.) (Figure 1). The new species has a 
Fig. 15 Microscopic features of Lactarius aurantiozonatus
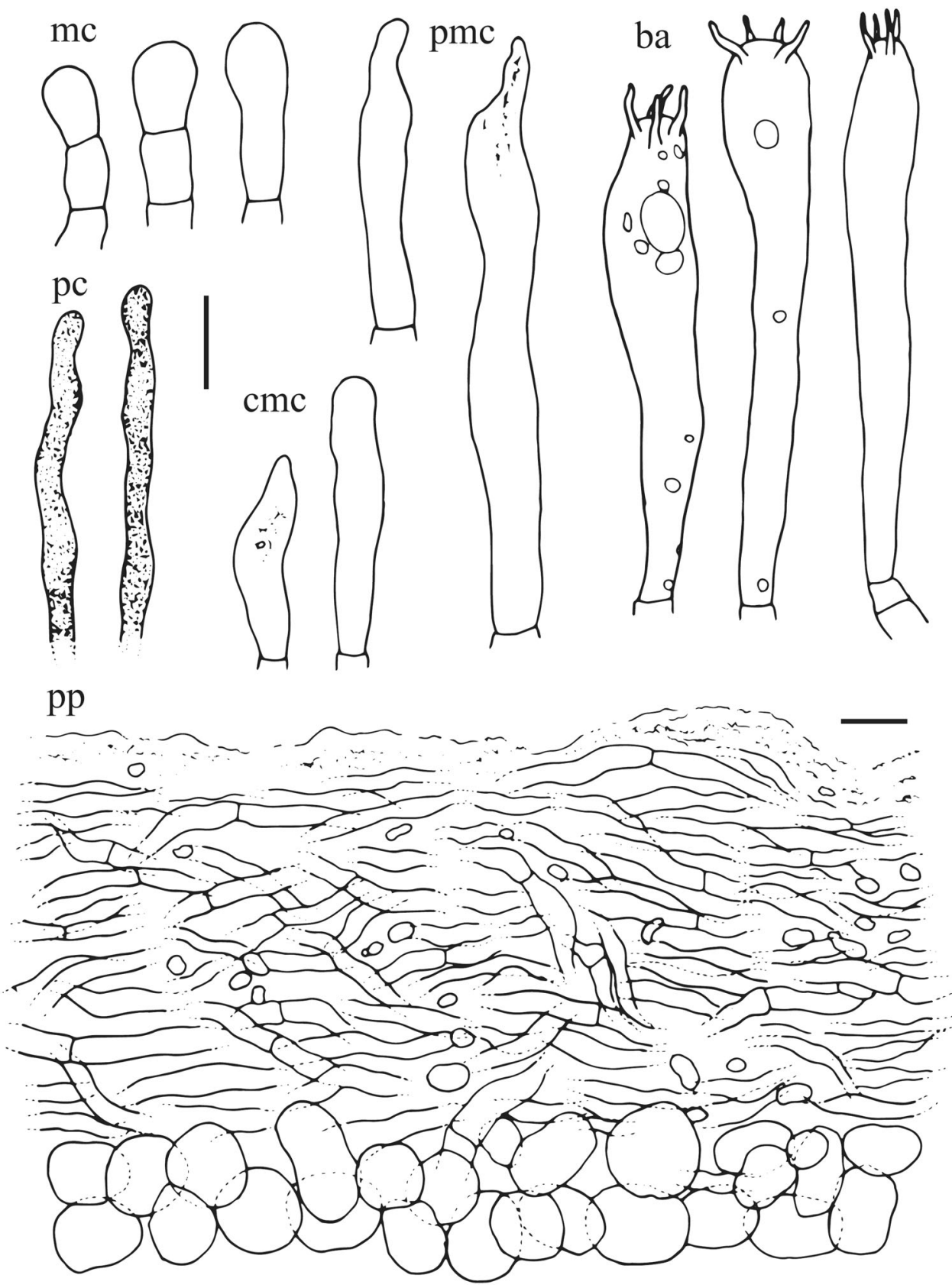

pinkish white to reddish grey pileus, while the others have cream to yellowish brown pigments in the pileus (Hesler and Smith 1979; Heilmann-Clausen et al. 1998).

Lactarius aurantiozonatus H. Lee, Wisitr. \& Y.W. Lim, sp. nov.

\section{MycoBank: MB 827932}

Etymology: 'aurantio' means orange coloured and 'zonatus' means zonation. This name refers to the orange coloured and zonate pileus of the species.
Holotypus: SOUTH KOREA, Jeollabuk-do, Jinan-gun, Unjangsan Natural Recreation Forest, alt. $414 \mathrm{~m}$,


Pileus 50-95 mm diam., convex then plano-convex to deeply funnel-shaped; margin first depressed, in age inrolled, often uneven to crenulate; surface pale yellow (3A2-3) to orange yellow (4A6), slightly darker when old, with darker to brownish orange scales, with distinct zonations, tomentose when young, viscid, shiny in moist condition. Lamellae rather distant, decurrent with long tooth, rarely forked, with abundant lamellulae, rather thick, up to $8 \mathrm{~mm}$ broad, cream-coloured when young, darker to orange 
yellow in age, staining greyish orange on places with dried latex. Stipe $20-45 \times 10-30 \mathrm{~mm}$, cylindrical, tapering downwards, fistulose; surface concolourous with lamellae or paler, locally with brownish orange spots. Odour pleasant, fruity. Taste mild. Latex scarce, white, unchanging on exposure.

Basidiospores $\quad(\mathrm{n}=40), \quad 6.9-7.8-8.3-9.0 \times$ $5.5-6.0-6.1-6.5 \mu \mathrm{m}, \quad \mathrm{Q}=1.23-1.29-1.31-$ 1.45 , broadly ellipsoid to ellipsoid; ornamentation amyloid, composed of up to $1 \mu \mathrm{m}$ high, parallel branched long ridges and isolated warts, forming an incomplete to almost complete reticulum, some ridges connected by thinner lines, closed meshes rare; plage amyloid in the distal part. Basidia $41-61.5 \times 7.5-11.5 \mu \mathrm{m}$, 4-spored, slender, cylindrical. Pleuromacrocystidia not abundant, $35.5-68 \times 5.5-8 \mu \mathrm{m}$, not emergent to slightly emergent beyond the hymenium, narrowly fusiform to cylindrical, sometimes indented at the middle, irregular to straight; apex round to mucronate. Lamellar edges consisting of marginal cells, cheilomacrocystidia and few basidia; marginal cells cylindrical to narrowly clavate; cheilomacrocystidia infrequent, $21.5-40.5 \times 5-8 \mu \mathrm{m}$, narrowly fusiform, slightly emergent, apex mucronate to moniliform. Pseudocystidia numerous, 3-6 $\mu \mathrm{m}$ broad, aseptate, embedded to inconspicuous emergent, irregular; apex rounded and slightly broader. Pileipellis $70-130 \mu \mathrm{m}$, ixocutis, comprised of parallel and cylindrical hyphae; terminal cells $20-45 \times 3-8 \mu \mathrm{m}$; subpellis comprised of inflated to isodiametric cells, $7-25 \times 5-17 \mu \mathrm{m}$; lactiferous hyphae present in subpellis layer.

Habitat: Solitary or scattered mixed forests with Pinus and Quercus.

Additional studied material: SOUTH KOREA, Gangwondo, Pyeongchang-gun, Mt. Odae, alt. $1426 \mathrm{~m}, \mathrm{~N} 37^{\circ} 47^{\prime} 47^{\prime \prime}$ E128 $32^{\prime} 25^{\prime \prime}, 20$ Aug 2005 (HCCN12999); Gyeonggi-do, Yangpyeong-gun, Saneum Natural Recreation Forest, alt. $352 \mathrm{~m}, \quad \mathrm{~N} 37^{\circ} 35^{\prime} 45^{\prime \prime} \quad \mathrm{E} 127^{\circ} 34^{\prime} 16^{\prime \prime}, \quad 3 \quad$ Sep 2012 (HCCN23407); Chungcheongnam-do, Gongju-si, Mt. Museong, alt. $162 \mathrm{~m}, \mathrm{~N} 36^{\circ} 31^{\prime} 04^{\prime \prime} \mathrm{E} 127^{\circ} 04^{\prime} 59^{\prime \prime}, 19$ Sep 2012 (SFC20120919-79).

Comments: Lactarius aurantiozonatus is characterized by the pileus with orange yellow, zonate and viscid, the white unchanging latex, and decurrent lamellae with long teeth. This species is a member of section Deliciosi and has similar colour and morphology with European $L$. salmonicolor R. Heim \& Leclair and Chinese L. abieticola X. H. Wang and L. vividus X. H. Wang et al. Lactarius aurantiozonatus is easily distinguished from the three species by unchanging white latex. Additionally, $L$. salmonicolor is associated with Abies and has larger basidiospores (Heilmann-Clausen et al. 1998). Lactarius abieticola can be easily distinguished from $L$. aurantiozonatus because of smaller basidiomata $(25-50 \mathrm{~mm}$ in diam.) and broader basidia (9-15 $\mu \mathrm{m}$ in width) than $L$. 
Fig. 16 Microscopic features of Lactarius betulinus

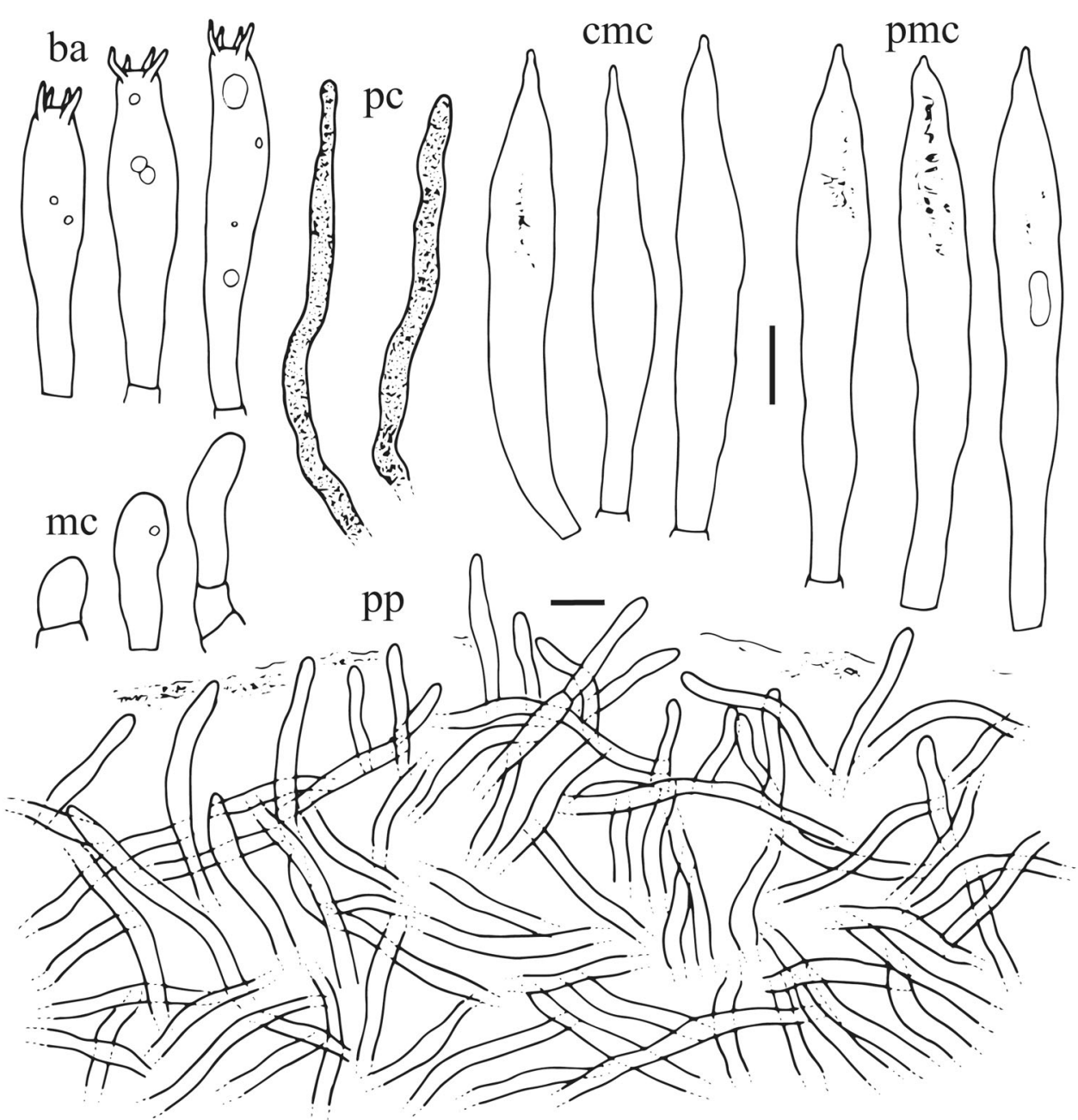

aurantiozonatus (Wang 2016). Lactarius vividus differs from $L$. aurantiozonatus by greenish tinges and shortly deccurent lamellae (Wang et al. 2015).

Lactarius betulinus H. Lee, Wisitr. \& Y.W. Lim, sp. nov.

\section{MycoBank: MB 827933}

Etymology: 'betulinus' means birch tree. The name refers to the presence of the species in Betula forests and the putative ectomycorrhizal association with Betula.

Holotypus: SOUTH KOREA, Gangwon-do, Inje-gun, Wondae-ri Betula forest, alt. $630 \mathrm{~m}, \mathrm{~N} 37^{\circ} 59^{\prime} 46^{\prime \prime}$ E128 ${ }^{\circ} 12^{\prime} 04^{\prime \prime}, 2$ Sep 2015 (SFC20150902-79)

Pileus $35-80 \mathrm{~mm}$ diam., convex to applanate then becoming infundibuliform; margin first slightly inrolled, in age decurved, uneven to crenulate; surface, pinkish white (7A2) to reddish brown (9D7), with azonate or inconspicuous zonations viscid, hygrophanous. Lamellae crowded, adnate to slightly decurrent, often forked near the stipe, sometimes multifurcate, with abundant lamellulae, up to $8 \mathrm{~mm}$ broad, whitish to pale cream, turning pale ocher when bruised. Stipe $30-60 \times 10-25 \mathrm{~mm}$, cylindrical to narrowly clavate, tapering downwards, fistulose in age; surface concolourous to pileus, paler to whitish at the base. Odour faintly fruity. Taste mild. Latex rather abundant, white, unchanging on exposure.

Basidiospores $(\mathrm{n}=40), \quad(5.8-) 5.9-6.5-7.2 \times 4.9$ $-5.5-5.6-6.2 \mu \mathrm{m}, \mathrm{Q}=1.00-1.16-1.17-1.34$, globose to broadly ellipsoid, few ellipsoid; ornamentation amyloid, composed of up to $1.1 \mu \mathrm{m}$ high, continuous and often branched ridges and isolated warts, forming an almost complete to occasionally a complete reticulum; plage inamyloid to slightly amyloid in distal part. Basidia $41-51 \times 7-9 \mu \mathrm{m}, 4$-spored, subcylindrical, sometimes cylindrical. Pleuromacrocystidia numerous, $72.5-83 \times 7-10.5 \mu \mathrm{m}, \quad$ conspicuous projecting beyond the hymenium, narrowly fusiform to lanceolate; apex mucronate, sometimes moniliform. Lamellar edges consisting of marginal cells, cheilomacrocystidia and basidia; marginal cells cylindrical to clavate; cheilomacrocystidia numerous, $54.5-68 \times 4-9.5 \mu \mathrm{m}$, emergent, narrowly fusiform to lanceolate, irregular to 
straight, apex mucronate to moniliform. Pseudocystidia not abundant, aseptate, irregular, $2.5-5 \mu \mathrm{m}$ broad; apex rounded, often slightly broader. Pileipellis $170-290 \mu \mathrm{m}$ thick, an ixotrichoderm, comprise of intricate and erect cylindrical hyphae, terminal cells $25-80 \times 2.5-4.5 \mu \mathrm{m}$.

Habitat: Solitary or scattered on soil in forests dominated by Betula.
Additional studied material: SOUTH KOREA: Gangwondo, Pyeongchang-gun, Mt. Odae, alt. 990 m, N37 $46^{\prime} 51^{\prime \prime}$ E128 34'19", 10 Sep 2013, TPML130910-017 (TPML).

Comments: Lactarius betulinus is morphologically similar to L. hysginus (Fr.) Fr. and L. ilicis Sanari. Lactarius hysginus has a reddish, brick-coloured pileus often with a yellowish shade and is associated with Pinus in Europe
Fig. 17 Microscopic features of Lactarius ciliatus
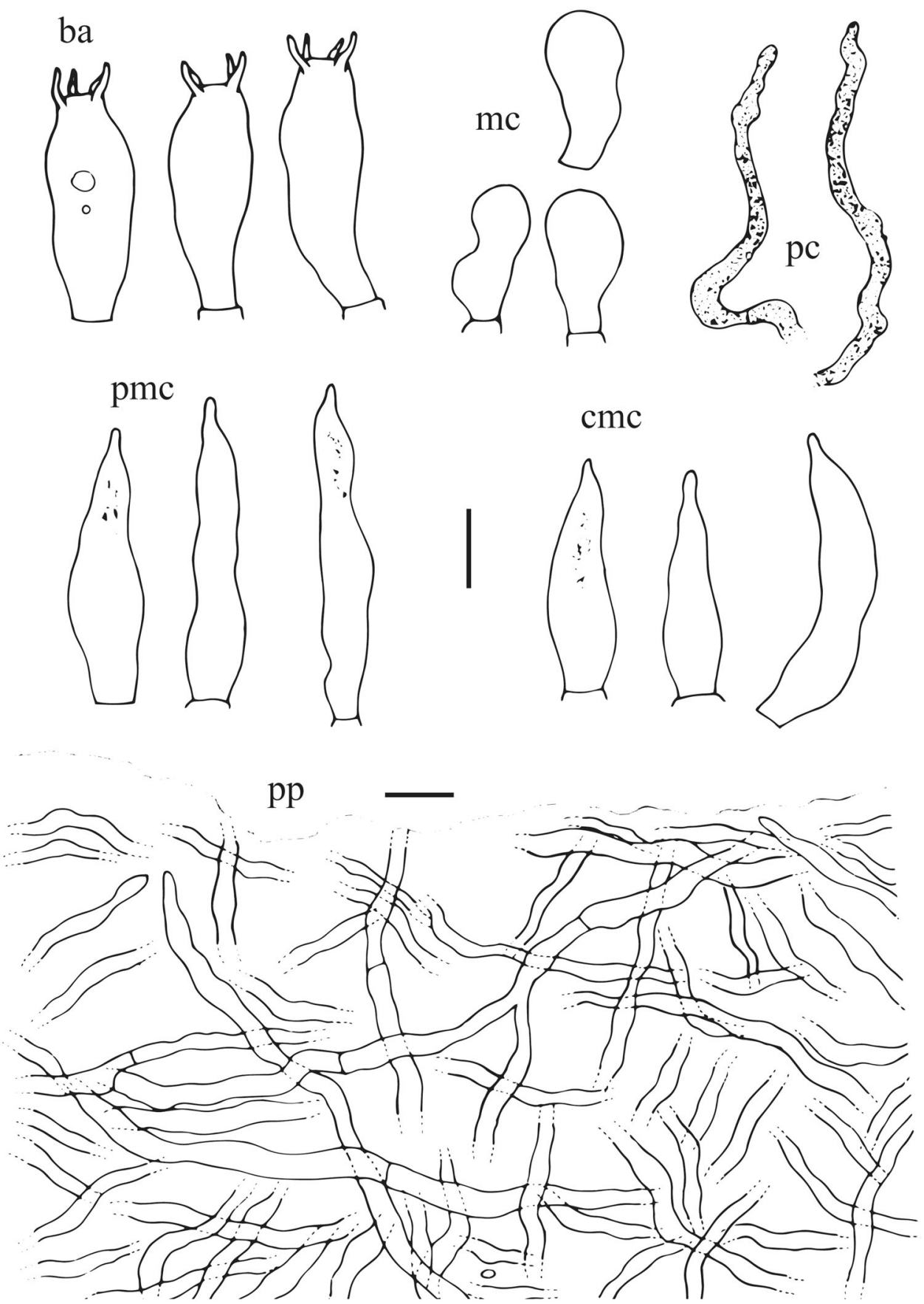
(Heilmann-Clausen et al. 1998). Lactarius ilicis has a darker pileus colour than L. betulinus and is associated with Quercus ilex (Heilmann-Clausen et al. 1998).

Lactarius ciliatus H. Lee, Wisitr. \& Y.W. Lim, sp. nov. MycoBank: MB 827934

Etymology: 'ciliatus' means hairy, referring to the hairy pileus of the species.

Holotypus: SOUTH KOREA, Gangwon-do, Wonju-si, Mt. Chiak, alt. 584 m, N37 $23^{\prime} 43^{\prime \prime}$ E128 02'34", 14 Jul 2003 (HCCN11325; isotypus, SFC)

Pileus 8-25 mm diam., convex to applanate with slightly depressed centre, sometimes with a small papilla; margin even, sometimes slightly uneven; surface reddish white (7A2) to dull red (8B3), sometimes with greyish red spots (8C5), tomentose to hairy, slightly viscid when young; marginal hairs dry. Lamellae rather distant, decurrent with long tooth, not forked, with lamellulae, up to $1 \mathrm{~mm}$ broad, white to pale cream, sometimes with curry colored spots. Stipe $10-20 \times 2-5 \mathrm{~mm}$, cylindrical to clavate, tapering downwards, fistulose; surface concolourous with pileus, tomentose. Latex rather abundant, white, changing to yellow buff on exposure.

Basidiospores $(\mathrm{n}=40), 6.3-6.9-7.0-7.6 \times 5.1-$ $5.6-5.7-6.0 \mu \mathrm{m}, \quad \mathrm{Q}=1.15-1.22-1.25-1.36$, broadly ellipsoid to ellipsoid; ornamentation amyloid, composed of up to $1 \mu \mathrm{m}$ high, short or long ridges and isolated warts, rarely connected but never forming a reticulum, sometimes arranged in zebra-like pattern; plage inamyloid. Basidia $25.5-32 \times 7.5-9.5 \mu \mathrm{m}$, 4-spored, 1 -spored present, narrowly clavate. Pleuromacrocystidia abundant, $24-41.5 \times 5-9 \mu \mathrm{m}$, slightly emergent beyond the hymenium, up to $25 \mu \mathrm{m}$, narrowly clavate, often irregular in shape, contents fine granules locally, apex mucronate to slightly acute. Lamellar edges consisting of marginal cells, cheilomacrocystidia and basidia; marginal cells narrowly clavate to clavate, sometimes irregular; cheilomacrocystidia abundant, $19.5-30 \times 5-9 \mu \mathrm{m}$, narrowly fusiform, fine granules near apex, apex slightly acute. Pseudocystidia numerous, aseptate, slightly emergent beyond the hymenium, cylindrical, straight to tortuous, 2.5-4.5 $\mu \mathrm{m}$ broad; apex rounded. Pileipellis 160-240 $\mu \mathrm{m}$ thick, an ixocutis, with a thin gelatinized layer locally, difficult to observe, parallel to ascending cylindrical hyphae, terminal cells $25-80 \times 2.5-5.0 \mu \mathrm{m}$, apex rounded.

Habitat: Scattered to gregarious on soil in forests dominated by Quercus.

Additional studied material: SOUTH KOREA: Gangwondo, Wonju-si, Mt. Chiak, alt. $428 \mathrm{~m}, \mathrm{~N} 37^{\circ} 23^{\prime} 47^{\prime \prime}$ E128 $03^{\prime} 14^{\prime \prime}, 28$ Aug 2002, HCCN10715.

Comments: Lactarius ciliatus is characterized by the smallsized basidiomata, reddish white to dull red colours, tomentose pileus, and white latex changing to yellowish buff. This species is similar to small-sized species in $L$. 
Fig. 18 Microscopic features of Lactarius cinereoroseus



subg. Russularia. The former can be distinguished from all small-sized species in L. subg. Russularia by its yellowing latex and hairy pileus.

Lactarius cinereoroseus H. Lee, Wisitr. \& Y.W. Lim, sp. nov.

\section{MycoBank: MB 827935}

Etymology: 'cinereo' means grey and 'roseus' means light red. The name refers to the colour of the basidiomata.

Holotypus: SOUTH KOREA, Gyeonggi-do, Gwangju-si, Seoul National University Forest, alt. 193 m, N37 $18^{\prime} 36^{\prime \prime}$ E127 $18^{\prime} 40^{\prime \prime}$, 19 Aug 2015 (SFC20150819-46)

Pileus 20-60 mm diam., convex to applanate with slightly depressed centre; margin first slightly inrolled, in age expanded, entire, sometimes slightly crenate; surface greyish rose (11C3) to greyish ruby (12E6), sometimes dull red (10B4) to greyish red (11C4) center with yellowish grey (4B2) surroundings and margin at times paler, azonate, viscid to glutinous, sometimes slimy, rugulose.
Lamellae sinuate to adnate, sometimes slightly decurrent, rather crowded, sometimes forked near the stipe, up to $3 \mathrm{~mm}$ broad, whitish to pale cream, yellowish ocher in age, sometimes with pale greyish brown spots. Stipe 30-80 × 5-25 mm, tapering upwards, sometimes slightly ventricose, fistulose; surface whitish when young, concolourous or paler to pileus in age, often with yellowish ocher to pale reddish brown tinge. Odour slightly spermatic. Taste mild, sometimes a little bit bitter. Latex rather abundant, translucent cream to watery white, unchanging on exposure.

Basidiospores $\quad(\mathrm{n}=40), \quad 8.2-9.0-9.1-10.0 \times 6.8$ $-8.0-8.2-9.1 \mu \mathrm{m}, \mathrm{Q}=1.02-1.15-1.17-1.33$, mostly globose to broadly ellipsoid, few ellipsoid; ornamentation amyloid, composed of up to $1.3 \mu \mathrm{m}$ high, irregular and forked long ridges and isolated warts, forming an incomplete reticulum; plage amyloid in the distal part. Basidia 47.5 - $64.5 \times 12-15.5 \mu \mathrm{m}$, 4-spored, cylindrical to narrowly clavate. Pleuromacrocystidia numerous, $63-82.5 \times 9.5-12 \mu \mathrm{m}$, mostly projecting beyond the 
hymenium, narrowly fusiform to lanceolate; apex mucronate to moniliform; contents needle-like. Lamellar edges consisting of marginal cells, cheilomacrocystidia and basidia; marginal cells cylindrical to narrowly clavate; cheilomacrocystidia numerous, $45-58.5 \times 7-11.5$ $\mu \mathrm{m}$, fusiform, apex mucronate. Pseudocystidia rare, aseptate, embedded in the hymenium, irregular, sometimes branched near apex, 2-5 $\mu \mathrm{m}$ broad; apex rounded, sometimes slightly broader. Pileipellis 175-275 $\mu \mathrm{m}$ thick, ixotrichoderm, comprised of intricate to erect cylindrical hyphae; terminal cells $45-120 \times 3-6 \mu \mathrm{m}$.
Habitat: Scattered to gregarious on humid soil in lowlands of mixed forests dominated by Pinus and Quercus.

Additional studied material: SOUTH KOREA, Chungcheongbuk-do, Yeongdong-gun, Mt. Minjuji, alt. $694 \mathrm{~m}, \mathrm{~N} 36^{\circ} 03^{\prime} 18^{\prime \prime}$ E127 52'38', 26 Jul 2012 (KA120680); Gyeonggi-do, Yangpyeong-gun Saneum Natural Recreation Forest, alt. 386 m, N37 $35^{\prime} 57^{\prime \prime}$ E127 $34^{\prime} 03^{\prime \prime}, 19$ Sep 2012 (KA12-1495).

Comments: Lactarius cinereoroseus is similar to the European species, L. trivialis (Fr.) Fr. The latter differs,
Fig. 19 Microscopic features of Lactarius cremicolour

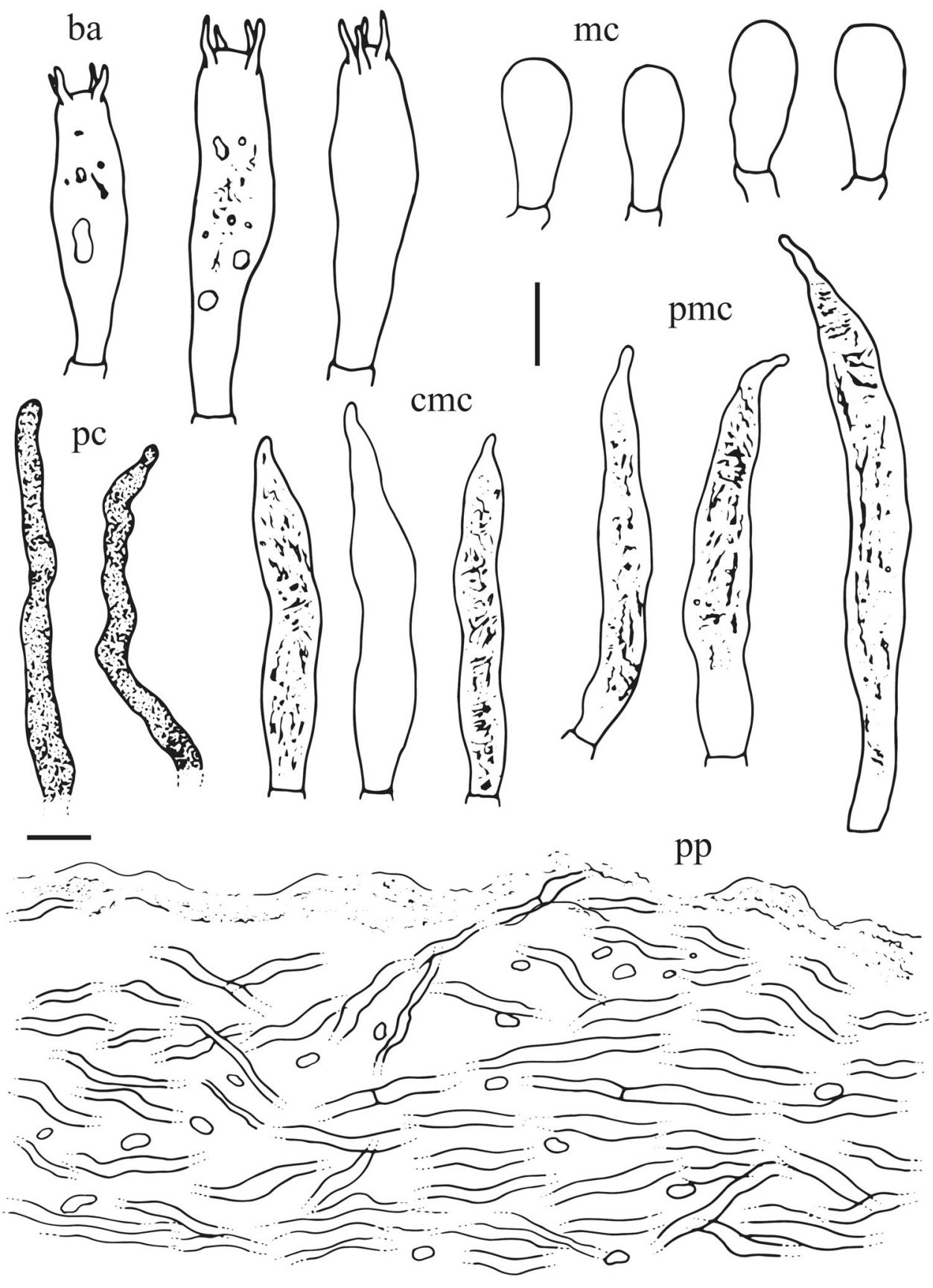


Fig. 20 Microscopic features of Lactarius cyaneocinereus

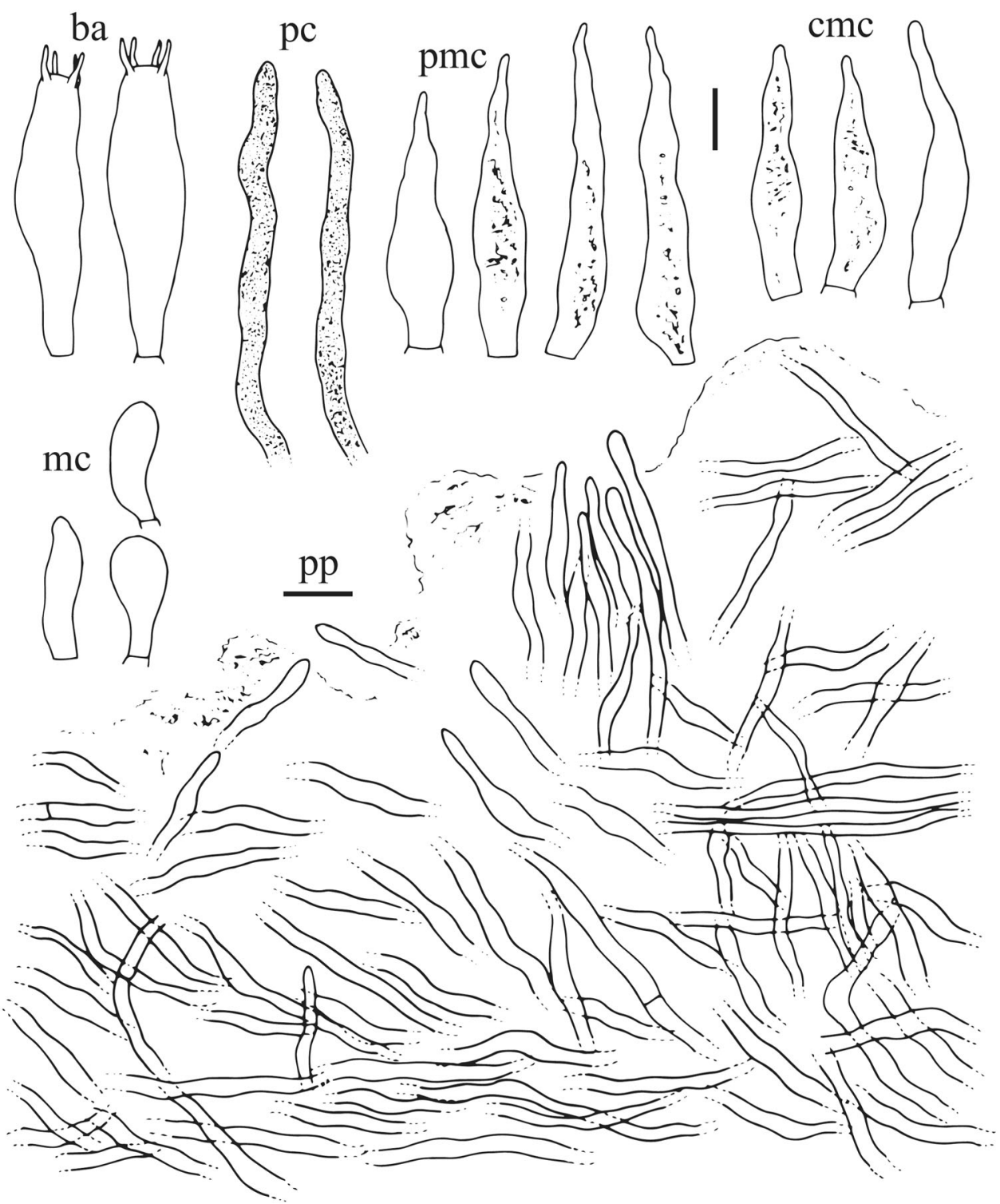

however, from the former by the cream latex changing to olivaceus grey and smaller pleurocystidia (HeilmannClausen et al. 1998).

Lactarius cremicolor H. Lee, Wisitr. \& Y.W. Lim, sp. nov.

\section{MycoBank: MB 827936}

Etymology: 'cremicolor' means cream-coloured. This name refers the cream-coloured fruiting body of the species.

Holotypus: SOUTH KOREA, Jeollanam-do, Gurye-gun,

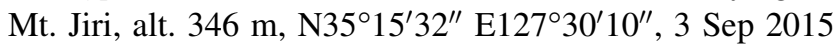
(SFC20150903-51)

Pileus $30-85 \mathrm{~mm}$ diam., convex to applanate then becoming infundibuliform with a deeper centre; margin slightly depressed and inrolled, in age expanded; surface, white (-A1) to yellowish white (4A2), orange white (6A2) when old, sometimes with ocher-buff spots, viscid to slightly slimy, slightly fibrillose, hygrophanous, with concentric zonation. Lamellae crowded, slightly decurrent to decurrent, rarely forked near the stipe, with abundant lamellulae, up to $5 \mathrm{~mm}$ broad, white when young, darker to pale cream in age. Stipe $30-100 \times 10-25 \mathrm{~mm}$, central to eccentric, cylindrical to tapering downwards, fistulose; surface white to cream, pale orange brown at the base, scrobiculate, with orange brown spots, turning dark brown when old. Odour unremarkable, sometimes fruity. Taste mild. Latex rather abundant, white, changing lemon yellow after a while, drying pale ocher on lamellae.

Basidiospores $(\mathrm{n}=40), 7.8-8.7-9.0-9.7 \times 6.3-$ $6.9-7.1-7.7 \mu \mathrm{m}, \quad \mathrm{Q}=1.16-1.23-1.30-1.41$ $\mu \mathrm{m}$, mostly broadly ellipsoid to ellipsoid; ornamentation 
amyloid, composed of up to $1.1 \mu \mathrm{m}$ high, short ridges and isolated warts, forming an incomplete partially, often connected by thinner lines; plage inamyloid to weakly amyloid in the distal part. Basidia $32-43.5 \times 9-$ $13.5 \mu \mathrm{m}, 4$-spored, narrowly clavate, contents small granule and guttulate. Pleuromacrocystidia numerous, $20-59.5 \times 4-7.5 \mu \mathrm{m}$, projecting up to $29 \mu \mathrm{m}$, cylindrical to narrowly fusiform, irregular to straight, apex mostly mucronate, occasionally moniliform. Lamellar edges consisting of marginal cells, cheilomacrocystidia and basidia; marginal cells cylindrical; cheilomacrocystidia numerous, $35-51 \times 5.5-7.5 \mu \mathrm{m}$, slightly emergent beyond the marginal cells, narrowly fusiform, apex mucronate to round, some contents small guttulate. Pseudocystidia numerous, aseptate, embedded to inconspicuous emergent, irregular, 2.5-5.5 $\mu \mathrm{m}$ broad; apex rounded, often slightly broader. Pileipellis 90-210 $\mu \mathrm{m}$ thick, an ixocutis to locally ixotrichoderm, with mounds of erect hyphae; suprapellis 4-7 $\mu \mathrm{m}$ broad of intricate, parallel and erect thin hyphae.

Habitat: Scattered to gregarious on soil in mixed forests dominated by Abies and Quercus.

Additional studied material: SOUTH KOREA, Jeollabukdo, Muju-gun, Mt. Jeoksang, alt. $751 \mathrm{~m}, \mathrm{~N} 35^{\circ} 57^{\prime} 27^{\prime \prime}$ E12741'59", 4 Sep 2010 (HCCN20394); Gyeonggi-do, Euijeongbu-si, Mt. Wondobong, alt. $135 \mathrm{~m}, \mathrm{~N} 37^{\circ} 42^{\prime} 24^{\prime \prime}$ E127 $02^{\prime} 07^{\prime \prime}$, 20 Jul 2011 (HCCN21514); Seoul, Gwanakgu, Mt. Gwanak, alt. $134 \mathrm{~m}, \mathrm{~N} 37^{\circ} 27^{\prime} 48^{\prime \prime} \mathrm{E} 126^{\circ} 56^{\prime} 42^{\prime \prime}, 31$ Aug 2012 (SFC20120831-09).

Comments: Lactarius cremicolor is morphologically similar to L. yazooensis Hesler \& A.H. Sm. originated from North America. However, this species differs from $L$. yazooensis by its hygrophanous pileus and abundant cheilomacrocystidia (Hesler and Smith 1979). Moreover, L. yazooensis has nearly zebroid spore ornamentation while L. cremicolor has incomplete reticulum (Hesler and Smith 1979).

Lactarius cyaneocinereus H. Lee, Wisitr. \& Y.W. Lim, sp. nov.

MycoBank: MB 827937

Etymology: 'cyaneo' means blue and 'cinereus' means grey. The name refers to colour change of the latex.

Holotypus: SOUTH KOREA, Jeollabuk-do, Jinan-gun, Mt. Cheonban, alt. $505 \mathrm{~m}, \mathrm{~N} 35^{\circ} 48^{\prime} 59^{\prime \prime}$ E1273 $31^{\prime} 57^{\prime \prime}, 11$ Sep 2014 (SFC20140911-26)

Pileus 30-90 mm diam., convex to applanate with slightly depressed centre; margin first inrolled, in age expanded, entire, hispid with $3 \mathrm{~mm}$ long hairs; surface light orange (5A4) to brownish yellow (5C7), darker towards the center, paler in age, in most cases inconspicuously zonate, occasionally distinctively zonate, tomentose, viscid to glutinous. Lamellae adnate to slightly deccurent, rather crowded, sometimes forked near the stipe, up to $4 \mathrm{~mm}$ broad, whitish to pale cream, greyish brown in age, turning lilac to ultramarine blue after bruising. Stipe $30-80 \times 10-25 \mathrm{~mm}$, cylindrical, sometimes tapering upward, fistulose; surface pale cream when young, concolourous to pileus in age, often with reddish brown. Odour faintly fruity. Taste mild to slightly bitter. Latex rather abundant, transparent turning white quickly when isolated, then becoming greyish lilac to bluish grey.

Basidiospores $\quad(\mathrm{n}=40), \quad 7.9-8.7-8.8-9.5$ $\times(6.1-) 6.2-7.0-7.4-8.0 \mu \mathrm{m}, \quad \mathrm{Q}=1.12-1.19$ $-1.25-1.37$, subglobose to broadly ellipsoid; ornamentation amyloid, composed of up to $1.1 \mu \mathrm{m}$ high, ridges forning an incomplete reticulum and isolated warts; plage inamyloid. Basidia 44.5 - $56 \times 8.5-13.5 \mu \mathrm{m}$, 4-spored, narrowly clavate, contents small granule and guttulate. Pleuromacrocystidia numerous, $26-67.5 \times 5.5-12 \mu \mathrm{m}$, often projecting beyond the hymenium, up to $35 \mu \mathrm{m}$, narrowly fusiform to cylindrical and broader in the middle or near the base, irregular to straight, apex mucronate to moniliform, contents needle-like. Lamellar edges comprised of marginal cells, cheilomacrocystidia and basidia; marginal cells mostly cylindrical to narrowly clavate with broader rounded apex; cheilomacrocystidia numerous, $25.5-45.5 \times 5.5-8.5 \mu \mathrm{m}$, often projecting beyond the marginal cells, up to $30 \mu \mathrm{m}$, narrowly fusiform with mucronate apex. Pseudocystidia numerous, aseptate, embedded to inconspicuous emergent, irregular, sometimes branched near apex, 3-7 $\mu \mathrm{m}$ broad; apex rounded, often slightly broader. Pileipellis an ixocutis to ixotrichoderm, 130-280 $\mu \mathrm{m}$ thick, intricate to parallel hyphae, locally with mounds of erect hyphae; terminal cells $40-75 \times 4-10 \mu \mathrm{m}$.

Habitat: Solitary or scattered on soil or rotten wood in Quercus forests.

Additional studied material: SOUTH KOREA, Gangwondo, Inje-gun, Baekdamsa temple, alt. $533 \mathrm{~m}, \mathrm{~N} 38^{\circ} 09^{\prime} 25^{\prime \prime}$ E128 23'05", 16 Aug 2002 (HCCN10496); Gyeongsangbuk-do, Sangju-si, Seongjubong Natural Recreation Forest, alt. $301 \mathrm{~m}, \quad \mathrm{~N} 36^{\circ} 32^{\prime} 02^{\prime \prime} \mathrm{E} 128^{\circ} 01^{\prime} 20^{\prime \prime}, \quad 19$ Jul 2013 (SFC20130719-71).

Comments: Lactarius cyaneocinereus is morphologically similar to Thai species (L. formosus H.T. Le \& Verbeken) and European species (L. repraesentaneus Britzelm and L. speciosus Burl.). Thai species differ from L. cyaneocinereus by the dark purple discolouration of latex upon exposure to air (Le et al. 2007a). L. repraesentaneus has a brighter yellow pileus and longer hairs on the pileus (up to 
Fig. 21 Microscopic features of Lactarius floridus
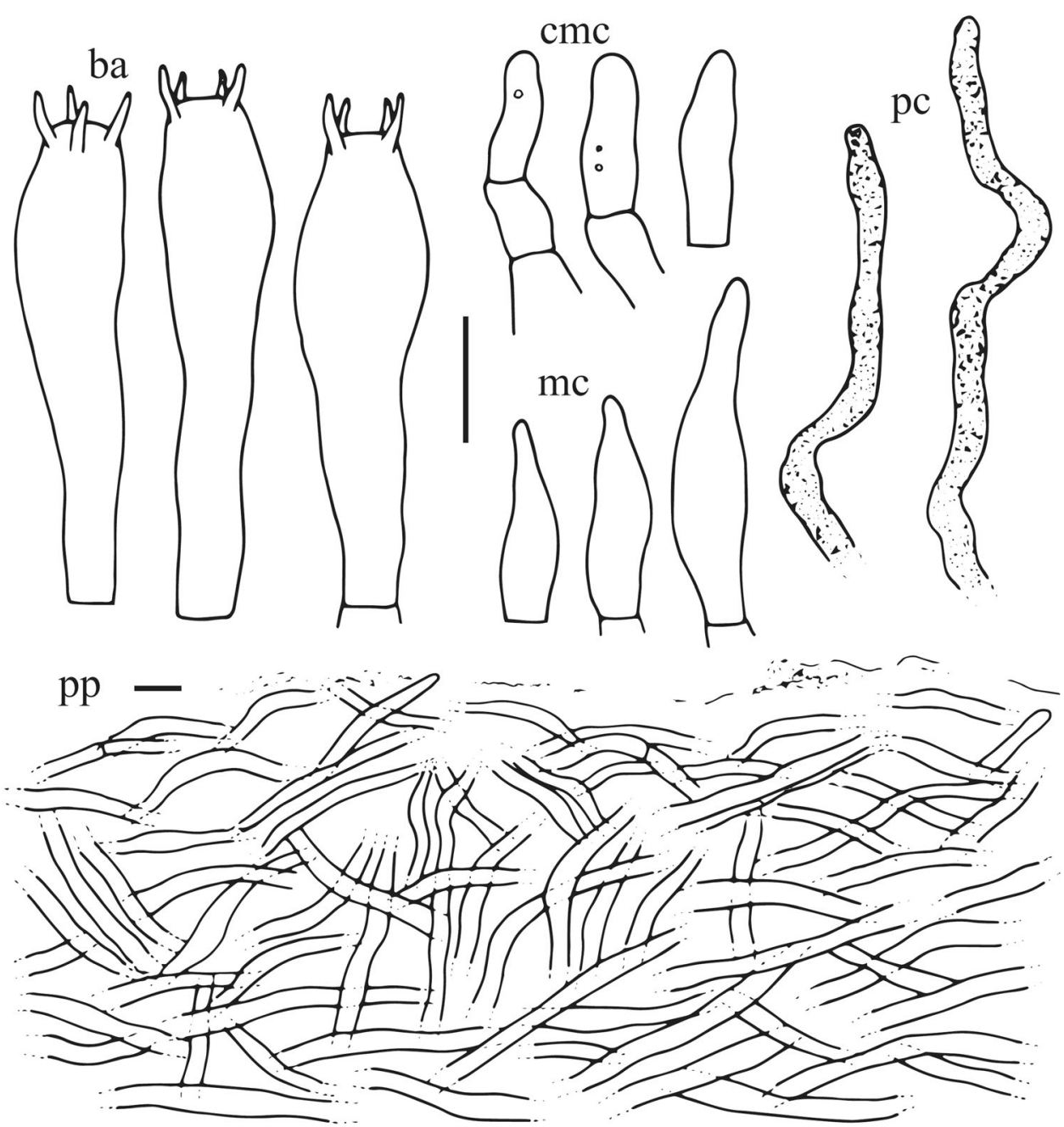

$5 \mathrm{~mm}$ ) than L. cyaneocinereus (Heilmann-Clausen et al. 1998). Lactarius speciosus differs from L. cyaneocinereus by the absence of pleurocystidia and the capitate apex of cheilocystidia (Heilmann-Clausen et al. 1998).

Lactarius floridus H. Lee, Wisitr. \& Y.W. Lim, sp. nov.

\section{MycoBank: MB 827938}

Etymology: 'floridus' means bright and fancy, referring to the vivid yellow fruiting body.

Holotypus: SOUTH KOREA, Chungcheongbuk-do, Chungju-si, Mt. Boryeon, alt. $301 \mathrm{~m}, \mathrm{~N} 37^{\circ} 04^{\prime} 38^{\prime \prime}$ E127 $47^{\prime} 02^{\prime \prime}$, 6 Sep 2012 (TPML120906-027; isotypus, SFC)

Pileus $35-80 \mathrm{~mm}$ diam., convex then applanate to infundibuliform with slightly depressed centre; margin first inrolled, in age decurved, even; surface light yellow (3A5) to orange (5A7), slightly viscid, tomentose when young, scaly, azonate when young, becoming more zonate when mature. Lamellae decurrent with long tooth, rather distant, rarely forked near the stipe, with abundant lamellulae, up to
$10 \mathrm{~mm}$ broad, cream to pale yellow, turning greyish brown when bruised. Stipe $40-95 \times 10-25 \mathrm{~mm}$, cylindrical to slightly ventricose, tapering downwards, fistulose; surface concolourous with pileus, often scrobiculate with darker colour, smooth. Odour unremarkable. Taste mild. Latex rather abundant, white to watery pale cream, unchanging on exposure.

Basidiospores $\quad(\mathrm{n}=20), \quad(6.2-) 6.5-7.6-8.7 \times 5.7$ $-6.6-7.5(-7.6) \mu \mathrm{m}, \mathrm{Q}=1.03-1.16-1.30$, subglobose to broadly ellipsoid; ornamentation amyloid, composed of up to $0.5 \mu \mathrm{m}$ high, branched long ridges and isolated warts, forming an incomplete to sometimes an almost complete reticulum, forming closed meshes, isolated warts not abundant; plage inamyloid to weakly amyloid in distal part. Basidia $42-55 \times 9.5-12.5 \mu \mathrm{m}$, 4-spored, cylindrical to narrowly clavate. Pleuromacrocystidia absent. Lamellar edges consisting of marginal cells and cheilomacrocystidia; marginal cells cylindrical to narrowly clavate; cheilomacrocystidia numerous, $13-29.4 \times 5.5-7 \mu \mathrm{m}$, emergent, fusiform to lanceolate; apex mucronate. Pseudocystidia not abundant, mostly 
embedded, aseptate, irregular, sometimes branched near the apex, $2-4 \mu \mathrm{m}$ broad; apex rounded, often slightly broader. Pileipellis $125-170 \mu \mathrm{m}$ thick, an ixocutis, comprise of parallel to intricate cylindrical hyphae, locally with erect hyphae, terminal cells $25-65 \times 3-7 \mu \mathrm{m}$.

Habitat: Solitary or scattered on soil in Quercus forests.
Comments: Lactarius floridus is well characterized by its vivid yellow to orange pileus, scrobiculate stipe, and white to watery cream latex with unchanging reaction. The closest relative of this species is L. austrozonarius H.T. Le \& Verbeken from Thailand (Fig. 1). The Thai species is distingusied from L. floridus by a pale yellow to orange
Fig. 22 Microscopic features of Lactarius inquinatus
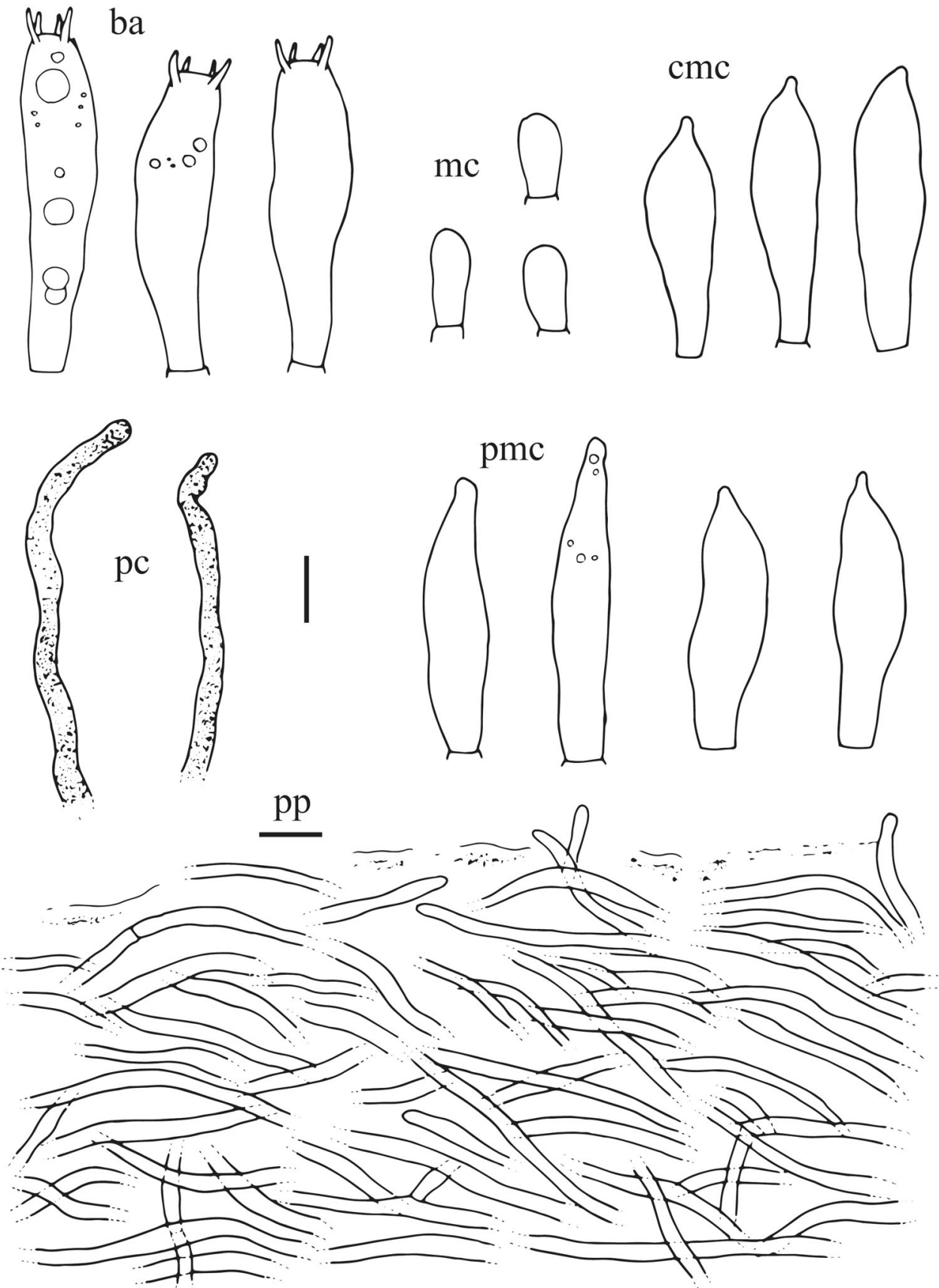
brown pileus, larger basidiospores (7.2-8.9-10.5$12.2 \times 7-8.4-9.2-10.2 \mu \mathrm{m})$, and higher basidiospore ornamentation (up to $2.5 \mu \mathrm{m}$ ) (Le et al. 2007a).

Lactarius inquinatus H. Lee, Wisitr. \& Y.W. Lim, sp. nov.

MycoBank: MB 827939

Etymology: 'inquinatus' means stained. It refers to the reddish brown tinges on the pileus and stipe.

Fig. 23 Microscopic features of Lactarius orientitorminosus

Holotypus: SOUTH KOREA, Gangwon-do, Inje-gun, Yongdae Natural Recreation Forest, alt. $489 \mathrm{~m}$, N38 $14^{\prime} 01^{\prime \prime}$ E128 $21^{\prime} 01^{\prime \prime}$, 1 Sep 2015 (SFC20150901-06) Pileus 55-80 mm diam., convex to funnel-shaped depression; margin slightly decurved, in age expanded, even, sometimes slightly uneven; surface white $(-\mathrm{A} 1)$ to yellowish white (4A2), with greyish brown (7D2) to reddish brown (8D5) patches or spots near the center, sometimes densely zonate with greyish orange (5B5) when dry, slightly viscid. Lamellae rather crowded, adnate to subdecurrent, rarely forked near stipe, with abundant lamellulae,
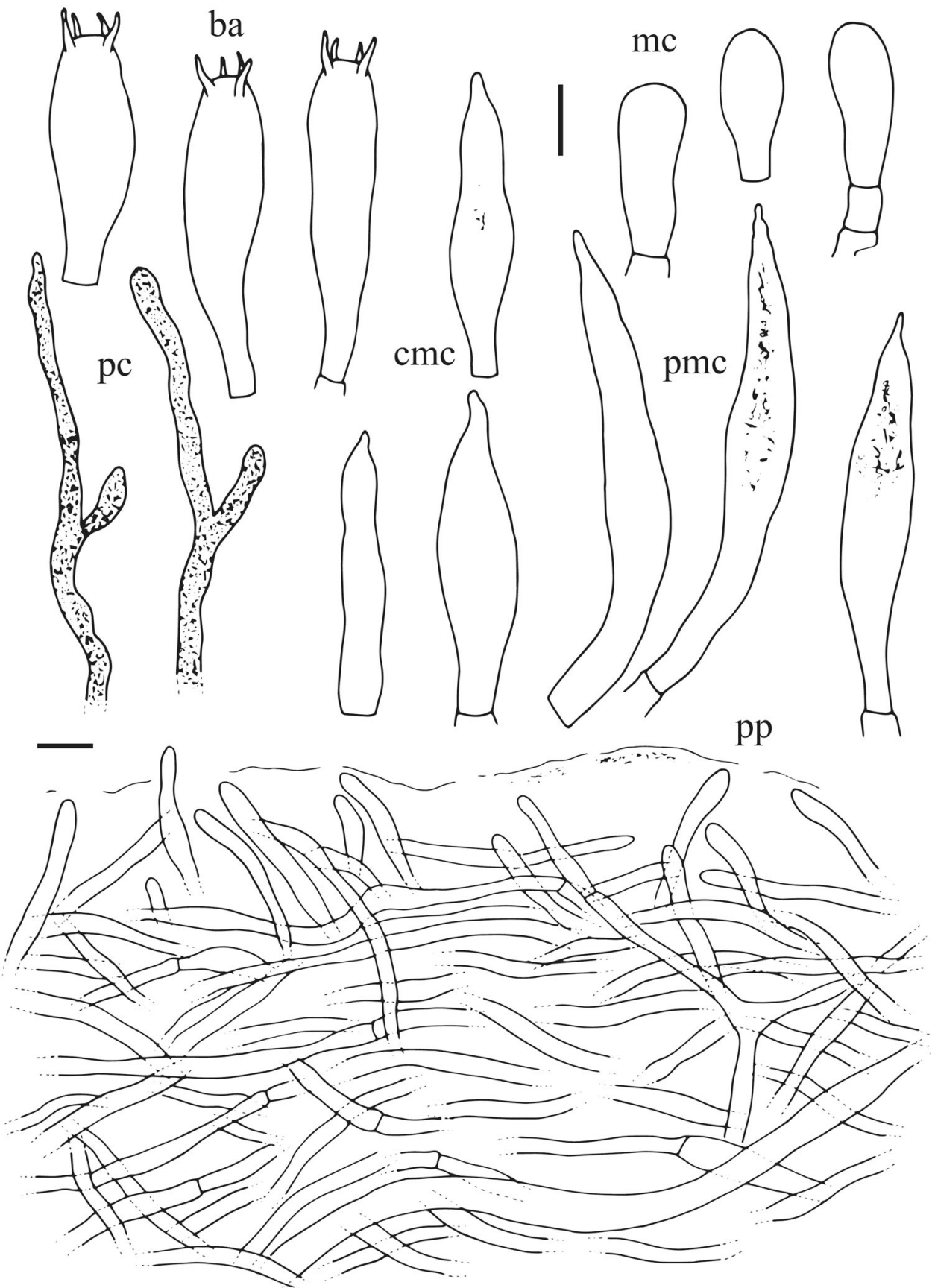
up to $6 \mathrm{~mm}$ broad, white to white chrome, turning pale reddish brown when bruised. Stipe $20-35 \times 10-25 \mathrm{~mm}$, cylindrical to narrowly clavate, tapering downwards, solid; surface white to white chrome, with greyish orange to reddish brown spots. Odour fruity. Taste mild. Latex rather abundant, watery white, unchanging on exposure.

Basidiospores $\quad(\mathrm{n}=40), \quad 6.0-7.0-7.2-8.4 \times 5.2$ $-5.7-5.8-6.4 \mu \mathrm{m}, \mathrm{Q}=1.03-1.19-1.24-1.43$, mostly subglobose to ellipsoid, few globose; ornamentation amyloid, composed of up to $1.1 \mu \mathrm{m}$ high, parallel with branches long ridges and isolated warts, sometimes connected by thin lines, forming an incomplete to almost complete reticulum; plage distally to totally amyloid. $\mathrm{Ba}$ sidia $34.5-50.5 \times 7-9.5 \mu \mathrm{m}, 2$ or 4-spored, cylindrical to narrowly clavate. Pleuromacrocystidia not abundant, $35-46.5 \times 7.5-10 \mu \mathrm{m}$, mostly embedded deep in the hymenium, fusiform, apex mucronate, contents needle-like. Lamellar edges consisting of marginal cells, cheilomacrocystidia; marginal cells cylindrical to clavate; cheilomacrocystidia rare, $28.5-41.5 \times 8-10 \mu \mathrm{m}$, fusiform to narrowly clavate, apex mostly mucronate. Pseudocystidia numerous, aseptate, mostly embedded, sometimes emergent, irregular, 2-6 $\mu \mathrm{m}$ broad, sometimes branched near apex; apex rounded, sometimes slightly broader. Pileipellis 100-220 $\mu \mathrm{m}$ thick, ixocutis, comprised of parallel to intricate cylindrical hyphae; terminal cells $55-130 \times 3-5 \mu \mathrm{m}$.

Habitat: Solitary or scattered on soil or litter layer in forests dominated by Quercus.

Additional studied material: SOUTH KOREA, Gangwondo, Inje-gun, Baekdamsa temple, alt. $510 \mathrm{~m}, \mathrm{~N} 38^{\circ} 09^{\prime} 28^{\prime \prime}$ E128 $22^{\prime} 34^{\prime \prime}, 10$ Sep 2006 (HCCN14668); ibid., Pyeongchang-gun Mt. odae, alt. $829 \mathrm{~m}, \mathrm{~N} 37^{\circ} 46^{\prime} 16^{\prime \prime} \mathrm{E} 128^{\circ} 34^{\prime} 42^{\prime \prime}$, 22 Jul 2012 (HCCN22638).

Comments: Lactarius inquinatus is characterized by a white to yellowish white pileus, lamellae staining pale reddish brown when bruised, and watery white latex. This species is similar to $L$. evosmus Kühner \& Romagn., but $L$. evosmus differs by having lower basidiospore ornamentation with less connected ridges and a distinct sweetish apple-like smell (Heilmann-Clausen et al. 1998). Lactarius zonarius (Bull.) Fr. also is similar morphologicaly to $L$. inquqinatus, but the former differs from the latter by its paler colour and subreticulate basidiospores (HeilmannClausen et al. 1998).

Lactarius orientitorminosus H. Lee, Wisitr. \& Y.W. Lim, sp. nov.

MycoBank: MB 827940
Etymology: 'orienti' means eastern and 'torminosus' refers to the European Lactarius torminosus. This name refers to the similar morphology with $L$. torminosus and its origin in East Asia (South Korea).

Holotypus: SOUTH KOREA, Gangwon-do, Taebaek-si, Mt. Hambaek, alt. 1365 m, N37 $09^{\prime} 24^{\prime \prime}$ E128 $54^{\prime} 59^{\prime \prime}, 28$ Sep 2011 (TPML110928-063; isotypus, SFC)

Pileus 30-65 mm diam., broadly convex to deep funnelshaped depression; margin inrolled; surface orange white (6A2) to brownish orange (6C6), slightly darker when old, with distinct brownish zonations, rather smooth in the center, with adpressed, up to $8 \mathrm{~mm}$ long hairs near the margin. Lamellae crowded, slightly decurrent to decurrent, rarely forked near the stipe, with abundant lamellulae, up to $3 \mathrm{~mm}$ broad, pinkish white when young, darker to pale ocher in age. Stipe $25-70 \times 10-20 \mathrm{~mm}$, cylindrical, tapering downwards, fistulose; surface pale brown to brownish orange, whitish at the base, sometimes with reddish brown spots. Latex rather scarce, white, unchanging on exposure. Basidiospores $\quad(\mathrm{n}=40), \quad(7.6-) 7.8-9.0-9.4-11.0$ $\times(6.4-) 6.5-7.1-7.3-8.2 \mu \mathrm{m}, \quad \mathrm{Q}=1.05-1.26$ $-1.32-1.59$, subglobose to ellipsoid; ornamentation amyloid, composed of up to $0.5 \mu \mathrm{m}$ high, parallel with branched ridges and isolated warts, forming an incomplete to sometimes an almost complete reticulum, some ridges connected by lower lines; plage mostly inamyloid. Basidia $38.5-48 \times 9-11.5 \mu \mathrm{m}$, 4-spored, narrowly clavate. Pleuromacrocystidia numerous, $52.5-71 \times 6-10 \mu \mathrm{m}$, mostly projecting beyond the hymenium, fusiform to lanceolate, sometimes moniliform, apex mucronate to slightly acute, contents needle-like. Lamellar edges consisting of marginal cells, cheilomacrocystidia and some basidia; marginal cells cylindrical to narrowly clavate; cheilomacrocystidia numerous, $34-52 \times 6-12.5 \mu \mathrm{m}$, fusiform to lanceolate, slightly emergent, apex mucronate. Pseudocystidia numerous, aseptate, mostly embedded, rarely inconspicuous emergent, irregular to bent, 4-7 $\mu \mathrm{m}$ broad; apex rounded, sometimes slightly broader. Pileipellis 150-230 $\mu \mathrm{m}$ thick, an ixocutis, comprised of parallel and cylindrical hyphae; terminal cells $20-75 \times 3-8 \mu \mathrm{m}$.

Habitat: Solitary or scattered on soil in mixed forests dominated by Quercus.

Additional studied material: SOUTH KOREA: Gangwondo, Pyeongchang-gun, Sangwonsa temple, alt. $903 \mathrm{~m}$, N $37^{\circ} 47^{\prime} 20^{\prime \prime}$ E128 $34^{\prime} 02^{\prime \prime}$, 15 Sep 2009, HCCN18837 $(\mathrm{HCCN})$.

Comments: Lactarius orientitorminosus is similar to two European species, L. torminosus (Schaeff.) Gray and $L$. torminosulus Knudsen \& T. Borgen. However, the Korean 
Fig. 24 Microscopic features of Lactarius parallelus
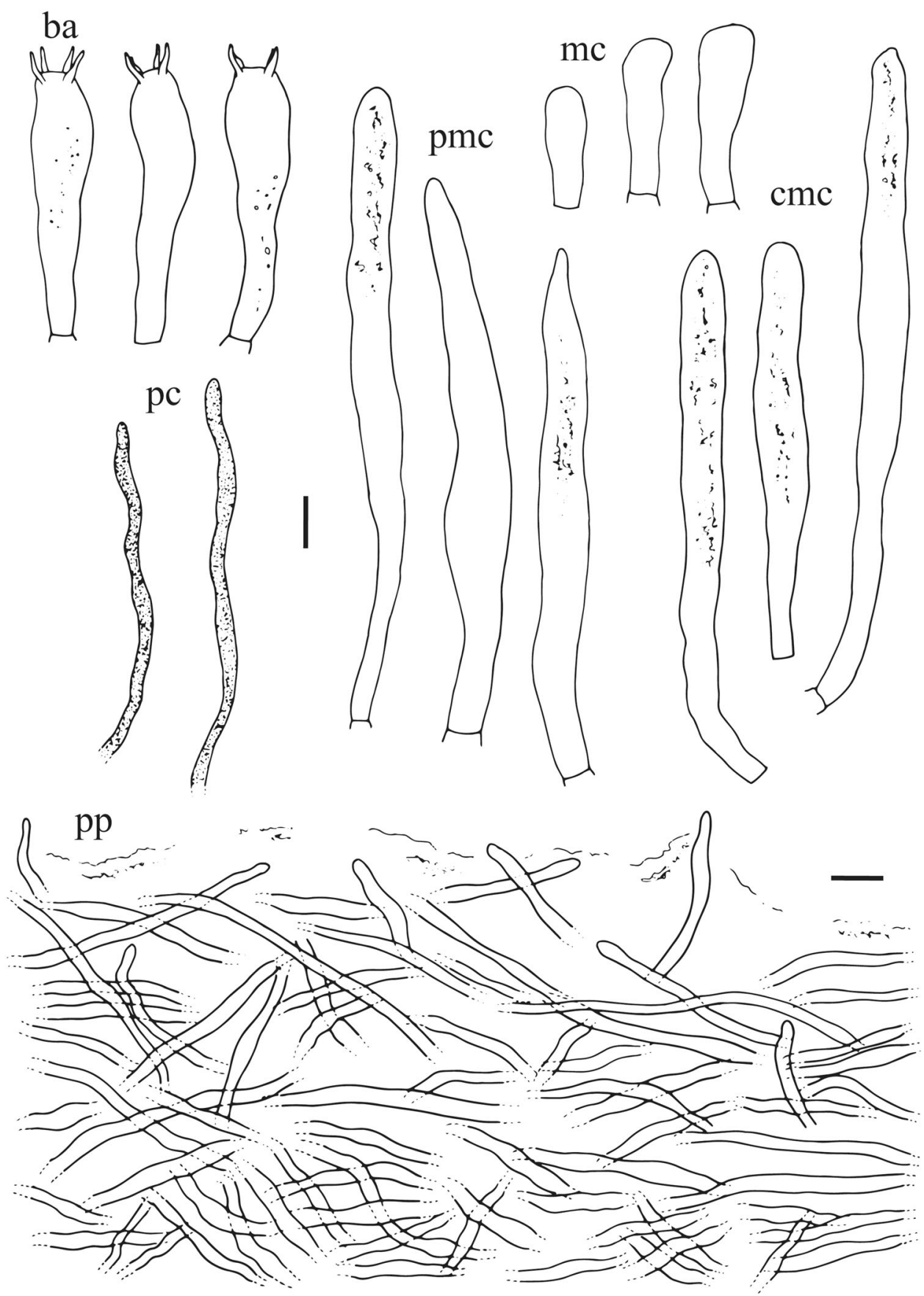

species differs in the length of pileus hairs, colour of basidiomata and spore size. The length of pileus hairs of this species is intermediate between $L$. torminosus (up to $10 \mathrm{~mm}$ ) and L. torminosulus (up to $5 \mathrm{~mm}$ ) (HeilmannClausen et al. 1998). Lactarius torminosus has orange white to brownish orange pileus while the pilei of other two species are more ochraceous.

Lactarius parallelus H. Lee, Wisitr. \& Y.W. Lim, sp. nov.

MycoBank: MB 827941
Etymology: 'parallelus' means parallel. The name defines the zebroid like ornamentation which consists of parallel ridges.

Holotypus: SOUTH KOREA, Jeju-do, Seogwipo-si, Mt. Geomunoreum, alt. 360 m, N33 $27^{\prime} 20^{\prime \prime}$ E $126^{\circ} 42^{\prime} 53^{\prime \prime}, 2$ Jul 2004 (HCCN12093; isotypus, SFC)

Pileus 45-70 mm diam., convex then applanate, sometimes slightly depressed centre; margin inrolled, even, sometimes slightly uneven; surface violet white (16A2) to violet grey (17B2), with distinct zonation, dull red (9B4) to dark 
magenta (13F7), rugose near the center, slightly pruinose when young, sometimes slightly viscid. Lamellae rather distant, adnate to slightly decurrent, sometimes forked, with lamellulae, up to $8 \mathrm{~mm}$ broad, pale cream to cream, sometimes pinkish buff. Stipe $40-60 \times 10-20 \mathrm{~mm}$, cylindrical, tapering downwards, firm; surface white to pale grey, with pale violet grey spots. Latex rather scarce, translucent white, unchanging on exposure.

Basidiospores $\quad(\mathrm{n}=60), \quad 6.0-6.6-6.8-7.6$ $\times(4.6-) 4.8-5.5-5.7-6.4 \mu \mathrm{m}, \mathrm{Q}=1.13-1.19-$ 1.23 - 1.41, subglobose to broadly ellipsoid to ellipsoid; ornamentation amyloid, composed of up to $1.4 \mu \mathrm{m}$ high, short paralle to long ridges and isolated warts, irregularly arranged in zebra-like pattern, forming a discontinuous line; plage amyloid in a distal part. Basidia $36-48.5 \times 9-10.5 \mu \mathrm{m}, 4$-spored, narrowly clavate to clavate. Pleuromacrocystidia abundant, $63-111 \times 6.5-7.5 \mu \mathrm{m}$, projecting beyond the hymenium, up to $55 \mu \mathrm{m}$, cylindrical, contents granules, apex mostly rounded to slightly acute, occasionally capitate. Lamellar edges consisting of marginal cells, cheilomacrocystidia and basidia; marginal cells cylindrical; cheilomacrocystidia abundant, $61-97.5 \times 6.5-9.5 \mu \mathrm{m}$, cylindrical, contents granules, apex rounded. Pseudocystidia numerous, aseptate, embedded to inconspicuous emergent, irregular, 2-4 $\mathrm{m}$ broad; apex rounded. Pileipellis 160-210 $\mu \mathrm{m}$ thick, an ixocutis to an intricate ixotrichoderm, with a thin gelatinized layer locally, difficult to observe; composed of ascending and sinuous hyphae, rarely erect and cylindrical, terminal cells $60-130 \times 2.5-5 \mu \mathrm{m}$.

Habitat: Solitary or scattered on ground in forests dominated by Pinus.

Additional studied material: SOUTH KOREA, Gyeongsangnam-do, Yangsan-si, Tongdosa temple, alt. $179 \mathrm{~m}, \quad \mathrm{~N} 35^{\circ} 29^{\prime} 18^{\prime \prime} \mathrm{E} 129^{\circ} 03^{\prime} 48^{\prime \prime}, 29$ May 1994 (HCCN1025G); Jeju-do, Jeju-si, Mt. hala, alt. $656 \mathrm{~m}$, N3325'09" E126³6'47", 1 Jul 1992 (HCCN4404); ibid., alt. $745 \mathrm{~m}, \mathrm{~N} 33^{\circ} 22^{\prime} 57^{\prime \prime}$ E126 $37^{\prime} 13^{\prime \prime}, 31$ Jul 2003 (HCCN11459); Gangwon-do, Wonju-si, Mt. Chiak, alt. $358 \mathrm{~m}, \quad \mathrm{~N} 37^{\circ} 24^{\prime} 08^{\prime \prime} \mathrm{E} 128^{\circ} 03^{\prime} 01^{\prime \prime}, 27$ May 2004 (HCCN11979).

Comments: Lactarius parallelus is easily recognized in the field by the violet grey pileus with magenta zonation, rather distant lamellae and white latex with unchanging reaction. The pale-colouration of this species is similar to the European L. circellatus Fr. but the latex color change and association with Carpinus trees differentiates the European species from L. parallelus (Heilmann-Clausen et al. 1998).
Fig. 25 Microscopic features of Lactarius pohangensis
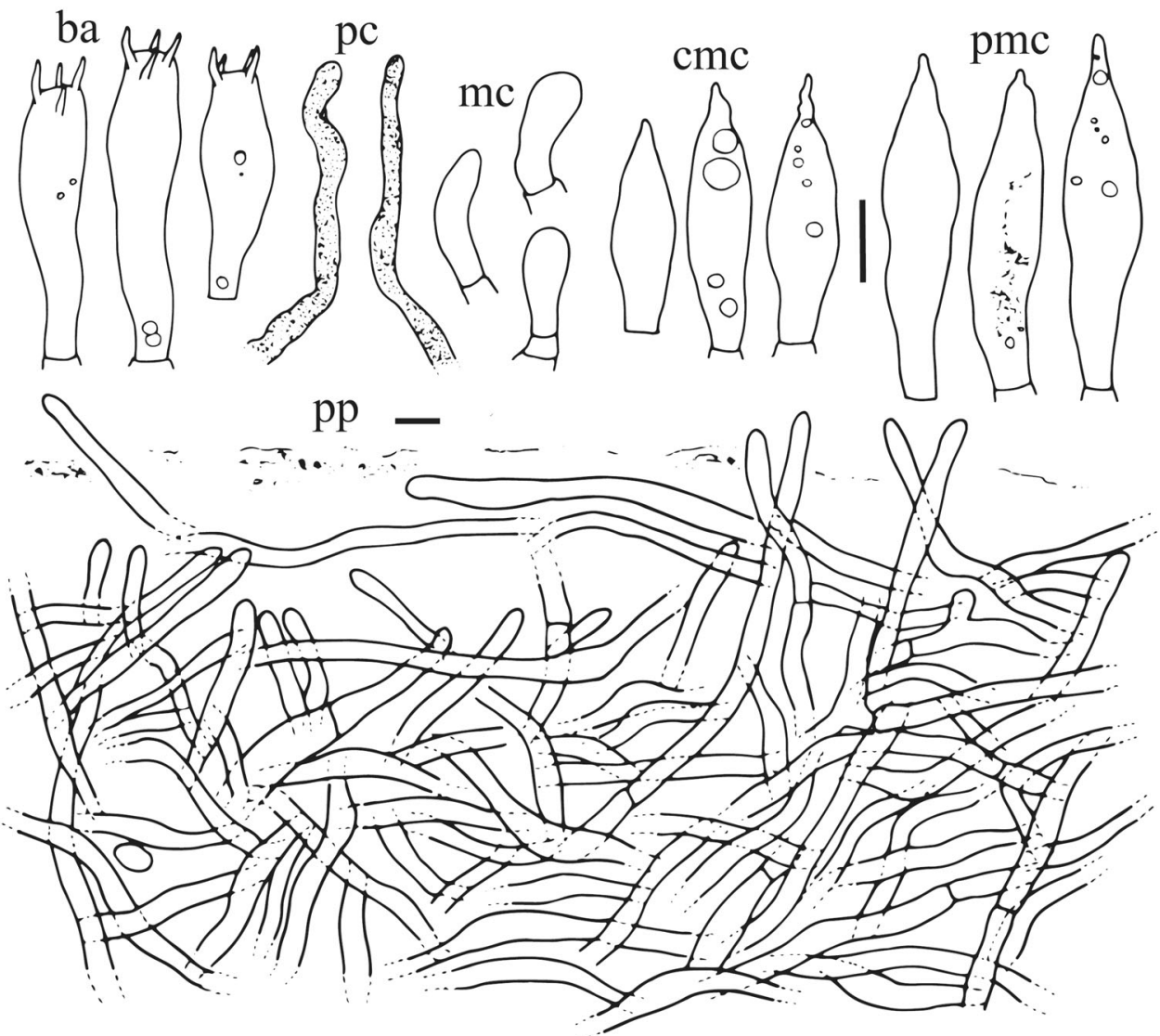
Microscopically, L. circellatus has smaller cystidia (pleuromacrocystidia: $45-70 \times 7.5-8.5 \mu \mathrm{m}$, cheilomacrocystidia: $35-60 \times 5.5-7 \mu \mathrm{m})$ and a thinner pileipellis (70-100 $\mu \mathrm{m}$ thick) than L. parallelus (Heilmann-Clausen et al. 1998).

Lactarius pohangensis H. Lee, Wisitr. \& Y.W. Lim, sp. nov.

\section{MycoBank: MB 827942}

Etymology: 'pohangensis' refers to the Pohang city, the locality of the type specimen.

Holotypus: SOUTH KOREA Gyeongsangbuk-do, Pohangsi, Mt. Sangdae, alt. 197 m, N36 $16^{\prime} 58^{\prime \prime}$ E129 $19^{\circ} 22^{\prime \prime}, 30$ Sep 2016 (SFC20160930-04)

Pileus 35-65 mm diam., convex to applanate with slightly depressed centre; margin decurved, margin uneven to crenulate; surface pale yellow (4A3) to orange white (5A2), light brown (7D8) to reddish brown (8E7) at the center, viscid, often rugulose, azonate to faintly zonate near the margin. Lamellae crowded, adnate to slightly decurrent, sometimes forked near the stipe, with abundant lamellulae, up to $5 \mathrm{~mm}$ broad, pale cream to cream, becoming pinkish buff when bruised. Stipe $30-70 \times 10-18 \mathrm{~mm}$, firm, cylindrical, slightly tapering downwards, solid; surface concolourous to pileus, longitudinally striated in age. Odour faintly fruity. Taste mild. Latex rather abundant, watery white, unchanging on exposure.

Basidiospores $\quad(\mathrm{n}=20), \quad 5.6-6.8-7.9 \times 5.0-$ $5.6-6.2 \mu \mathrm{m}, \quad \mathrm{Q}=1.03-1.22-1.52$, subglobose to ellipsoid; ornamentation amyloid, composed of up to $0.5 \mu \mathrm{m}$ high, rarely branched short ridges and isolated warts, forming an incomplete reticulum; plage amyloid in distal part. Basidia $35.5-46 \times 8.5-11.5 \mu \mathrm{m}$, 4-spored, cylindrical to narrowly clavate. Pleuromacrocystidia rather abundant, $35.5-59 \times 7.5-10.5 \mu \mathrm{m}$, conspicuously projecting beyond the hymenium, narrowly fusiform to lanceolate; apex mucronate, sometimes moniliform, rarely obtuse. Lamellar edges consisting of marginal cells, cheilomacrocystidia and basidia; marginal cells cylindrical to narrowly clavate; cheilomacrocystidia numerous, $34.5-41.5 \times 9.5$ $-11 \mu \mathrm{m}$, emergent, narrowly fusiform to lanceolate, apex mucronate to moniliform. Pseudocystidia not abundant, aseptate, irregular, sometimes branched near the apex, 3-7 $\mu \mathrm{m}$ broad; apex round, often slightly broader. Pileipellis 150-210 $\mu \mathrm{m}$ thick, an ixocutis, comprised of parallel to intricate cylindrical hyphae, locally with erect hyphae; terminal cells $20-70 \times 4-9 \mu \mathrm{m}$.

Habitat: Scattered to gregarious on soil in Pinus densifolia forests with numerous Tricholoma matsudake.

Comments: Lactarius pohangensis is characterized by the pale yellow to orange white pileus with darker center, watery white latex, and the association with Pinus trees.
This species is similar to L. alpinus Peck. However, the latter differs by having thin macrocystidia $(4-7 \mu \mathrm{m}$ in width), the presence of a papilla on the pileus, and its association with Alnus (Hesler and Smith 1979).

Lactarius puniceus H. Lee, Wisitr. \& Y.W. Lim, sp. nov. MycoBank: MB 827943

Etymology: 'puniceus' means reddish violet which refers to the reddish violet discolouration of latex.

Holotypus: SOUTH KOREA, Jeollabuk-do, Muju-gun, Mt. Deogyu, alt. $744 \mathrm{~m}, \mathrm{~N} 35^{\circ} 53^{\prime} 36^{\prime \prime} \mathrm{E} 127^{\circ} 45^{\prime} 03^{\prime \prime}, 28$ Aug 2015 (SFC20150828-51)

Pileus 70-130 mm diam., convex then applanate with more deep depression; margin slightly inrolled, in age expanded, even to slightly uneven; surface yellowish white (4A2) to greyish orange (5B3), sometimes reddish lilac (14C5) tinges, viscid. Lamellae fairly crowded, decurrent with rather long tooth, without forking, with abundant lamellulae, up to $10 \mathrm{~mm}$ broad, pale cream to cream, dark reddish violet when bruised. Stipe $50-85 \times 20-40 \mathrm{~mm}$, cylindrical, sometimes clavate, tapering downwards, solid; surface white to whitish chrome, scrobiculate, with conspicuous, olivaceousbuff, lilac to dark reddish violet spots. Odour unremarkable. Taste slightly acrid. Latex rather abundant, translucent to watery white turning reddish violet on exposure, drying dark reddish violet on lamellae.

Basidiospores $\quad(\mathrm{n}=40), \quad(9.4-) 9.6-10.7-11.2-$ $12.8 \times(8.0-) 8.2-9.3-9.7-11.1 \mu \mathrm{m}$,

$\mathrm{Q}=1.02-1.14-1.16-1.33$, mostly globose to broadly ellipsoid, few ellipsoid; ornamentation amyloid, composed of up to $1.2 \mu \mathrm{m}$ high, irregular and branched long ridges and isolated warts, forming an incomplete reticulum; plage inamyloid. Basidia $54-67.5 \times 13-17 \mu \mathrm{m}$, 4-spored, narrowly clavate, sometimes contents small granules and guttate. Pleuromacrocystidia numerous, $85-113.5 \times$ $14-18.5 \mu \mathrm{m}$, mostly projecting beyond the hymenium, narrowly fusiform to lanceolate; apex mucronate to moniliform; contents needle-like. Lamellar edges consisting of marginal cells, cheilomacrocystidia and few basidia; marginal cells cylindrical to clavate; cheilomacrocystidia numerous, $31.5-55.5 \times 8.5-12 \mu \mathrm{m}$, fusiform to narrowly clavate, apex mostly obtuse. Pseudocystidia numerous, aseptate, embedded to slightly emerging, irregular, 3-7 $\mu \mathrm{m}$ broad, sometimes branched near apex; apex rounded, sometimes slightly broader. Pileipellis $190-310 \mu \mathrm{m}$ thick, an ixocutis to ixotrichoderm, comprised of parallel to intricate cylindrical hyphae, locally with erect hyphae; terminal cells $35-90 \times 2-8 \mu \mathrm{m}$.

Habitat: Solitary or scattered on soil or litter layer in forests dominated by Quercus. 
Fig. 26 Microscopic features of Lactarius puniceus


$\mathrm{cmc}$
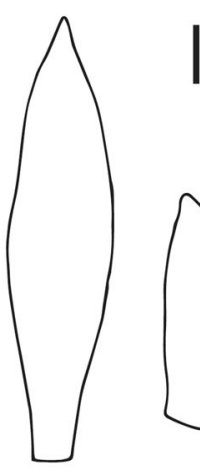

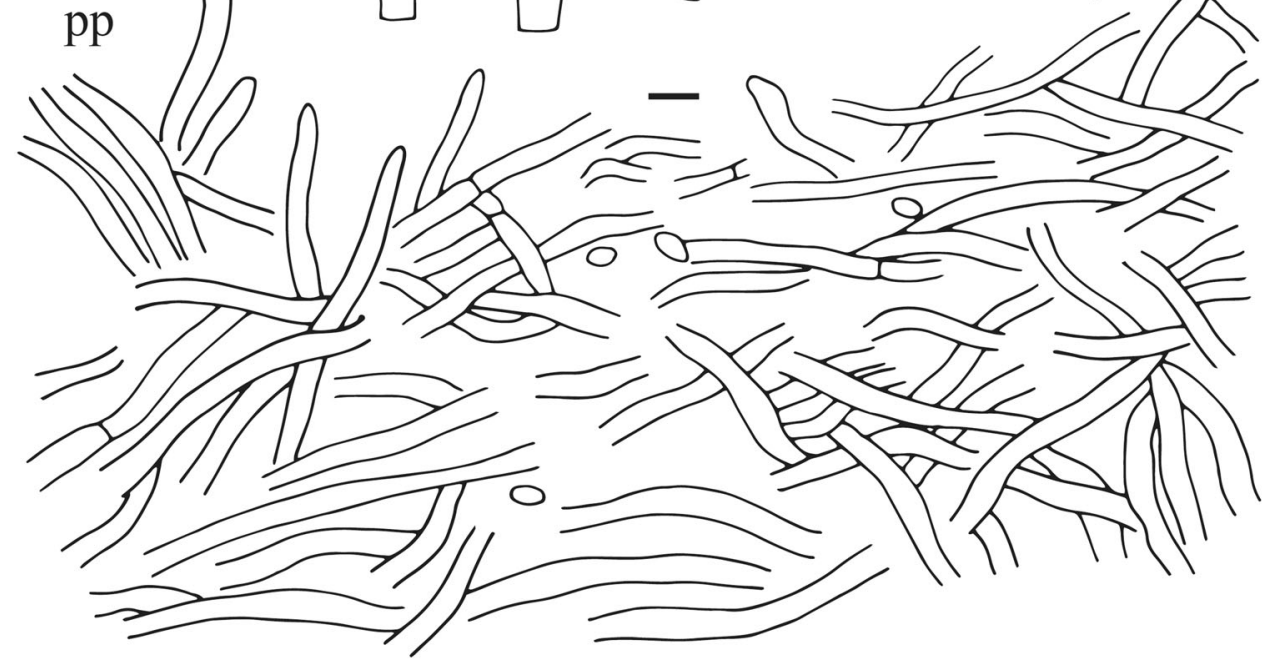

Additional studied material: SOUTH KOREA, Seoul, Gangdong-gu, Gildong ecological Park, alt. $54 \mathrm{~m}$, N37 $32^{\prime} 29^{\prime \prime}$ E12709 $23^{\prime \prime}$, 7 Sep 2012 (HCCN23527).

Comments: Lactarius puniceus is similar to members in the European 'uvidus' group such as Lactarius aspideus (Fr.) Fr., L. uvidus (Fr.) Fr., and L. violascens (J. Otto) Fr. Lactarius aspideus has smaller basidiospores $(6.7-9.5 \times 5.6-7.8 \mu \mathrm{m})$ with lower ornamentation ( $0.5 \mu \mathrm{m}$ high) and is associated with Salix trees (HeilmannClausen et al. 1998). Lactarius uvidus has a greyish pink pileus and is associated with Betula and Picea trees. Microscopically, this species has smaller pleurocystidia $(50-65 \times 8-10 \mu \mathrm{m})$ and slender terminal hyphae (1-4 $\mu \mathrm{m}$ broad) in pileipellis than those of $L$. puniceus (Heilmann-Clausen et al. 1998). Morphological characters that distinguish $L$. violascens from the new species are dark purple latex discolouration and smaller pleurocystidia $(40-80 \times 8-13 \mu \mathrm{m})$ (Heilmann-Clausen et al. 1998).

Lactarius reticulisporus H. Lee, Wisitr. \& Y.W. Lim, sp. nov.

MycoBank: MB 827944

Etymology: 'reticulisporus' refers to the complete reticulum on basidiospores of this species.

Holotypus: SOUTH KOREA, Gangwon-do, Yangyanggun, Mt. Jeombong, alt. $868 \mathrm{~m}, \mathrm{~N} 38^{\circ} 02^{\prime} 49^{\prime \prime} \mathrm{E} 128^{\circ} 27^{\prime} 58^{\prime \prime}$, 7 Sep 2016 (SFC20160907-41)

Pileus 40-150 mm diam., convex then funnel-shaped depression; margin slightly inrolled, in age decurved, even 
Fig. 27 Microscopic features of Lactarius reticulisporus
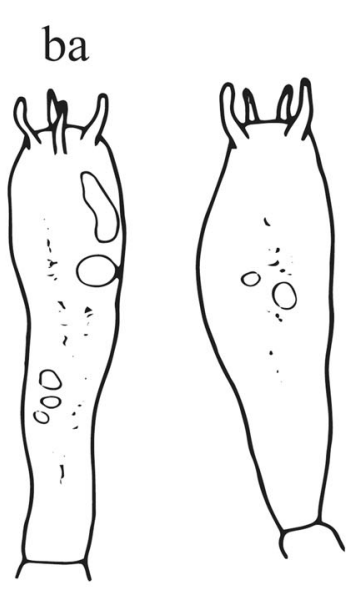
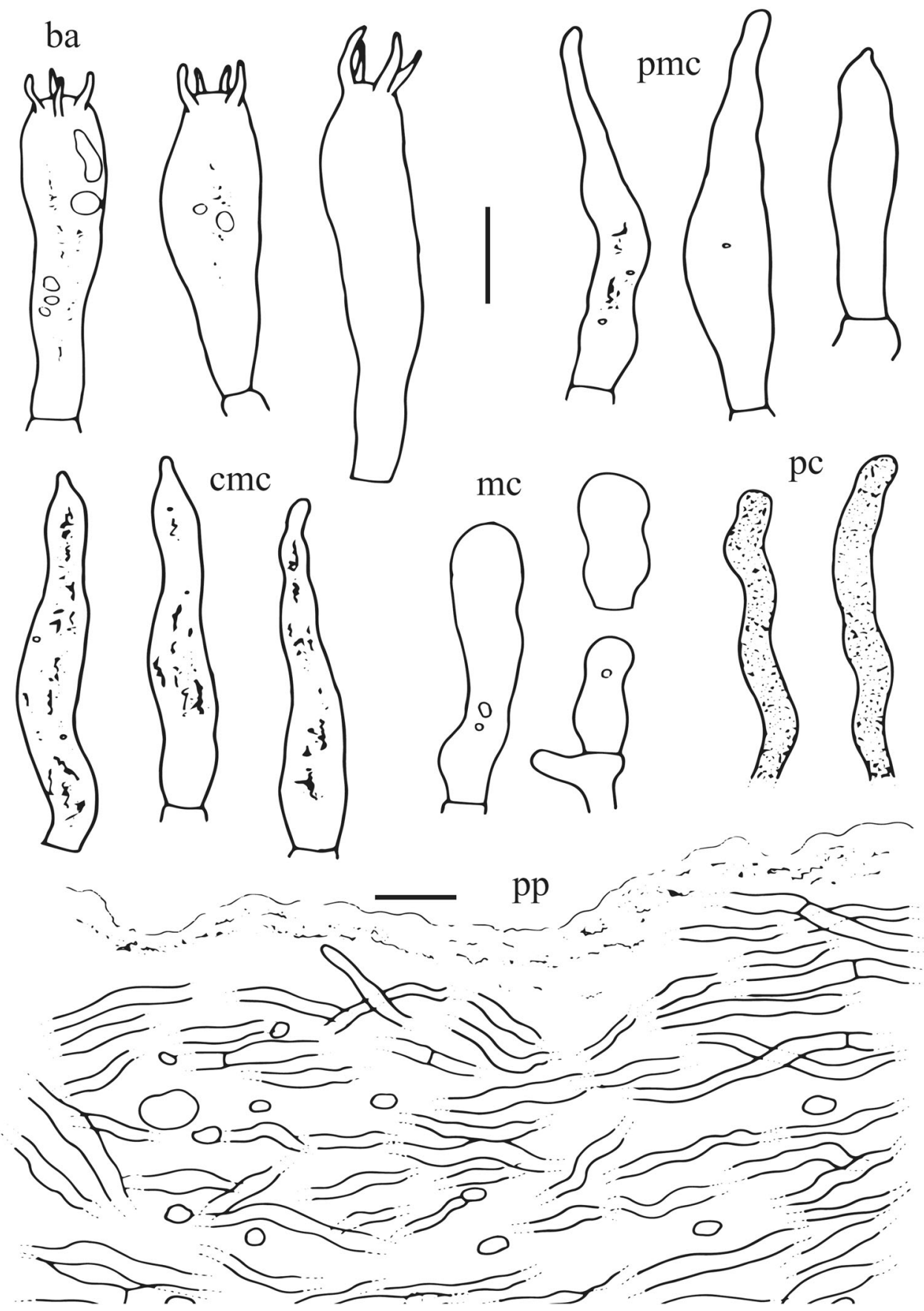

to uneven; surface white (-A1) to orange white $(5 \mathrm{~A} 2)$, sometimes with pale orange to pink and when old ocherbuff spots, dry, smooth, sometimes rugose. Lamellae rather distant, slightly decurrent to decurrent, rather thick, fimbriate, with abundant lamellulae, up to $10 \mathrm{~mm}$ broad, pale cream when young, small brown spots on lamellar edge in age, turning pale ocher when bruised. Stipe $15-70 \times 15-35 \mathrm{~mm}$, cylindrical, sometimes ventricose, rarely clavate, tapering downwards, solid; surface white to pale grey, with orange white to orange brown spots. Latex white drying orange brown on lamellae.
Basidiospores $\quad(\mathrm{n}=60), \quad 5.9-6.5-7.4-8.0 \times 4.6$ $-5.1-5.6-6.1(-6.2) \quad \mu \mathrm{m}, \quad \mathrm{Q}=1.19-1.27-$ $1.31-1.41$, broadly ellipsoid to ellipsoid; ornamentation amyloid, composed of up to $0.8 \mu \mathrm{m}$ high, ridges, forming a complete reticulum, densely reticulate locally; plage inamyloid. Basidia 37.3 - $48.6 \times 6-11.1 \mu \mathrm{m}$, 4-spored, narrowly clavate. Pleuromacrocystidia abundant, $35-59 \times 2.5-6.5 \mu \mathrm{m}$, slightly emergent beyond the hymenium, cylindrical to narrowly clavate, irregular, contents granules and needle-like, apex mucronate to moniliform. Lamellar edges consisting of marginal cells, 
Fig. 28 Microscopic features of Lactarius spadiceus

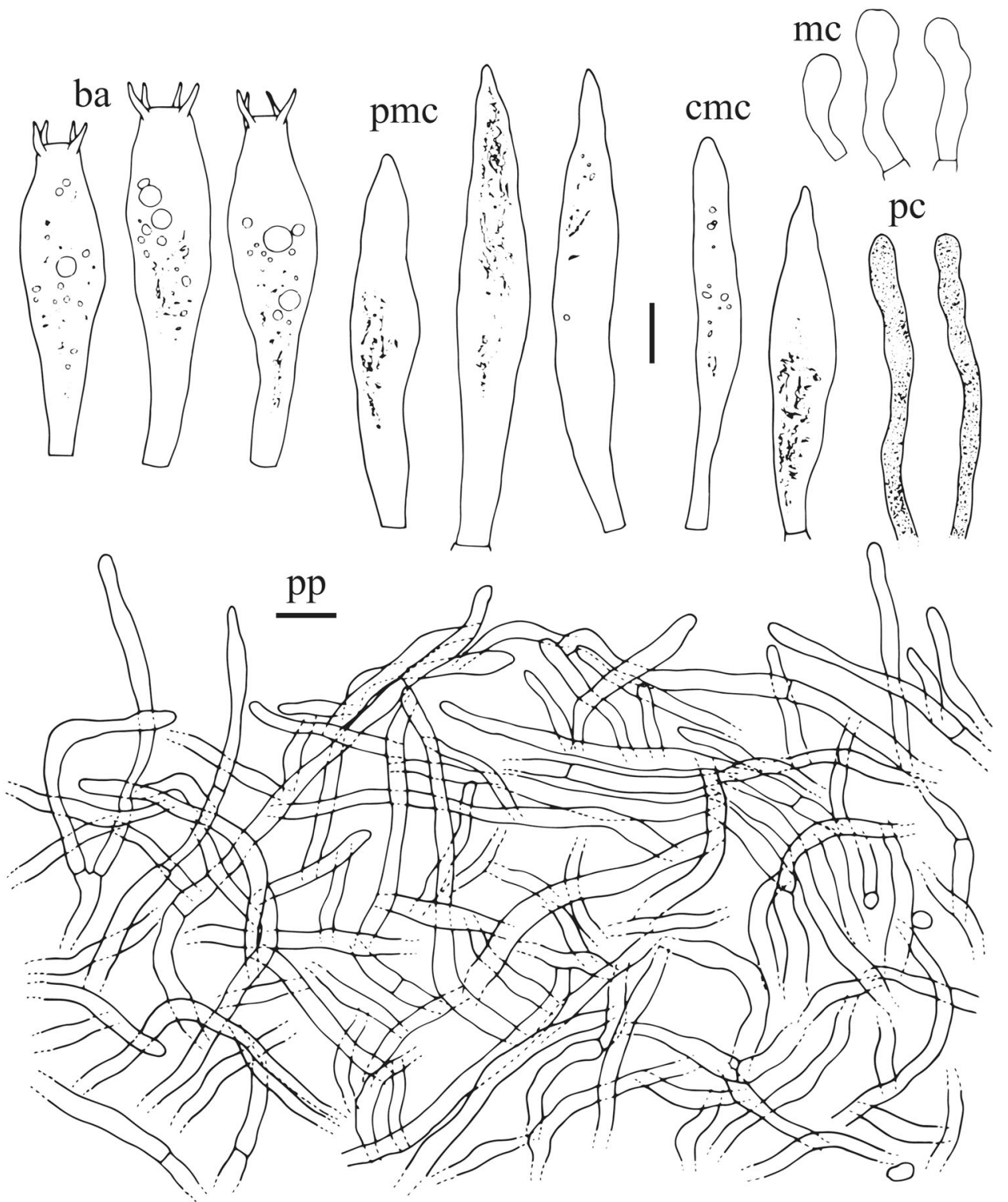

cheilomacrocystidia and basidia; marginal cells cylindrical to narrowly clavate; cheilomacrocystidia abundant, $26.5-53 \times 4-6.5 \mu \mathrm{m}$, cylindrical to narrowly clavate, contents granules, apex mucronate to moniliform. Pseudocystidia numerous, aseptate, embedded to slightly emergent, cylindrical, tortuous, $2.5-5 \mu \mathrm{m}$ broad; apex rounded. Pileipellis 170-260 $\mu \mathrm{m}$ thick, an ixocutis, a dense layer of parallel and cylindrical hyphae underneath a thin gelatinized layer; terminal cells $20-85 \times 2-6.5 \mu \mathrm{m}$.

Habitat: Solitary or scattered on soil in forests dominated by Quercus.

Additional studied material: SOUTH KOREA, Jeollanamdo, Gurye-gun, Mt. Jiri, alt. $504 \mathrm{~m}, \mathrm{~N} 35^{\circ} 14^{\prime} 04^{\prime \prime}$ E127 $36^{\prime} 23^{\prime \prime}$, 8 Sep 2005 (HCCN13149); Gangwon-do,
Wonju-si, Mt. Chiak, alt. 440 m, N37 $23^{\prime} 46^{\prime \prime}$ E128 $03^{\prime} 16^{\prime \prime}$, 12 Sep 2006 (HCCN14705).

Comments: Lactarius reticulisporus is phylogenetically closely related to L. alboscrobiculatus H.T. Le \& Verbeken and L. alboscrobiculatus var. roseopurpureus H.T. Le \& Verbeken (Fig. 1). While the new species has white latex drying to orange brown, $L$. alboscrobiculatus has white to cream latex with an unchanging reaction (Le et al. 2007a) and L. alboscrobiculatus var. roseopurpureus has lamellae staining greyish on places with dried latex (Le et al. 2007a).

Lactarius spadiceus H. Lee, Wisitr. \& Y.W. Lim, sp. nov. MycoBank: MB 827945 
Etymology: 'spadiceus' means bright brown which refers to the light brown coloured pileus.

Holotypus: SOUTH KOREA, Jeollabuk-do, Muju-gun, Mt. Bakseok, alt. $549 \mathrm{~m}, \mathrm{~N} 36^{\circ} 00^{\prime} 24^{\prime \prime} \mathrm{E} 127^{\circ} 50^{\prime} 30^{\prime \prime}, 7$ Aug 2012 (TPML120807-021; isotypus, SFC)

Pileus 30-95 mm diam., convex then infundibuliform with a depressed centre; margin inrolled, in age decurved, even; surface brownish orange (6C3) to light brown (7D5), distinctively zonate, slightly fibrillose, viscid. Lamellae adnate to slightly deccurent, crowded, rarely forked near the stipe, up to $3 \mathrm{~mm}$ broad, whitish to pale cream, often with yellowish ocher tinges. Stipe $60-90 \times 10-20 \mathrm{~mm}$, cylindrical, sometimes slightly ventricose, fistulose in age; surface whitish, with yellowish ocher to pale orange brown scrobicules. Latex rather scarce, white and unchanging on exposure.

Basidiospores $\quad(\mathrm{n}=20), \quad 9.4-10.7-11.7 \times 7.8$ $-8.7-9.7(-10.0) \quad \mu \mathrm{m}, \quad \mathrm{Q}=1.11-1.19-1.22$ - 1.28, subglobose to broadly ellipsoid; ornamentation amyloid, composed of up to $2.2 \mu \mathrm{m}$ high, irregular ridges and isolated warts, forming almost complete reticulate, closed meshes present locally, crests slightly acute; plage amyloid in the distal part. Basidia $41.5-63.5 \times 13.5-16.5 \mu \mathrm{m}$, 4-spored, narrowly clavate. Pleuromacrocystidia numerous, $44-97.5 \times 9-15.5 \mu \mathrm{m}$, mostly projecting beyond the hymenium, up to $55 \mu \mathrm{m}$, narrowly fusiform to fusiform; apex mucronate to slightly acute; contents needle-like. Lamellar edges sterile, comprised of marginal cells and cheilomacrocystidia; marginal cells mostly cylindrical with capitate apex, some flexuous cylindrical to narrowly clavate; cheilomacrocystidia numerous, $21.5-71 \times 4-10.5 \mu \mathrm{m}$, slightly projecting beyond the marginal cells, narrowly fusiform, apex mucronate to slightly acute, contents partially needle-like, small granules present. Pseudocystidia numerous, aseptate, embedded to inconspicuous emergent, irregular to bent, 3-6 $\mu \mathrm{m}$ broad; apex rounded. Pileipellis a loose and poorly differentiated cutis to trichoderm, 250-350 $\mu \mathrm{m}$ thick, composed of intricate to erect hyphae; terminal cells $25-70 \times 2-4 \mu \mathrm{m}$.

Habitat: Scattered to gregarious on soil in mixed forests dominated by Pinus and Quercus.

Additional studied material: SOUTH KOREA, Chuncheongbuk-do, Yeongdong-gun, Mt. Minjuji, alt. $674 \mathrm{~m}$, N36 ${ }^{\circ} 3^{\prime} 08^{\prime \prime}$ E12749'50", 19 Jun 2012 (KA12-0268).
Comments: Lactarius spadiceus forms a clade with members of section Deliciosi. Before this study, only two species (L. porninsis Rolland and L. splendens Hesler \& A.H. $\mathrm{Sm}$.) in this section have been known to have white unchanging latex (Nuytinck et al. 2017). From this study, two species (L. aurantiozonatus, see above, and L. spadiceus) with unchanging white latex are added. Among four species with white latex, L. porninsis can be distinguished from $L$. spadiceus by its smaller basidiospores $(6.3-9.6 \times 5.2-7.3 \mu \mathrm{m})$ and the absence of scrobicules on the stipe (Heilmann-Clausen et al. 1998). The pileus of L. spendens is more vivid and azonate (Hesler and Smith 1979). Microscopically, this species lacks cheilocystidia on lamellar edges. Lactarius aurantiozonatus can be easily distinguished from $L$. spadiceus by its orange yellow and vivid pileus colour. The other closely related species in the phylogeny, L. rubrilacteus Hesler \& A.H. Sm., has an orange brown pileus with concentric zonation and reddish latex (Hesler and Smith 1979).

\section{Key to the species of Lactarius subgenus Plinthogalus in South Korea}

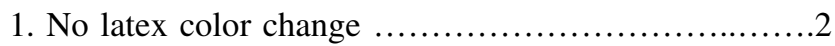

1. Latex color change ...............................5

2. Pileus with concentric light brown zones ............... L. fulvescens

2. Pileus without zonation............................ 3

3. Dark coloured basidiomata, commonly dark brown and more blackish brown in the centre ............ L. ustulatus

3. Pale coloured basidiomata, orange to pale brown...... 4

4. Pileipellis thicker than $100 \mu \mathrm{m}$................ alutaceus

4. Pileipellis thinner than $100 \mu \mathrm{m}$............ cucurbitoides

5. Latex color change to lilac on exposure. L. atromarginatus

5. Latex color change to pinkish and lamellae medium crowded ........................................6

6. Spore ornamentation lower than $1.5 \mu \mathrm{m}$.

.L. albidocinereus

6. Spore ornamentation higher than $1.5 \mu \mathrm{m}$............. 7

7. Latex changing immediately pinkish.

L. alboroseus

7. Latex changing to pinkish in few minutes .......... 8

8. Pileipellis 150-190 $\mu \mathrm{m}$ thick; basidia smaller than $40 \mu \mathrm{m} ; 2$-spored basidia present ........... L. incarnatus

8. Pileipellis $90-150 \mu \mathrm{m}$ thick; basidia larger than $45 \mu \mathrm{m} . . . . . . . . . . . . . . . . . . . . . . . .$. L. aurantiacopallens 

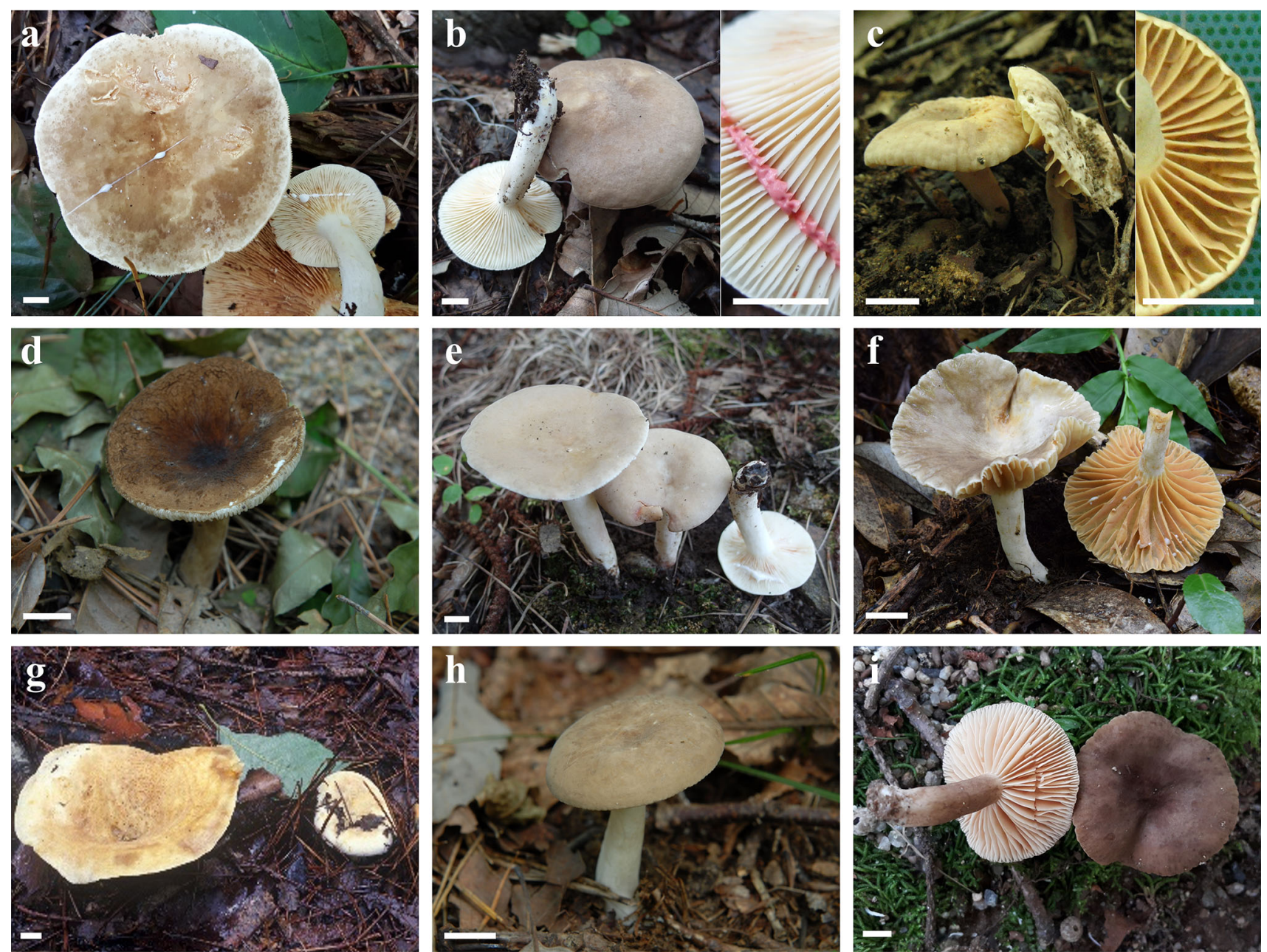

Fig. 29 Fruiting bodies of Korean species of Lactarius subg. Plinthogalus. a L. albidocinereus, b L. alboroseus, c L. alutaceus, d $L$. atromarginatus, e $L$. aurantiacopallens, $\mathbf{f} L$. cucurbitoides, $\mathbf{g} L$.

\section{Lactarius subgenus Plinthogalus}

Lactarius alboroseus H. Lee, Wisitr. \& Y.W. Lim, sp. nov.

\section{MycoBank: MB 827946}

Etymology: 'alboroseus' means pink or pale rose, referring to the pink discolouration of latex.

Holotypus: SOUTH KOREA, Jeollabuk-do, Muju-gun, Mt. Deogyu, alt. $914 \mathrm{~m}, \mathrm{~N} 35^{\circ} 53^{\prime} 08^{\prime \prime} \mathrm{E} 127^{\circ} 43^{\prime} 39^{\prime \prime}, 28$ Aug 2015 (SFC20150828-39)

Pileus 40-90 $\mathrm{mm}$ diam., convex then applanate with slightly depressed centre; margin first decurved, in age expanded, even to crenate, sometimes radially folded; surface greyish orange (5B3) to light brown (6D6), often with cream (4A3) tinges, dry, pruinose, slightly tomentose slightly tomentose, sometimes rugose in age. Lamellae slightly deccurent to deccurent, rather crowded, sometimes forked near the stipe, up to $5 \mathrm{~mm}$ broad, whitish to pale fulvescens, h L. incarnatus, i L. ustulatus. Scale bar $=1 \mathrm{~cm}$. d and f are reproduced from Lee et al. (2018) and (2015a), respectively

cream when young, yellowish ocher to buff in age. Stipe $40-100 \times 8-20 \mathrm{~mm}$, cylindrical, sometimes tapering upwards, often irregularly compressed, fistulose with age; surface whitish, often with yellowish ocher to pinkish ocher tinges. Odour unremarkable. Taste extremely acrid. Latex abundant, white changing to pink in a few seconds, finally drying whitish.

Basidiospores $\quad(\mathrm{n}=60), \quad 6.9-7.7-8.0-8.7 \times$ $6.0-6.8-7.0-7.6 \mu \mathrm{m}, \quad \mathrm{Q}=1.06-1.12-1.13$ -1.28 , subglobose to broadly ellipsoid; ornamentation amyloid, composed of up to $1.6 \mu \mathrm{m}$ high, often branched long ridges intermixed with lower short ridges and warts; plage distally amyloid to almost totally amyloid. Basidia $36-52 \times 10.5-16.5 \mu \mathrm{m}$, 4-spored, narrowly clavate. Pleuromacrocystidia absent. Lamellar edges consisting of marginal cells, cheiloleptocystidia and basidia; marginal cells narrowly clavate to clavate; cheiloleptocystidia abundant, $37-46 \times 5.5-9 \mu \mathrm{m}$, narrowly fusiform to fusiform, apex rounded to mucronate. Pseudocystidia 

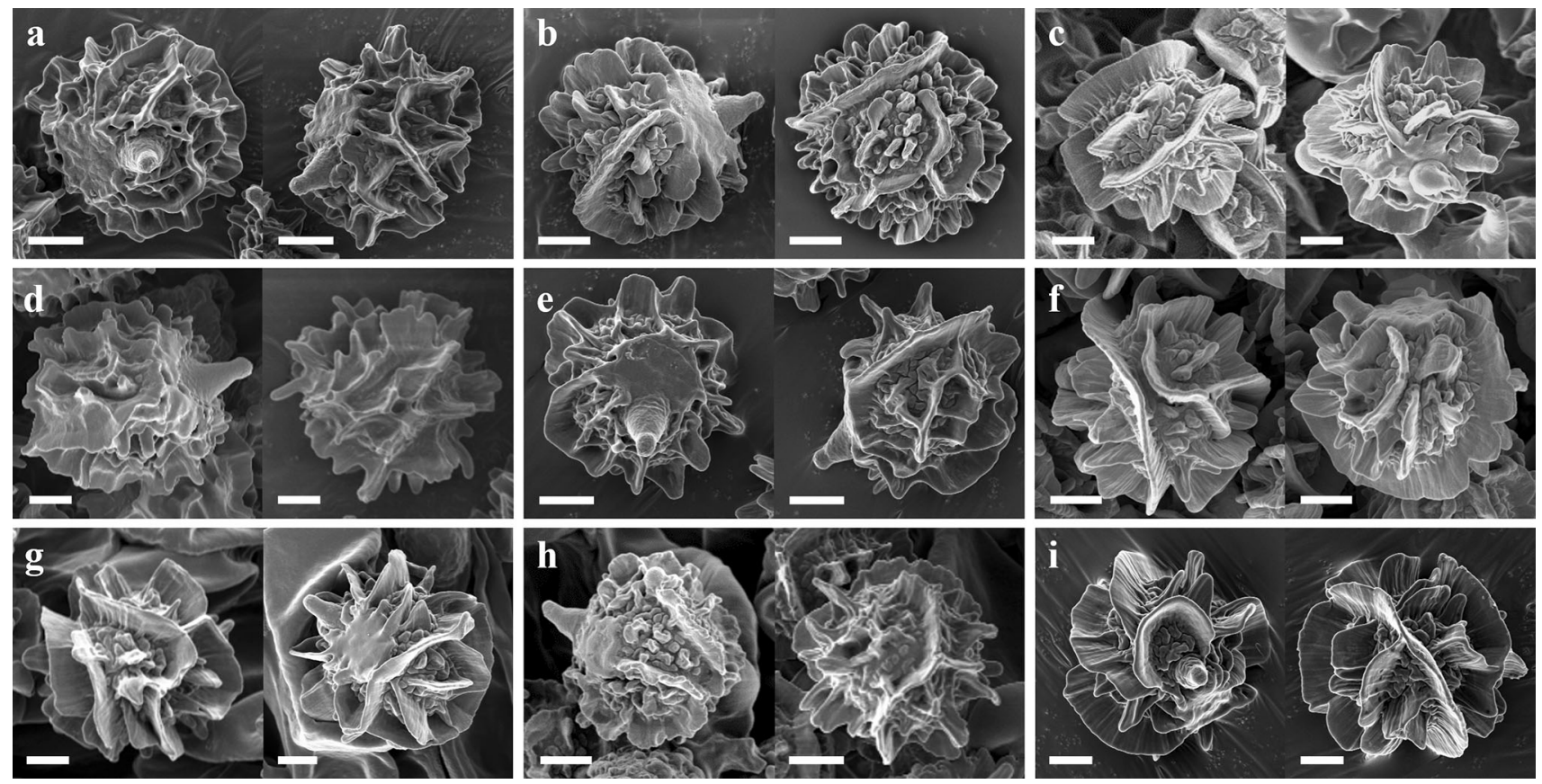

Fig. 30 Basidiospores (SEM) of Korean species of Lactarius subg. Plinthogalus. a L. albidocinereus, b L. alboroseus, c L. alutaceus, d $L$. atromarginatus, e $L$. aurantiacopallens, $\mathbf{f} L$. cucurbitoides, $\mathbf{g} L$.

numerous, aseptate, emergent beyond the hymenium, cylindrical, 3-6 $\mu \mathrm{m}$ broad, often branched, with refringent contents; apex rounded, Pileipellis $150-180 \mu \mathrm{m}$ thick, a trichopalisade; terminal hyphae parallel to ascending to erect, cylindrical, apex rounded, terminal cells $20-38.5 \times 3-4.5 \mu \mathrm{m}$; subpellis composed of globose to ovoid to lanceolate elements $11.5-25 \times 10-$ $19.5 \mu \mathrm{m}$.

Habitat: Scattered to gregarious on humid soil in mixed forests dominated by Fraxinus and Pinus. fulvescens, $\mathbf{h}$ L. incarnatus, $\mathbf{i}$ L. ustulatus. Scale bar $=2 \mu \mathrm{m}$. d and f are adapted from Lee et al. (2018) and (2015a), respectively

Additional studied material: SOUTH KOREA, Gangwondo, Inje-gun, Baekdamsa temple, alt. $533 \mathrm{~m}, \mathrm{~N} 38^{\circ} 09^{\prime} 12^{\prime \prime}$ E128 $23^{\prime} 28^{\prime \prime}, 1$ Sep 2007 (HCCN15640); Chungcheongnam-do, Geumsan-gun, Mt. Jinak, alt. 383 m, N36 $04^{\prime} 51^{\prime \prime}$ E12726 $51^{\prime \prime}, 25$ Sep 2012 (KA12-1557).

Comments: Lactarius alboroseus can be distinguished from a morphologically similar species, L. incarnatus (see below) by immediate pinkish discoloration of latex after exposure to air, while the latter species showed slow latex colour change. The host tree of the two species is different: Lactarius alboroseus is associated with Fraxinus and Pinus while L. incarnatus with Quercus. 
Fig. 31 Microscopic features of Lactarius alboroseus
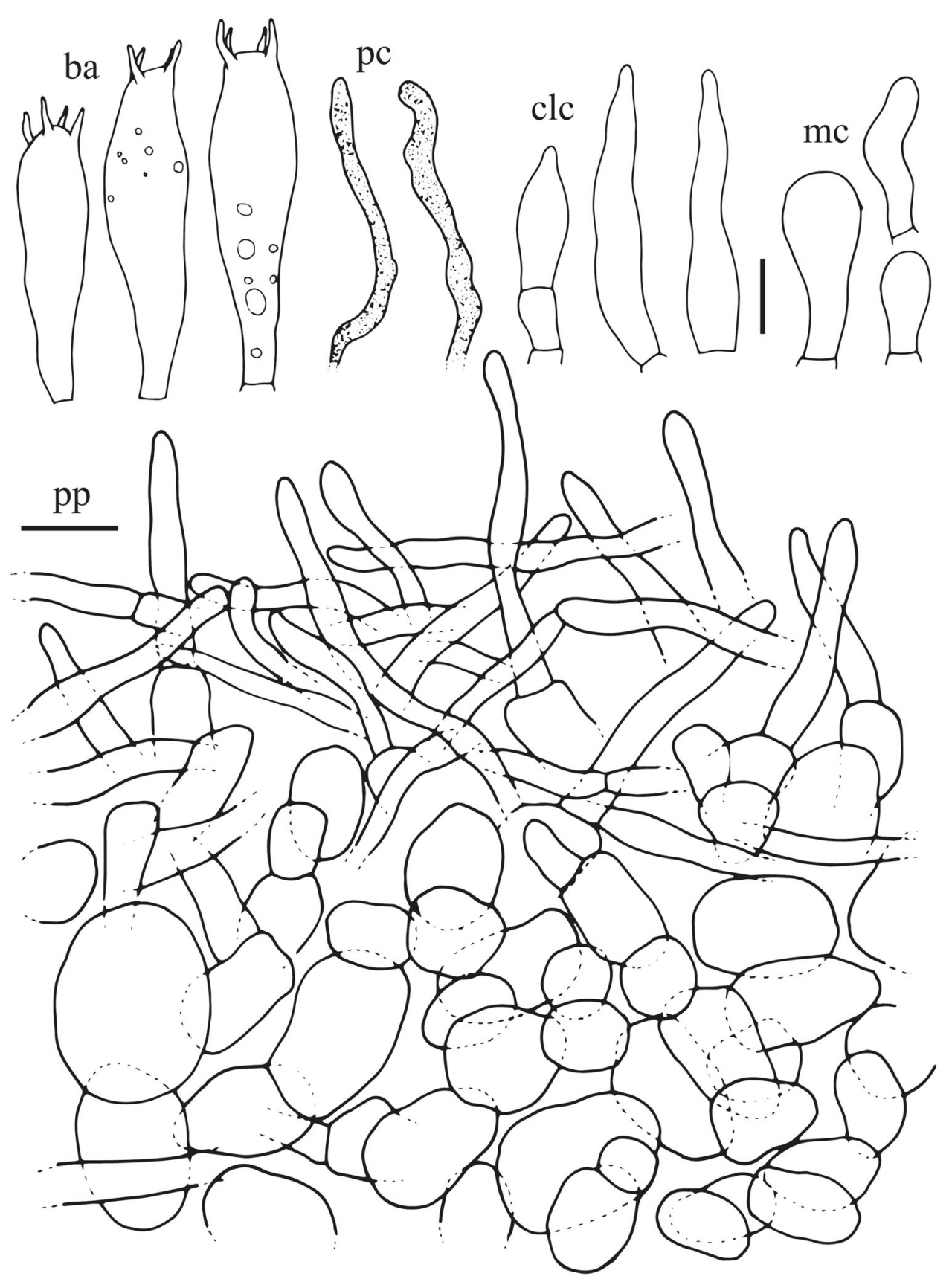
Fig. 32 Microscopic features of Lactarius alutaceus
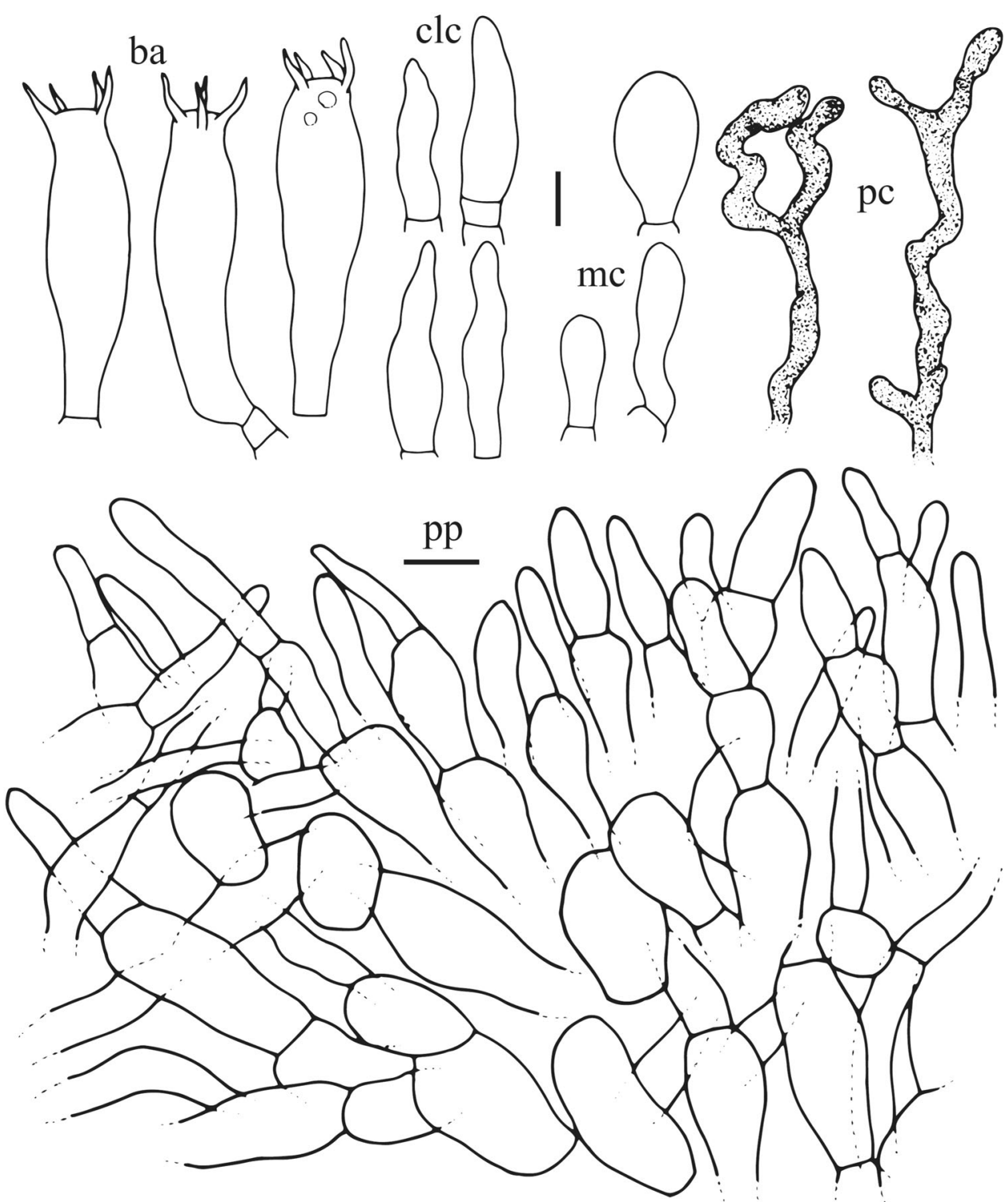

Lactarius alutaceus H. Lee, Wisitr. \& Y.W. Lim, sp. nov. MycoBank: MB 827947

Etymology: 'alutaceus' means leather-yellow, referring to the pale and dull yellow colour of the pileus.

Holotypus: SOUTH KOREA, Chungcheongnam-do, Boryeong-si, Seongjusan Natural Recreation Forest, alt. $238 \mathrm{~m}, \quad \mathrm{~N} 36^{\circ} 20^{\prime} 08^{\prime \prime} \quad \mathrm{E} 126^{\circ} 39^{\prime} 56^{\prime \prime}, \quad 25$ Jul 2012 (SFC20120725-22)

Pileus 20-45 mm diam., convex to applanate with slightly depressed centre; margin decurved, shortly grooved to rugluose, sometimes crenate; surface yellowish white (3A2) to cream (4A3), greyish brown (5D3) at the center, often with greyish brown tinges, dry, slightly tomentose, radially rugose to rugulose in age. Lamellae adnate to slightly deccurent, distant, never forked, up to $6 \mathrm{~mm}$ broad, with only one lamellulae between 2 lamellae, cream to greyish yellow, slowly staining pinkish when bruised. Stipe $20-40 \times 5-15 \mathrm{~mm}$, cylindrical to tapering downwards, fistulose; surface whitish or concolourous to pileus, often with pale greyish brown tinges, slightly pubescent when young. Odour agreeable. Taste mild. Latex rather scarce, white, unchanging on exposure.

Basidiospores $\quad(\mathrm{n}=60), \quad 7.1-7.8-8.0$ $-8.7(-8.9) \times 6.6-7.2-7.5-8.1 \mu \mathrm{m}$,

$\mathrm{Q}=1.01-1.06-1.09-1.14$, globose to subglobose; ornamentation amyloid, composed of up to $2.1 \mu \mathrm{m}$ high, thick ridges and clusters of warts, short ridges between thick ridges, winged; plage distally to almost totally amyloid. Basidia $41-50 \times 12-14 \mu \mathrm{m}, 4$-spored, narrowly clavate. Pleuromacrocystidia absent. Lamellar edges 
consisting of marginal cells, cheiloleptocystidia and few basidia; marginal cells narrowly clavate to clavate, sometimes cylindrical; cheiloleptocystidia abundant, $24.5-39.5 \times 5.5-8.5 \mu \mathrm{m}$, cylindrical to narrowly fusiform, apex rounded. Pseudocystidia numerous, aseptate, emergent from the hymenium, cylindrical, $3-4.5 \mu \mathrm{m}$ broad, often branched, filled with granules; apex rounded. Pileipellis 100-190 $\mu \mathrm{m}$ thick, a trichopalisade; terminal hyphae erect, cylindrical, terminal cells $10.5-23 \times 6.5-10 \mu \mathrm{m}$, apex rounded; subpellis composed of inflated to narrowly clavate or ovoid cells, $11.5-21 \times 6.5-10 \mu \mathrm{m}$.

Fig. 33 Microscopic features of Lactarius aurantiacopallens
Habitat: Solitary or scattered on loam or sandy loam soil in forests dominated by Quercus.

Additional studied material: SOUTH KOREA, Gangwondo, Pyeongchang-gun, Mt. Odae, alt. 989 m, N37 $46^{\prime} 50^{\prime \prime}$ E129³4'20", 23 Aug 1993 (HCCN849G).

Comments: Lactarius alutaceus is easily confused with $L$. cucurbitoides. Both species are found in Quercus forest in South Korea. However, the new species has greyish brown tinges and less numerous lamellulae while L. cucurbitoides is rather pale orange to pale yellow. Microscopically, $L$. alutaceus differs from $L$. cucurbitoides by having pileipellis layer (Lee et al. 2015b) and less helically arranged spore ornamentation.

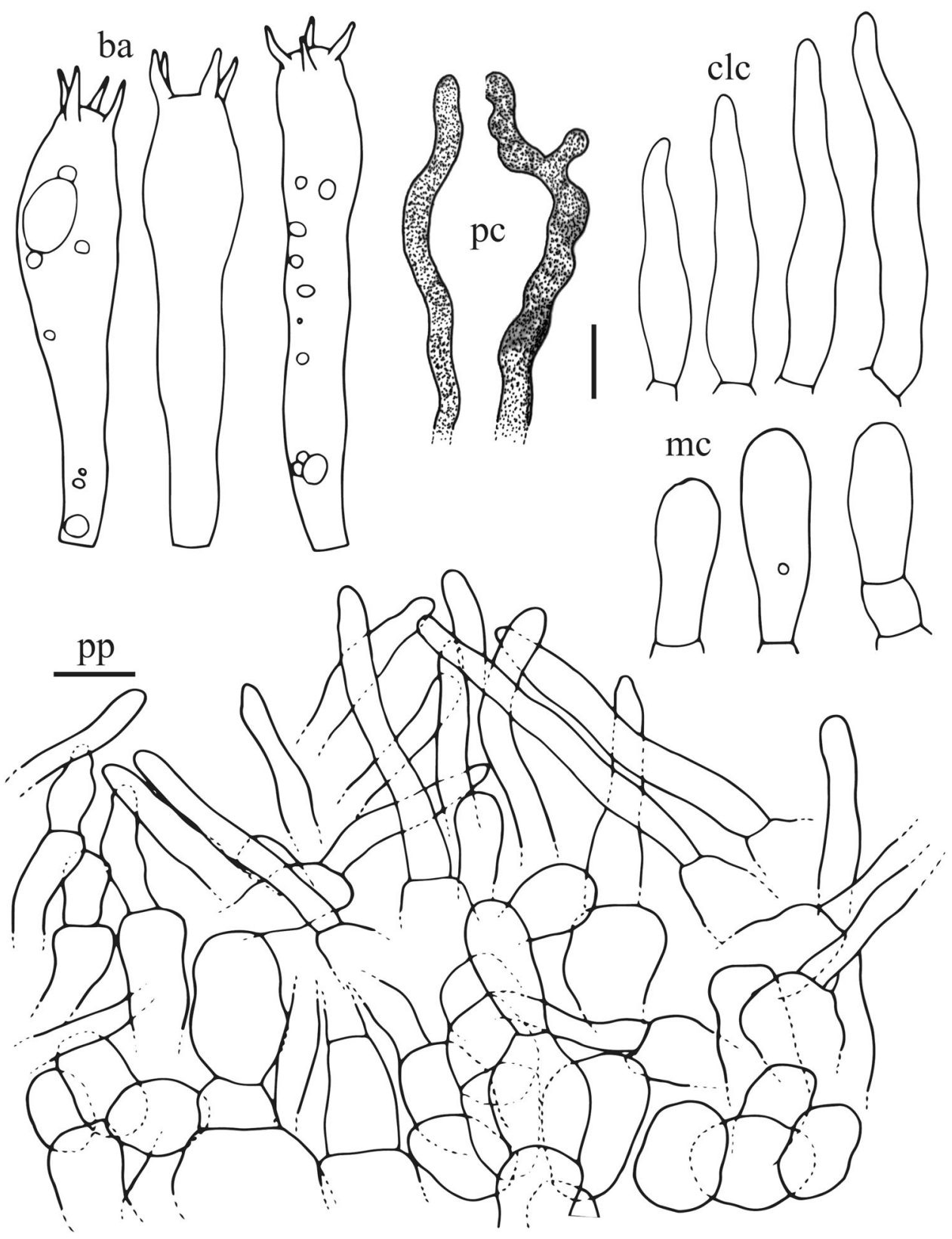


Lactarius aurantiacopallens H. Lee, Wisitr. \& Y.W. Lim, sp. nov.

\section{MycoBank: MB 827948}

Etymology: 'aurantiaco' means orange and 'pallens' means pale. The name refers to the unicoloured pale orange basidiomata.

Holotypus: SOUTH KOREA, Jeollabuk-do, Muju-gun, Mt. Deogyu, alt. $614 \mathrm{~m}, \mathrm{~N} 35^{\circ} 54^{\prime} 03^{\prime \prime} \mathrm{E} 127^{\circ} 46^{\prime} 29^{\prime \prime}, 28$ Aug 2015 (SFC20150828-26)

Pileus 40-90 mm diam., convex to applanate with slightly depressed centre, sometimes with tiny umbo; margin first decurved, in age expanded, even to uneven, sometimes crenate; surface orange white (5A2) to pale brownish orange (6C3), dry, slightly pruinose, slightly tomentose. Lamellae adnate to slightly deccurent, rather crowded, rarely forked near the stipe, up to $4 \mathrm{~mm}$ broad, whitish to pale cream when young, yellowish ocher to pinkish buff in age. Stipe $50-110 \times 10-15 \mathrm{~mm}$, cylindrical, often tapering downwards, sometimes irregularly compressed, fistulose in age; surface whitish, often with yellowish ocher to pinkish tinges. Odour unremarkable. Taste acrid. Latex abundant, white changing to pink in a few minutes, pale cream when dry.

Basidiospores $(\mathrm{n}=60), 6.2-6.8-7.4-8.0 \times 5.4$ $-6.0-6.5-7.2 \mu \mathrm{m}, \mathrm{Q}=1.05-1.13-1.16-1.28$, mostly subglobose to broadly ellipsoid; ornamentation amyloid, composed of up to $1.8 \mu \mathrm{m}$ high, often branched long and high ridges and small warts, sometimes forming an incomplete reticulum; plage distally amyloid. Basidia $47-66 \times 10-12 \mu \mathrm{m}, 4$-spored, narrowly clavate. Pleuromacrocystidia absent. Lamellar edges consisting of marginal cells, cheiloleptocystidia and basidia; marginal cells cylindrical; cheiloleptocystidia abundant, $22-45 \times 3.5-7 \mu \mathrm{m}$, narrowly fusiform, occasionally tortuous, apex rounded. Pseudocystidia numerous, aseptate, emergent beyond the hymenium, cylindrical, 3-5 $\mu \mathrm{m}$ broad, branched, contents refringent and crystalline; apex rounded. Pileipellis 90-150 $\mu \mathrm{m}$ thick, a trichopalisade to palisade; terminal hyphae erect, cylindrical, terminal cells $16-36 \times 3-4 \mu \mathrm{m}$, apex rounded; subpellis composed of globose to inflated cells, $8-16.5 \times 6-10 \mu \mathrm{m}$.

Habitat: Solitary or scattered on soil in lowland of mixed forests dominated by Acer, Fraxinus, and Quercus.

Additional studied material: SOUTH KOREA, Gangwondo, Wonju-si, Mt. Chiak, alt. $403 \mathrm{~m}, \mathrm{~N} 37^{\circ} 25^{\prime} 02^{\prime \prime}$ E128 56'24", 5 Sep 2006 (HCCN14564); Gangwon-do, Taebaek-si, Mt. Taebaek, alt. $1119 \mathrm{~m}, \mathrm{~N} 37^{\circ} 06^{\prime} 42^{\prime \prime}$ E128 56'24", 24 Jul 2012 (HCCN22693).

Comments: Lactarius aurantiacopallens is morphologically similar to two new species, L. alboroseus (see above) and L. incarnatus (see below). This species has a thinner pileipellis (90-150 $\mu \mathrm{m}$ thick) than those of L. alboroseus (150-180 $\mu \mathrm{m}$ thick) and L. incarnatus $(150-190 \mu \mathrm{m}$ thick).

Lactarius fulvescens H. Lee, Wisitr. \& Y.W. Lim, sp. nov. MycoBank: MB 827949

Etymology: 'fulvescens' means becoming tawny, referring to the orange brown tinges on full-grown specimens.

Holotypus: SOUTH KOREA, Chungcheongbuk-do, Goe-


4 Sep 2012 (TPML120904-023; isotypus, SFC)

Pileus 30-120 mm diam., convex then applanate to infundibuliform with deeply depressed centre; margin first decurved, in age expanded, often uneven, sometimes crenate; surface dull, cream (4A3) to orange white (5A2), greyish brown (5D3) at the center, dry, tomentose, rugulose in age, azonate when young, later getting faint brownish (5D8) zones near the margin, with light brown tinges. Lamellae adnate to slightly deccurent, rather distant, rarely forked near the stipe, up to $6 \mathrm{~mm}$ broad, whitish to pale cream, turning pinkish or unchanging when bruised. Stipe $30-70 \times 8-30 \mathrm{~mm}$, cylindrical, sometimes tapering upwards; surface white, pubescent when young, sometimes longitudely striated. Latex rather abundant, white, unchanging on exposure.

Basidiospores $\quad(\mathrm{n}=60), 7.2-8.1-9.4-10.4 \times 6.4$ $-7.3-8.1-9.3(-9.7) \mu \mathrm{m}, \mathrm{Q}=1.07-1.12-1.16$ - 1.29, subglobose to broadly ellipsoid; ornamentation amyloid, composed of up to $2.3 \mu \mathrm{m}$ high, thick and coarse ridges often branched to arranged in zebra-like pattern, short ridges or isolated warts present; plage totally amyloid. $B a$ sidia $53.5-66.5 \times 9.5-15 \mu \mathrm{m}$, 4-spored, narrowly clavate to clavate. Pleuromacrocystidia absent. Lamellar edges consisting of marginal cells, cheiloleptocystidia and basidia; marginal cells cylindrical to narrowly clavate, occasionally capitate; cheiloleptocystidia abundant, $13-37.5 \times 3.5-$ $6.5 \mu \mathrm{m}$, mostly cylindrical, straight to tortuous, apex rounded. Pseudocystidia numerous, aseptate, embedded to slightly emergent beyond the hymenium, irregularly cylindrical, straight to tortuous, 2-6 $\mu \mathrm{m}$ broad; apex rounded. Pileipellis 60-100 $\mu \mathrm{m}$ thick, a trichopalisade; terminal hyphae mostly erect, cylindrical, terminal cells $16.5-36.5 \times 3-5.5 \mu \mathrm{m}$; subpellis composed of globose to narrowly clavate cells, $10.5-27.5 \times 6-15.5 \mu \mathrm{m}$.

Habitat: Solitary or scattered on soil in mixed forests dominated by Pinus and Quercus.

Additional studied material: SOUTH KOREA, Gangwondo, Donghae-si, alt. 206 m, N37 $30^{\prime} 49^{\prime \prime}$ E129 $02^{\prime} 54^{\prime \prime}, 4$ Oct 2007 (HCCN15868); ibid., Yeongweol-gun, 
Fig. 34 Microscopic features of Lactarius fulvescens
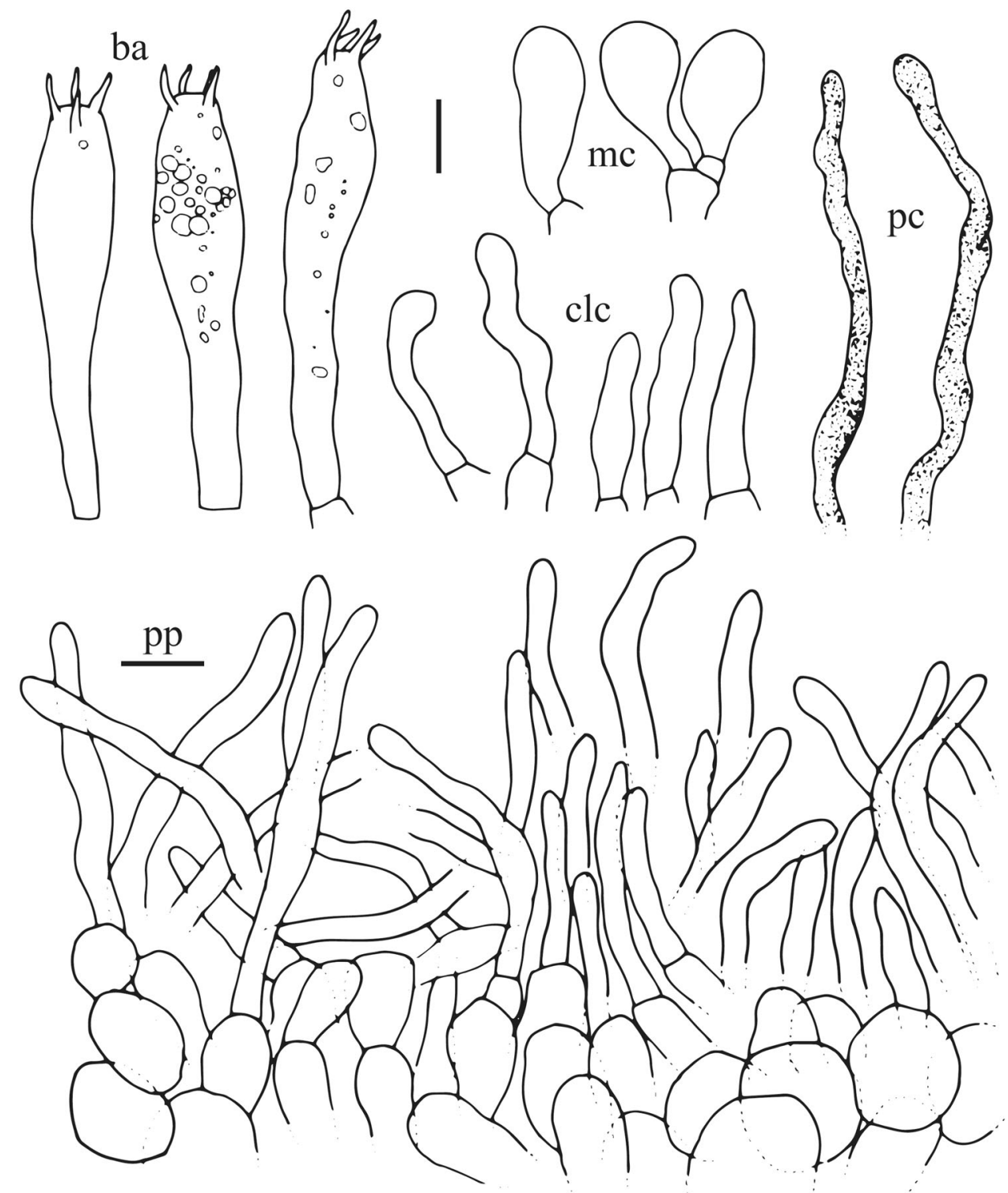

Beopheungsa temple, alt. $484 \mathrm{~m}, \quad \mathrm{~N} 37^{\circ} 22^{\prime} 21^{\prime \prime}$ E128 ${ }^{\circ} 15^{\prime} 26^{\prime \prime}$, 8 Sep 2012 (HCCN23574).

Comments: This species is reminiscent of L. oomsisiensis Verbeken \& Halling reported from Paupa New Guinea, Thailand, and Laos. The latter differs from $L$. fulvescens by having latex changing to yellow and smaller basidiospores ornamented with an incomplete reticulum (Le et al. 2007b). Another similar species is $L$. friabilis H.T. Le \& D. Stubbe from Thailand, which has a similar coloured pileus surface but white latex turning pinkish (Le et al. 2007b). 
Lactarius incarnatus H. Lee, Wisitr. \& Y.W. Lim, sp. nov. MycoBank: MB 827950

Etymology: 'incarnatus' means flesh-coloured or pink, referring to the pink discolouration of latex.

Holotypus: SOUTH KOREA, Chungcheongbuk-do, Boeun-gun, Mt. Songni, alt. $397 \mathrm{~m}, \quad \mathrm{~N} 36^{\circ} 32^{\prime} 60^{\prime \prime}$ $\mathrm{E} 127^{\circ} 50^{\prime} 20^{\prime \prime}$, 20 Sep 2011 (TPML110920-069; isotypus, SFC)

Pileus $30-50 \mathrm{~mm}$ diam., convex to applanate with slightly depressed centre, sometimes with tiny umbo; margin first decurved, in age expanded, even to crenate; surface greyish orange (5B3) to brownish orange (6D3), often with greyish brown tinges, dry, pruinose, sometimes rugose in age. Lamellae adnate to slightly deccurent, rather crowded, very rarely forked, up to $4 \mathrm{~mm}$ broad, whitish to pale cream when young, cream to buff in age. Stipe $35-60 \times 8-15 \mathrm{~mm}$, cylindrical, sometimes tapering upwards, fistulose with age; surface whitish to pale ocher, often with yellowish ocher tinges. Odour unremarkable, sometimes faintly fruity. Taste very acrid. Latex rather abundant, white changing to pink in a few minutes, finally drying whitish.

Basidiospores $\quad(\mathrm{n}=80), \quad(6.1-) 6.2-6.9-7.5$ $-8.5 \times(5.2-) 5.4-6.0-6.6-7.5(-8.0) \quad \mu \mathrm{m}$, $\mathrm{Q}=1.05-1.11-1.15-1.28$, mostly subglobose to broadly ellipsoid; ornamentation amyloid, composed of up to $1.9 \mu \mathrm{m}$ high, often forked irregular ridges intermixed with smaller warts; plage distally amyloid. Basidia $34.5-39 \times 11-12 \mu \mathrm{m}, 2$ or 4-spored, narrowly clavate. Pleuromacrocystidia absent. Lamellar edges consisting of marginal cells, cheiloleptocystidia and basidia; marginal cells cylindrical to narrowly clavate; cheiloleptocystidia abundant, $22-45 \times 4-6 \mu \mathrm{m}$, narrowly fusiform, apex rounded. Pseudocystidia numerous, aseptate, often emergent beyond the hymenium, cylindrical, 3-4.5 $\mu \mathrm{m}$ broad, branched to tortuous, contents with refringent particles; apex rounded. Pileipellis 150-190 $\mu \mathrm{m}$ thick, a trichopalisade; terminal hyphae intricate to erect, cylindrical, terminal cells $20.5-50.5 \times 3-4 \mu \mathrm{m}$, apex rounded; subpellis composed of inflated to ovoid cells, $10.5-18.5 \times 6.5-10 \mu \mathrm{m}$.

Habitat: Solitary or scattered on humid soil near brooks in forests dominated by Quercus.

Additional studied material: SOUTH KOREA, Jeollabukdo, Muju-gun, Mt. Deogyu, alt. $731 \mathrm{~m}$, N35 $53^{\prime} 09^{\prime \prime}$ E12746'26", 7 Jul 2006 (HCCN13840); Gyeonggi-do, Gapyeong-gun, Mt. Yumyeong, alt. $378 \mathrm{~m}, \mathrm{~N} 37^{\circ} 35^{\prime} 13^{\prime \prime}$ E127²9'33", 23 Jul 2010 (HCCN19933).

Comments: Lactarius incarnatus is one of the Korean species with pinkish discoloring latex and can be confused with three Asian species (L. albidocinereus, L. alboroseus, see above, and $L$. aurantiacopallens, see above). The basidiospores of $L$. albidocinereus have modest ornamentation and more interconnections between ridges compared to L. incarnatus (Shi et al. 2018). Immediate latex discoloration of $L$. alboroseus and a thin pileipellis of $L$. aurantiacopallens are characters that distinguish these species from $L$. incarnatus (See the descriptions of the species in the present paper). 
Fig. 35 Microscopic features of Lactarius incarnatus

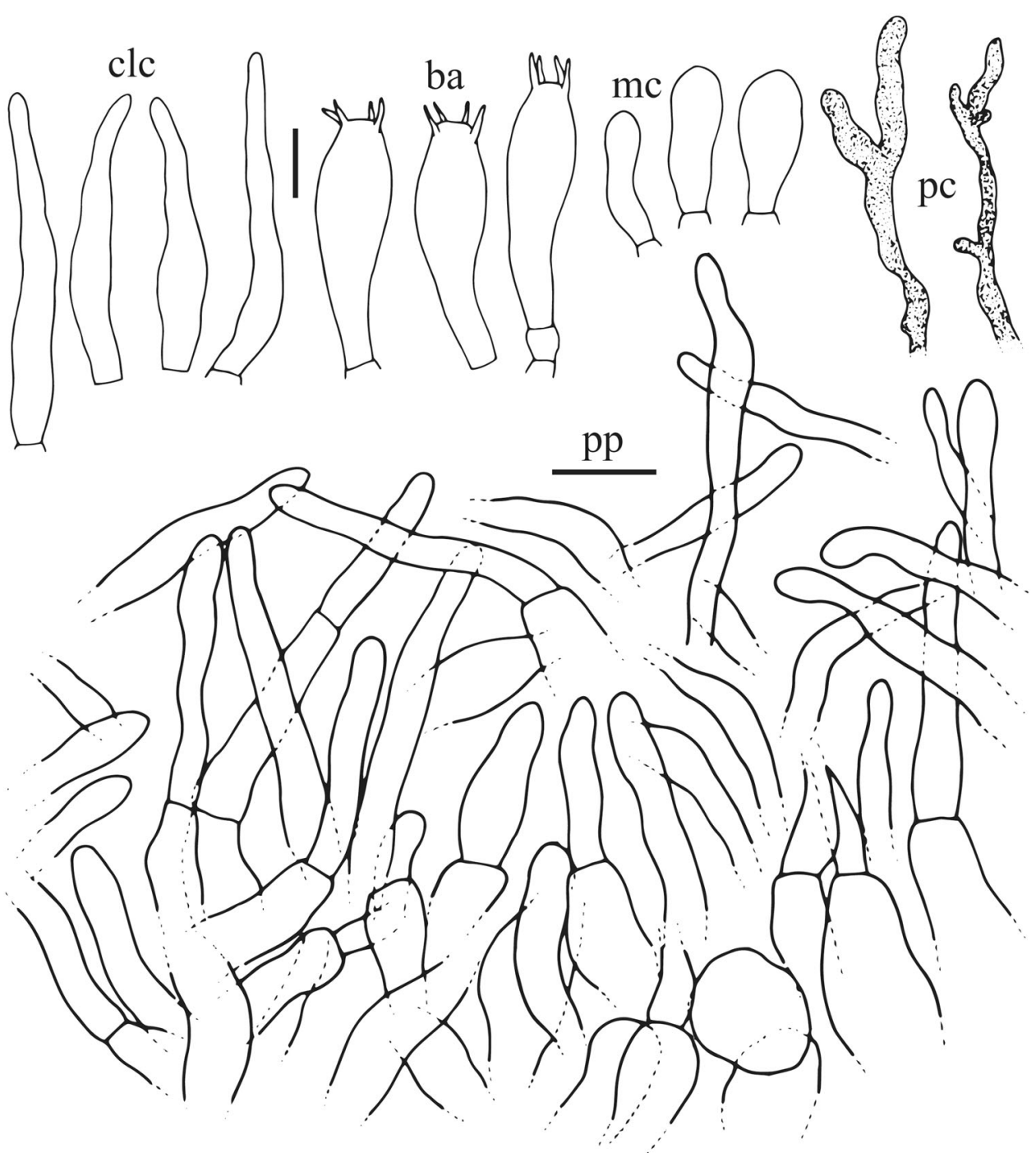

Lactarius ustulatus H. Lee, Wisitr. \& Y.W. Lim, sp. nov.

MycoBank: MB 827952

Etymology: 'ustulatus' means scorched wood, referring to the blackish brown colour of pileus.

Holotypus: SOUTH KOREA, Gyeonggi-do, Goyang-si, Seo-o-reung Royal Tombs, alt. $60 \mathrm{~m}, \mathrm{~N} 37^{\circ} 37^{\prime} 47^{\prime \prime}$ E1265'ㄷㅇ', 26 Jul 2016 (SFC20160726-79)

Pileus 20-70 mm diam., convex to applanate with slightly depressed centre; margin first decurved, in age slightly uplifted, shortly grooved to rugulose, sometimes crenate; surface greyish orange (6B3) to light brown (7D6), dark brown (7F4-6) to almost black at the center, darker toward center, dry, pruinose to velutinous, uneven. Lamellae adnate to slightly deccurent, rather distant, very rarely forked near the stipe, up to $10 \mathrm{~mm}$ broad, pale cream to greysh orange, turning pinkish slowly when bruised. Stipe
$20-40 \times 5-18 \mathrm{~mm}$, cylindrical, sometimes tapering downwards, fistulose with age; surface concolourous to pileus, pubescent, sometimes fasciculate with stipes of 2-4 basidiomata. Odour unremarkable. Taste mild to slightly acrid. Latex rather scarce, white, unchanging on exposure. Basidiospores $\quad(\mathrm{n}=60), \quad 7.6-8.4-8.8-9.6$ $(-9.8) \times 7.1-7.6-8.0-8.7(-8.8) \quad \mu \mathrm{m}$, $\mathrm{Q}=1.00-1.08-1.12-1.23, \quad$ globose to broadly ellipsoid; ornamentation amyloid, composed of up to $2.1 \mu \mathrm{m}$ high, thick ridges and clusters of lower warts, short ridges between the thick ridges; plage distally to almost totally amyloid. Basidia $45-63 \times 11.5-16 \mu \mathrm{m}$, 4-spored, narrowly clavate to clavate. Pleuromacrocystidia absent. Lamellar edges consiting of marginal cells, cheiloleptocystidia and few basidia; marginal cells narrowly clavate to clavate, sometimes cylindrical; cheiloleptocystidia numerous, $20.5-34.5 \times 5.5-9 \mu \mathrm{m}$, cylindrical to narrowly fusiform, apex rounded. 
Fig. 36 Microscopic features of Lactarius ustulatus
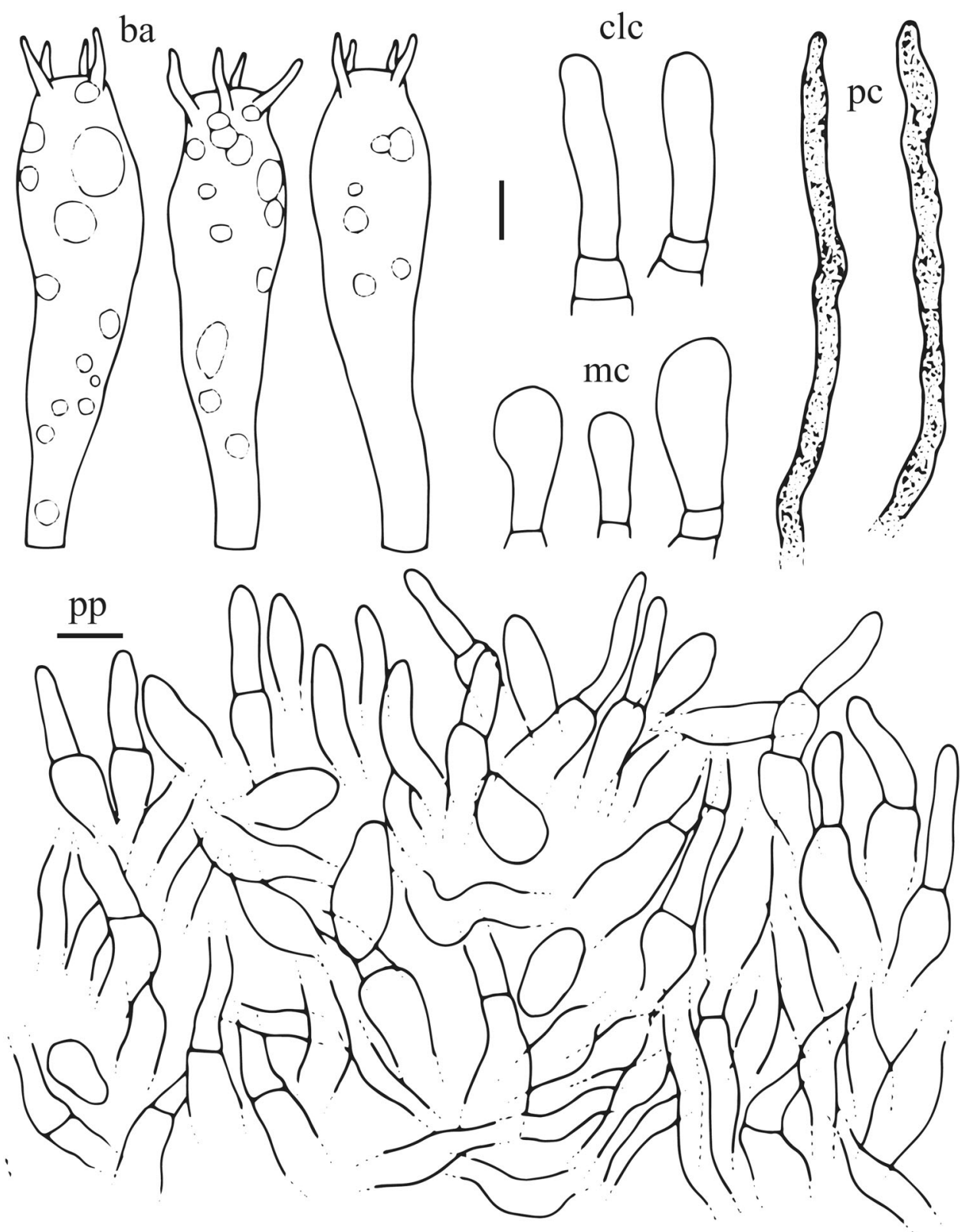

Pseudocystidia numerous, aseptate, emergent from the hymenium, sometimes projecting between basidia and basidioles, cylindrical, 3-6 $\mu \mathrm{m}$ broad, often branched near the apex; apex rounded. Pileipellis $60-125 \mu \mathrm{m}$ thick, a trichopalisade; terminal hyphae erect, cylindrical, terminal cells $8-26 \times 5.5-9 \mu \mathrm{m}$, apex rounded; subpellis composed of inflated to isodiametric cells, $6-19.5 \times 5-10 \mu \mathrm{m}$.

Habitat: Solitary or scattered on soil with moss or short grass under very old Acer and Quercus trees in mixed forests.

Additional studied material: SOUTH KOREA, Gyeonggido, Guri-si, Dong-gu-reung Royal Tombs, alt. $38 \mathrm{~m}$,
N37 $37^{\prime} 07^{\prime \prime}$ E127 $07^{\prime} 57^{\prime \prime}$, 11 Aug 2015 (SFC2015081151); ibid., Goyang-si, Seo-o-reung Royal Tombs, alt. 54 m, N37 $37^{\prime} 58^{\prime \prime}$ E126 53'32", 13 Aug 2015 (SFC20150813$63)$.

Comments: Lactarius ustulatus is easily recognized by its dry surface, dark reddish brown with darker center, wrinkled pileus, contrasting lamellae colour, and unchanging white latex. This species can be confused with $L$. cucurbitoides. However, the latter often has a darker lamellae and smaller basidiospores $(7.0-8.4 \times 6.8-8.0 \mu \mathrm{m})$ than those of L. ustulatus (Lee et al. 2015b). 


\section{Discussion}

\section{Diversity of Lactarius in South Korea}

Through a comprehensive analysis of 729 Lactarius specimens collected over 57 years, a total of 49 species were identified in a multilocus phylogenetic analysis. Surprisingly, only 17 species were previously described Lactarius species, while at least 28 others were confirmed as new species. These results indicate that identification of $\mathrm{Lac}$ tarius species based on morphology alone is insufficient, and that a multilocus phylogenetic approach is necessary. This study also highlights the problems associated with using European and North American nomenclature with Asian Lactarius species. Among the 17 previously described species, 15 were described from Asia while only two (L. tabidus and L. vietus) were conspecific with European species. Our results strongly suggest that Asian Lactarius species are rarely conspecific to those of other continents (Le et al. 2007a; Nuytinck et al. 2007; Wisitrassameewong et al. 2016).

Recent studies suggest that the majority of Lactarius species do not have intercontinental distributions, but are endemic to specific geographical regions or a single continent (Miller and Hilton 1986; Verbeken and Horak 2000; Verbeken 2001). The low intercontinental conspecificity of Lactarius between Asia and Europe or North America is probably due to the geographical barriers such as high mountain ranges and the oceans. On the other hand, Korean species that are also found in Europe, such as L. tabidus and $L$. vietus, are associated with a wide range of host trees with a broad distribution such as Betula spp. (HeilmannClausen et al. 1998; Lee et al. 2018). Many Latarius species are distributed throughout Korean Peninsula due to similar vegetation and host range. Four species ( $L$. akahatsu, L. hatsudake, L. laeticolor, and L. subzonarius) that were originally reported from Japan (Tanaka 1890; Hongo 1957b, 1960) are common in East Asia. L. akahatsu and $L$. hatsudake have been recorded in pine forests in China (Nuytinck et al. 2006), Japan (Hongo 1977), and Thailand (Le et al. 2007a). L. subzonarius was collected in Abies forests in this study, which is consistent with previous studies (Hongo 1957b; Nuytinck et al. 2006). L. atromarginatus and $L$. austrotorminosus are associated with the Fagaceae in the tropical rain forests of New Guinea and Thailand (Verbeken and Horak 2000; Le et al. 2007a, b). Similarly, Korean samples were found in Fagaceae forests. Lactarius cinnamomeus is associated with 2-3-needle pines, Pinus yunnanensis in China (Wang 2007) and $P$. kesiya in both Thailand and Vietnam (Wisitrassameewong et al. 2015). It was also collected in 2-needle pine ( $P$. densiflora) forest in Korea (this study).
Previously, 49 species belonging to Lactarius s.str. were reported in Korea (Lee et al. 2015b), yet only 10 were detected in this study. Of the 39 remaining recorded species, five, 27 and seven species were originally reported from Asia, Europe and North America, respectively. Considering the very low intercontinental conspecificity of Lactarius, few European and North American species are likely to be distributed in Korea, and most nomenclature currently on record for Asian species at large is likely incorrect. For example, L. subatlanticus, L. subhirtipes, and L. subomphaliformis were misidentified as the European species L. camphoratus (Bull.) Fr. When L. camphoratus was reported in Korea, detailed morphological descriptions were not provided (Park et al. 1986). The sequence data from European specimens of L. camphoratus (KT165318, Belgium) did not match those of our specimens, and thus $L$. camphoratus does not seem to exist in Korea ( $L$. subgenus Russularia 1 in Fig. 1). In the case of Asian species, $L$. gracilis Hongo was first described in Japan (Hongo 1957a) and later reported in Korea (Bok and Shin 1985). The Korean specimens labeled as $L$. gracilis were identified as L. qinlingensis. However, L. gracilis may indeed be present in Korea because it was originally described in Japan and has a wide distribution in Asia (Wang 2007; Wisitrassameewong et al. 2014b). Further study is needed to determine whether the other four Asian species ( $L$. castanopsidis Hongo, L. cyathula f. japonicus Hongo, $L$. flavidulus S. Imai, and L. sakamotoi S. Imai) exist in Korea.

Two subgenera (subg. Russularia and Plinthogalus) of the genus Lactarius are supported by the phylogenetic analysis using the ITS, nrLSU, and rpb2 regions (Stubbe 2012; Verbeken et al. 2014; Wisitrassameewong et al. 2016). However, the basal branch of subg. Lactarius is not well supported, nor does it form a clade (Buyck et al. 2008). We used the $\mathrm{mcm} 7$ locus in the phylogenetic analysis because it clarified phylogenetic relationships of many fungal taxonomic groups at taxonomic ranks ranging from genus to class (Schmitt et al. 2009; Tretter et al. 2013). $m c m 7$ as well as $r p b 2$ are powerful molecular markers for resolving phylogenetic clades of the genus Lactarius, both at low and high taxonomic ranks. However, the monophyly of $L$. subg. Lactarius is not supported by sequence data from these two loci.

\section{Morphological characters of Korean Lactarius species}

Together with genetic information, the use of a combination of characters was effective for species delimitation of the genus Lactarius: latex colour and latex discolouration, hispid pileus margin, basidiospore ornamentation, pileipellis structure and the presence/absence of macrocystidia (Stubbe 2012; Wisitrassameewong 2015). As some 
morphological characters were previously used for infrageneric classification, similar characters such as pileipellis type, pileus zonation, macrocystidia, and spore ornamentation seem to be important for distinguishing subgenera of Lactarius. However, none of these characters clearly support the subgeneric classification when many species are included globally. Rather, there is a tendency to change from the basal subgenus Plintothogalus to the derived subgenera, Lactarius and Russularia: from azonation to zonation, macrocystidia absence to presence, trichopalisade pileipellis to typically (ixo \pm ) cutis or trichoderm pileipellis or other forms, white or transparent latex to various colors (Fig. 2).

Most members of the L. subg. Russularia have a dry surface and orange brown to warm reddish brown basidiomata with unchanging latex (Wisitrassameewong 2015; Wisitrassameewong et al. 2016). Other common characters in this group are diverse pileipellis structures and either cheilo- or pleuro-macrocystia or both macrocystia. Nine out of 16 Korean species have unchanging white latex with three possible forms: opaque, translucent, and transparent. Yellow latex discolouration and pileus zonation are shared characters among species in the chrysorrheus group within subg. Russularia (L. chrysorrheus, L. citrinus, $L$. indochrysorrheus, $L$. lutescens, $L$. vinaceorufescens, and $L$. xanthogalactus) (Hesler and Smith 1979; Heilmann-Clausen et al. 1998; Wisitrassameewong 2015; Wisitrassameewong et al. 2016). Species in the quietus group (L. aquosus H.T. Le \& K.D. Hyde, L. quietus (Fr.) Fr., $L$ orientaliquietus, and L. subzonarius) typically have white to watery white latex with zonate pilleus and both of cheilo- and pleuro-macrocystidia (Heilmann-Clausen et al. 1998; Wisitrassameewong et al. 2015, 2016). Small sized species (average pileus diameter smaller than $25 \mathrm{~mm}$ ) were detected in this subgenus. They are phylogenetically closely related and divided into two groups. One group includes four Chinese species (L. neglectus, L. qinlingensis, $L$. subatlanticus, and $L$. subhirtipes), two Thai species ( $L$. glabrigracilis Wisitr. \& Nuytinck and $L$. perparvus Wisitr. $\&$ F. Hampe), and a Japanese species (L. gracilis). Another includes a new Korean species and a European species $(L$. omphaliformis) (Fig. 1).

The sticky surface, pileus zonation, both type of macrocystidia, typically (ixo \pm ) cutis or trichoderm pileipellis, presence of scrobicules in the stipe and/or pileus, hairy or woolly pileus margin, and gelatinuous pileipellis are general characters in the $L$. subg. Lactarius (Hesler and Smilth 1979; Heilmann-Clausen et al. 1998; Le et al. 2007a; Nuytinck and Verbeken 2007). Latex colour and discolouration are especially important for specific identification in L. subg. Lactarius (Hesler and Smith 1979; Heilmann-Clausen et al. 1998). Various colours of latex, zonated pileus, and presence of both types of macrocystida seem to be autapomorphic. Many Korean species show various latex discolouration: yellow (L. cremicolor), buff (L. ciliatus), orange brown (L. reticulisporus), greenish grey (L. vietus), greysh lilac ( $L$. cyaneocinereus), and reddish violet (L. puniceus). All species in the uvidus group, L. formosus, L. dryadophilus Kühner, L. repraesentaneus Britzelm., L. speciosus, L. uvidus, L puniceus, and $L$. cyaneocinereus have pinkish to violet discolouration of latex. Some species can be easily recognized by basidiospore ornamentation. For example, L. reticulisporus has complete reticulate basidiospores and $L$. parallelus has zebroid basidiospores (Fig. 16). Yet, these characters do not reflect phylogenetic signals at any level greater than species.

Lactarius subg. Plinthogalus is characterized by a dull greyish or brownish coloured pileus with a dry, velvety, and azonate surface, pinkish context discolouration, trichopalisade pileipellis, absence of macrocystidia and presence of cheiloleptocystidia (Heilmann-Clausen et al. 1998; Le et al. 2007b; Stubbe et al. 2008; Lee et al. 2015a). These characters appear to be plesiomorphic because this subgenus is located in the basal clade. Korean species have these characters with the exception of L. fulvescens, which is easily recognized by its concentric zonation. None of the species found in Korea have macrocystidia. However, three African species (L. miniatescens Verbeken \& Van Rooij, $L$. nudus R. Heim, and L. pulchrispermus Verbeken) and two Southeast Asian species (L. javanicus Verbeken \& E. Horak and L. crassiusculus H.T. Le \& D. Stubbe) are known to have macrocysitida (Heim 1955; Verbeken 1996; Verbeken et al. 2001; Van Rooija et al. 2003; Le et al. 2007b). Korean species in clade 8 are closely related to species from South East Asia (L. friabilis H.T. Le \& D. Stubbe and L. oomsisiensis Verbeken \& Halling) and North America (L. subplinthogalus Coker). This clade is consistent with the Asian-American clade presented by Stubbe (2012). Members in this clade have broad and distantly spaced lamellae and high spore ornamentation (up to 2-2.5 $\mu \mathrm{m}$ ) (Hesler and Smith 1979; Verbeken et al. 2002; Le et al. 2007b). The Korean species in clade 9 are intermingled with species in the European-American clade suggested by Stubbe (2012) (Lactarius acris (Bolton) Gray, L. azonites (Bull.) Fr., L. picinus Fr., L. pterosporus Romagn., L. romagnesii Bon, $L$. ruginosus Romagn., and $L$. subruginosus J. Blum ex Bon from Europe and $L$. fumosibrunneus A.H. Sm. \& Hesler and L. fumosus Peck from North America). This is the first report of an Asian species in this clade. The Asian and European species in this clade have pink to red latex discolouration while the North American species have unchanging white latex (Figs. 1 and 2, Hesler and Smith 1979; Heilmann-Clausen et al. 1998). All Korean species in this subgenus also have trichopalisade pileipellis. A few tropical species such as $L$. 
mirabilis D. Stubbe et al. and L. sect. pseudofuliginosi) and one subalpine species, L. ferruginascens K. Das et al., in the subg. Plinthogalus have ixotrichoderm type pileipellis (Verbeken 2000; Stubbe et al. 2007; Das et al. 2017).

In conclusion, we confirmed 49 species of Lactarius from Korea, including at least 28 species new to science, based on morphological and multilocus phylogenetic approaches. Our results show that identification of Lactarius species using morphological data alone is often unreliable due to considerable overlap of characters among species. In addition to the combination of defining characters such as pileipellis, macrocystidia, spore ornamentation, and latex colour, the application of molecular methods is necessary for infrageneric classification and species identification in Korean Lactarius. Since many previously collected specimens had no associated information regarding host plants, the ecological relevance of Lactarius species remains unclear. Therefore, further investigation of the host plants of Lactarius is required in order to better understand the general ecology of Lactarius species.

Acknowledgements We would like to thank Dr. Soon Ja Seok, Prof. Jong Kyu Lee, Dr. Sang-Kuk Han, and Dr. Changmu Kim for providing sample support. This research was supported by the project on the survey and excavation of Korean indigenous species of the National Institute of Biological Resources (NIBR 201701104 and NIBR 201801105) under the Ministry of Environment of the Republic of Korea.

Open Access This article is distributed under the terms of the Creative Commons Attribution 4.0 International License (http://creative commons.org/licenses/by/4.0/), which permits unrestricted use, distribution, and reproduction in any medium, provided you give appropriate credit to the original author(s) and the source, provide a link to the Creative Commons license, and indicate if changes were made.

\section{References}

Basso MT 1999. Lactarius Pers. Fungi Europaei, vol. 7. Mykoflora, Alassio

Bok JD, Shin GC (1985) Taxonomic studies on the genus Lactarius of Korea (I). Korean J Mycol 13(4):249-262

Buyck B, Hofstetter V, Eberhardt U, Verbeken A, Kauff F (2008) Walking the thin line between Russula and Lactarius: the dilemma of Russula subsect. Ochricompactae. Fungal Divers 28: $15-40$

Buyck B, Hofsetter V, Verbeken A, Walleyn R (2010) Proposal 1919: to conserve Lactarius nom. Cons. (Basidiomycota) with avconserved type. Taxon 59:295-296

Castresana J (2000) Selection of conserved blocks from multiple alignments for their use in phylogenetic analysis. Mol Biol Evol 17(4):540-552

Cho HJ, Park MS, Lee H, Oh S-Y, Wilson AW, Mueller GM, Lim YW (2018) A systematic revision of the ectomycorrhizal genus Laccaria from Korea. Mycologia 110(5):948-961

Clémençon H (1973) Zwei verbesserte Präparierlösungen für die microskopische Untersuchung von Pilze. Z Pilzkd 38:49-53
Cui YY, Cai Q, Tang LP, Liu JW, Yang ZL (2018) The family Amanitaceae: molecular phylogeny, higher-rank taxonomy and the species in China. Fungal Divers 91:5-230

Darriba D, Taboada GL, Doallo R, Posada D (2012) jModelTest 2: more models, new heuristics and parallel computing. Nat Methods 9(8):772

Das K, Verbeken A, Nuytinck J (2015) Morphology and phylogeny of four new Lactarius species from Himalayan India. Mycotaxon 130(1):105-130

Das K, Verbeken A, Chakraborty D, Avchar R, Baghela A (2017) Morphological and phylogenetic evidence for two new Lactarius species (Russulales, Basidiomycota) from India. Cryptogam Mycol 38(4):453-467

Eberhardt U, Verbeken A (2004) Sequestrate Lactarius species from tropical Africa: L. angiocarpus sp. nov. and L. dolichocaulis comb. nov. Mycol Res 108(9):1042-1052

Gardes M, Bruns TD (1993) ITS primers with enhanced specificity for basidiomycetes-application to the identification of mycorrhizae and rusts. Mol Ecol 2:113-118

Heilmann-Clausen J, Verbeken A, Vesterholt J (1998) The genus Lactarius: fungi of Northern Europe, vol 2. Svampetryk, Mundelstrup, DK

Heim R (1955) Les lactaires d'Afrique intertropicale. Bull Jard Bot l'État Brux 25:1-91

Herrera M, Montoya L, Bandala VM (2018) Two Lactarius species (subgenus Plinthogalus) in ectomycorrhizal association with tropical Quercus trees in eastern Mexico. Mycologia 110:1033-1046

Hesler LR, Smith AH (1979) North American species of Lactarius. University of Michigan Press, Ann Arbor, p 841

Hongo T (1957a) Notes on Japanese larger fungi 10. J Jpn Bot 32(5): 141-146

Hongo T (1957b) Notes on Japanese larger fungi 11. J Jpn Bot 32(7):208-214

Hongo T (1960) Agaricales of Japan 1-3. Russulaceae. Acta Phytotaxon Geobot 18:129-146

Hongo T (1971) Notulae mycologicae 10. Mem Shiga Univ 21:62-68

Hongo T (1977) Higher fungi of the Bonin Islands I. Mem Natl Sci Mus (Tokyo) 10:31-41

Hongo T (1979) Notes on Japanese larger fungi 22. J Jpn Bot 54(10):301-310

Imai S (1935) Studies on the Agaricaceae of Japan. II. Lactarius in Hokkaido. Bot Mag (Tokyo) 49:603-610

Katoh K, Standley DM (2013) MAFFT multiple sequence alignment software versions 7: improvement in performance and usability. Mol Biol Evol 30:772-780

Kim CS, Jo JW, Kwag YN, Sung GH, Lee SG, Kim SY, Shin CH, Han SK (2015) Mushroom flora of Ulleung-gun and a newly recorded Bovista species in the Republic of Korea. Mycobiology 43(3):239-257

Kirk PM, Cannon PF, Minter DW, Stalpers JA (2008) Dictionary of the fungi. $\mathrm{CAB}$ International, Wallingford, Wallingford

Kornerup A, Wanscher JH (1978) Methuen handbook of colour, 3rd edn. Eyre Methuen Ltd., London

Kränzlin F 2005. Fungi of Switzerland, vol 6, Russulaceae: Lactarius, Russula. Verlag Mykologia, Luzern

Largent D, Johnson D, Watling R (1977) How to identify mushrooms to genus III: microscopic features. Mad River Press Inc., Eureka, California

Le HT, Stubbe D, Verbeken A, Nuytinck J, Lumyong S, Desjardin DE (2007a) Lactarius in Northern Thailand: 1. Lactarius subgenus Piperites. Fungal Divers 24:173-224

Le HT, Stubbe D, Verbeken A, Nuytinck J, Lumyong S, Desjardin DE (2007b) Lactarius in Northern Thailand: 2. Lactarius subgenus Plinthogali. Fungal Divers 27:61-94 
Lee WD, Lee H, Fong JJ, Oh SY, Park MS, Quan Y, Jung PE, Lim YW (2014) A checklist of the Basidiomycetous macrofungi and a record of five new species from Mt. Oseo in Korea. Mycobiology 42(2):132-139

Lee H, Park MS, Jung PE, Fong JJ, Oh SY, Verbeken A, Lim YW (2015a) Lactarius cucurbitoides (Russulales, Basidiomycota), a new species from South Korea supported by molecular and morphological data. Phytotaxa 205(3):168-176

Lee YS, Lim YW, Kim JJ, Yun HY, Kim C, Park JY (2015b) National list of species of Korea: Basidiomycota. National Institute of Biological Resources, Korea, p 364

Lee H, Park MS, Jung PE, Eimes JA, Seok SJ, Lim YW (2017) Reevaluation of the taxonomy and diversity of Russula section Foetentinae (Russulales, Basidiomycota) in Korea. Mycoscience 58:351-360

Lee H, Park JY, Wisitrassameewong K, Kim MJ, Park MS, Kim NK, Lee JK, Lim YW (2018) First report of eight milkcap species belonging to Lactarius and Lactifluus in Korea. Mycobiology 46(1): $1-12$

Liu YL, Whelen S, Hall BD (1999) Phylogenetic relationships among ascomycetes: evidence from an RNA polymerase II subunit. Mol Biol Evol 16:1799-1808

Matheny PB (2005) Improving phylogenetic inference of mushrooms with RPB1 and RPB2 nucleotide sequences (Inocybe, Agaricales). Mol Phylogenet Evol 35:1-20

Matheny PB, Wang Z, Binder M, Curtis JM, Lim YW, Nilsson RH, Hughes KW, Hofstetter V, Ammirati JF, Schoch CL, Langer E, Langer G, Mclaughlin DJ, Wilson AW, Frøslev T, Ge Z-W, Kerrigan RW, Slot JC, Yang Z-L, Baroni TJ, Fischer M, Hosaka K, Matsuura K, Seidl MT, Vauras J, Hibbett DS (2007) Contributions of rpb2 and tef1 to the phylogeny of mushrooms and allies (Basidiomycota, Fungi). Mol Phylogenet Evol 43(2):430-451

Miller OK, Hilton RN (1986) New and interesting Agarics from Western Australia. Sydowia 39:126-137

Miller MA, Pfeiffer W, Schwartz T 2010. Creating the CIPRES science gateway for inference of large phylogenetic trees. SC10 Workshop on Gateway Computing Environments (GCE10)

Montoya L, Bandala VM (1996) Additional new records on Lactarius from Mexico. Mycotaxon 57:425-450

Montoya L, Bandala VM (2003) Studies on Lactarius: a new combination and two new species from Mexico. Mycotaxon 85:393-407

Neuhoff W 1956 Die Milchlinge (Lactarii). Die Pilze Mitteleuropas, vol. 2b. Julius Klinkhardt, Bad Heilbrunn Obb

Nuytinck J, Ammirati JF (2014) A new species of Lactarius sect. Deliciosi (Russulales, Basidiomycota) from western North America. Botany 92(10):767-774

Nuytinck J, Verbeken A (2003) Lactarius sanguifluus versus Lactarius vinosus-molecular and morphological analyses. Mycol Progress 2(3):227-234

Nuytinck J, Verbeken A (2007) Species delimitation and phylogenetic relationships in Lactarius section Deliciosi in Europe. Mycol Progress 111:1285-1297

Nuytinck J, Wang XH, Verbeken A (2006) Descriptions and taxonomy of the Asian representatives of Lactarius sect. Deliciosi. Fungal Divers 22:171-203

Nuytinck J, Verbeken A, Miller SL (2007) Worldwide phylogeny of Lactarius section Deliciosi inferred from ITS and glyceraldehyde-3-phosphate dehydrogenase gene sequences. Mycologia 99(6):820-832

Nuytinck J, Verbeken A, Saar I, Lambert H, Bérubé J, Voitk A (2017) Lactarius splendens, a second species with white latex in Lactarius section Deliciosi. Botany 95(8):859-863

Park WH, Lee JH (2011) New wild fungi of Korea. Kyo-Hak Publishing Co., Seoul
Park SS, Cho DH, Lee JY (1986) The flora of higher fungi in Mt. Jiri Areas (I). Korean J Mycol 15:71-75

Park MS, Fong JJ, Lee H, Oh SY, Jung PE, Min YJ, Lim YW (2013) Delimitation of Russula subgenus Amoenula in Korea using three molecular markers. Mycobiology 414:191-201

Pegler DN, Fiard JP (1979) Taxonomy and ecology of Lactarius (Agaricales) in the Lesser Antilles. Kew Bull 33:601-628

Persoon CH (1797) Tentamen dispositionis methodicae fungorum in classes, ordines, genera et familias, cum supplemento adjecto. Petrum Philippum Wolf, Leipzig

Rogers SO, Bendich AJ (1994) Extraction of total cellular DNA from plants, algae and fungi. In: Gelvin SB, Schilperoort RA (eds) Plant molecular biology manual. Kluwer Academic Publishers, Boston, pp 183-190

Romagnesi H (1985) Les Russules d' Europe et d' Afrique du Nord. Reprint with supplement. J. Cramer, Lehre

Ronquist F, Huelsenbeck JP (2003) MrBayes 3: Bayesian phylogenetic inference under mixed models. Bioinformatics 19:1572-1574

Rozen S, Skaletsky HJ (2000) Primer3 on the WWW for general users and for biologist programmers. Methods Mol Biol 132:365-386

Sanmee R, Dell B, Lumyong P, Izumori K, Lumyong S (2003) Nutritive value of popular wild edible mushrooms from northern Thailand. Food Chem 82(4):527-532

Schmitt I, Crespo A, Divakar PK, Fankhauser JD, Herman-Sackett E, Kalb K, Nelsen MP, Nelson NA, Rivas-Plata E, Shimp AD, Widhelm T, Lumbsch HT (2009) New primers for promising single-copy genes in fungal phylogenetics and systematics. Persoonia 23:35-40

Schoch CL, Seifert KA, Huhndorf S, Robert V, Spouge JL, Levesque CA, Chen W, Bolchacova E, Voigt K, Crous PW (2012) Nuclear ribosomal internal transcribed spacer (ITS) region as a universal DNA barcode marker for Fungi. Proc Natl Acad Sci 109:6241-6246

Shi SF, Wang XH, Bau T (2018) Three new species of Lactarius (Russulaceae, Russulales) from Northeast China. Mycoscience 59(3):206-217

Singer R (1986) The Agaricales in modern taxonomy, 4th edn. Koeltz, Koenigstein

Singer R, Araujo I, Ivory MH (1983) The ectotrophically mycorrhizal fungi of the neotropical lowlands, especially central Amazonia. Beih Nova Hedwig 77:1-352

Stamatakis A (2006) RAxML-VI-HPC: maximum likelihood-based phylogenetic analyses with thousands of taxa and mixed models. Bioinformatics 22:2688-2690

Stubbe D (2012) Systematics and phylogeny of Lactarius subgenus Plinthogalus sensu lato. Ph.D. thesis, Ghent University, Gent, Belgium

Stubbe D, Verbeken A, Watling R (2007) Blue-staining species of Lactarius subgenus Plinthogali in Malaysia. Belg J Bot 140(2): 197-212

Stubbe D, Nuytinck J, Verbeken A (2008) Lactarius subgenus Plinthogalus of Malaysia. Fungal Divers 32:125-156

Stubbe D, Nuytinck J, Verbeken A (2010) Critical assessment of the Lactarius gerardii species complex (Russulales). Fungal Biol 114(2-3):271-283

Stubbe D, Wang XH, Verbeken A (2012) New combinations in Lactifluus. 2. L. subg. Gerardii. Mycotaxon 119(1):483-485

Suortti T, Von Wright A, Koskinen A (1983) Necatorin, a highly mutagenic compound from Lactarius necator. Phytochemistry 22(12):2873-2874

Tamura K, Stecher G, Peterson D, Filipski A, Kumar S (2013) MEGA6: molecular evolutionary genetics analysis version 6.0. Mol Biol Evol 30(12):2725-2729

Tanaka N (1890) On Hatsudake and Akahatsu, two species of Japanese edible fungi. Bot Mag (Tokyo) 4:392-396 
Tretter ED, Johnson EM, Wang Y, Kandel P, White MM (2013) Examining new phylogenetic markers to uncover the evolutionary history of early-diverging fungi: comparing MCM7, TSR1 and rRNA genes for single-and multi-gene analyses of the Kickxellomycotina. Persoonia 30:106-125

Unipal P, Das K, Bhatt RP (2018) Two novel species of Lactarius subgenus Plinthogalus from Uttarakhand Himalaya. Phytotaxa 338(3):255-264

Uyeki H (1936) Vegetation in the Kwa-San hill and the environs of Suigen. Bull Agric For College 5:1-155

Van Rooija P, De Keselb A, Verbeken A (2003) Studies in tropical African Lactarius species (Russulales, Basidiomycota) 11. Records from Benin. Nova Hedwig 77(1-2):221-251

Verbeken A (1996) New taxa of Lactarius (Russulaceae) in tropical Africa. Bull Jard Bot Natl Belgique 65:197-213

Verbeken A (2000) Studies in tropical African Lactarius species. 8. A synopsis of the subgenus Plinthogali. Persoonia 17(3):377-406

Verbeken A (2001) Worldwide systematics of Lactarius: a state of art. Micol Veg Mediterr 16:71-88

Verbeken A, Horak E (1999) Lactarius (Basidiomycota) in Papua New Guinea. 1. Species of tropical lowland habitats. Aust Syst Bot 12(6):767-779

Verbeken A, Horak E (2000) Lactarius (Basidiomycota) in Papua New Guinea. 2. Species of tropical-montane rainforests. Aust Syst Biol 13(5):649-707

Verbeken A, Nuytinck J (2013) Not every milkcap is a Lactarius. Scripta Bot Belgica 51:162-168

Verbeken A, Walleyn R (2010) Fungus flora of tropical Africa vol 2: monograph of Lactarius in tropical Africa. National Botanic Garden of Belgium, Belgium

Verbeken A, Horak E, Desjardin DE (2001) Agaricales of Indonesia. 3. New records of the genus Lactarius (Basidiomycota, Russulales) from Java. Sydowia 53(2):261-289

Verbeken A, Bougher NL, Halling R (2002) Lactarius (Basidiomycota, Russulaceae) in Papua New Guinea. 3. Two new Lactarius species in subgenus Plinthogali. Aust Syst Bot 15(6):765-771

Verbeken A, Nuytink J, Buyck B (2011) New combinations in Lactifluus. 1. L. subgenera Edules. Lactariopsis and Russulopsis. Mycotaxon 118:447-453

Verbeken A, Van de Putte K, De Crop E (2012) New combinations in Lactifluus. 3. L. subgenera Lactifluus and Piperati. Mycotaxon 120:443-450

Verbeken A, Stubbe D, Van de Putte K, Eberhardt U, Nuytinck J (2014) Tales of the unexpected: angiocarpous representatives of the Russulaceae in tropical South East Asia. Persoonia 32:13-24

Vilgalys R, Hester M (1990) Rapid genetic identification and mapping of enzymatically amplified ribosomal DNA from several Cryptococcus species. J Bacteriol 172(8):4238-4246

Vincenot L, Popa F, Laso F, Donges K, Rexer KH, Kost G, Yang ZL, Nara K, Selosse MA (2017) Out of Asia: biogeography of fungal populations reveals Asian origin of diversification of the Laccaria amethystina complex, and two new species of violet Laccaria. Fungal Biol 121:939-955

Von Wright A, Knuutinen J, Lindroth S, Pellinen M, Widen KG, Seppä EL (1982) The mutagenicity of some edible mushrooms in the Ames test. Food Chem Toxicol 20(3):265-267

Wang XH (2007) Type studies of Lactarius species published from China. Mycologia 99(2):253-268
Wang XH (2016) Three new species of Lactarius sect. Deliciosi from subalpine-alpine regions of central and southwestern China. Cryptogam Mycol 37(4):493-508

Wang XH (2017a) Seven new species of Lactarius subg. Lactarius (Russulaceae) from southwestern China. Mycosystema 36:1463-1482

Wang XH (2017b) Two new species of Lactarius subg Russularia from subalpine regions of southwestern China. J Fungal Res 15(4):222-228

Wang XH (2018) Fungal biodiversity profiles 71-80. Cryptogam Mycol 39(4):419-446

Wang XH, Liu PG (2002) Lactarius chichuensis and L. hirtipes, two easily confused species. Mycotaxon 84:391-400

Wang XH, Nuytinck J, Verbeken A (2015) Lactarius vividus sp. nov. (Russulaceae, Russulales), a widely distributed edible mushroom in central and southern China. Phytotaxa 231(1):63-72

Wang GS, Song Y, Li JW, Xia SY, Qiu LH (2018a) Lactarius verrucosporus sp. nov. and $L$. nigricans sp. nov., two new species of Lactarius (Russulaceae) from southern China. Phytotaxa 364(3):227-240

Wang XH, Das K, Horman J, Antonin V, Baghela A, Chakraborty D, Hembrom ME, Nakasone K, Ortiz-Santana B, Vizzini A, Hofstetter V, Buyck B (2018b) Fungal biodiversity profiles 51-60. Cryptogam Mycol 39(2):211-258

White TJ, Bruns T, Lee S, Taylor J (1990) Amplification and direct sequencing of fungal ribosomal RNA genes for phylogenetics. In: Innis MA, Gelfand DH, Sninsky JJ, White TJ (eds) PCR protocols: a guide to methods and applications. Academic Press, San Diego, pp 315-322

Wisitrassameewong K (2015) Diversity and phylogeny of Lactarius subgenus Russularia in Southeast Asia. Ph.D. thesis, Ghent University, Gent, Belgium

Wisitrassameewong K, Nuytinck J, Hyde KD, Verbeken A (2014a) Lactarius subgenus Russularia (Russulaceae) in Southeast Asia: 1. Species with very distant gills. Phytotaxa 158(1):23-42

Wisitrassameewong K, Nuytinck J, Hampe F, Hyde KD, Verbeken A (2014b) Lactarius subgenus Russularia (Russulaceae) in SouthEast Asia: 2. Species with remarkably small basidiocarps. Phytotaxa 188(4):181-197

Wisitrassameewong K, Nuytinck J, Le Thanh H, De Crop E, Hampe F, Hyde K, Verbeken A (2015) Lactarius subgenus Russularia (Russulaceae) in South-East Asia, 3: new diversity in Thailand and Vietnam. Phytotaxa 207(3):215-241

Wisitrassameewong K, Looney BP, Le HT, De Crop E, Das K, Van de Putte K, Eberhardt U, Jiayu G, Stubbe D, Hyde KD, Verbeken A, Nuytinck J (2016) Lactarius subgenus Russularia (Basidiomycota, Russulales): novel Asian species, worldwide phylogeny and evolutionary relationships. Fungal Biol 120(12):1554-1581

Yamin-Pasternak S (2008) A means of survival, a marker of feasts: mushrooms in the Russian Far East. Ethnology 47(2):95-107

Zhao Q, Feng B, Yang ZL, Dai YC, Wang Z, Tolgor B (2013) New species and distinctive geographical divergences of the genus Sparassis (Basidiomycota): evidence from morphological and molecular data. Mycol Progress 12:445-454

Publisher's Note Springer Nature remains neutral with regard to jurisdictional claims in published maps and institutional affiliations. 